\title{
The Misguided Renaissance of Social Choice
}

\author{
Maxwell L. Stearns ${ }^{\dagger}$
}

\section{CONTENTS}

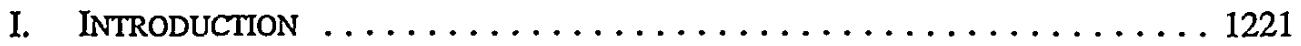
A. The Intellectual History of Social Choice . . . . . . . . . . 1221
B. Social-Choice-Based Normative Proposals . . . . . . . . . . 1225
C. The Nirvana, Isolation, and Composition Fallacies . . . . . . . . 1229

II. Markets, Legislatures, AND the EMPTy Core $\ldots \ldots \ldots \ldots \ldots \ldots$

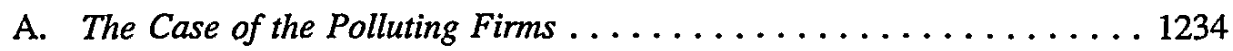
B. Location of Toxic-Waste Disposal Facility ............. 1240
FIGURE 1. Proposed Locations of Toxic Waste Dump . . . . . . 1241

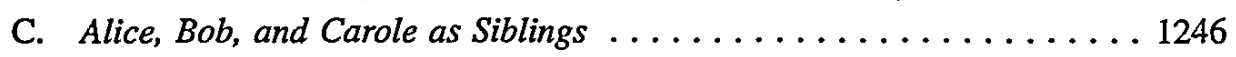

III. DEFINING THE "IDEAL" NoRM $\ldots \ldots \ldots \ldots \ldots \ldots \ldots \ldots \ldots \ldots \ldots$
A. The Arrow's Theorem Criteria . . . . . . . . . . . . . . 1247
B. The Condorcet-Winner Criterion ................. 1252

IV. The Supreme Court and Congress Through an ARrovian Lens . . . 1257

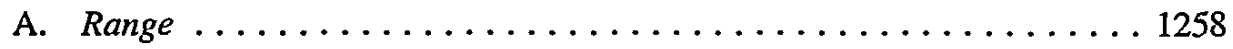
B. Universal Domain . . . . . . . . . . . . . . . . 1271
C. Unanimity and Independence of Irrelevant Alternatives . . . . . . 1276

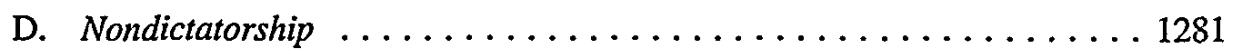

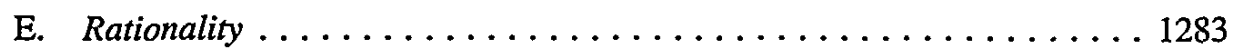
F. Summary ........................... 1285

TABLE 1. The Supreme Court and Congress Through

an Arrovian Lens . . . . . . . . . . . . . . . . 1286

$\dagger$ Assistant Professor of Law, George Mason University School of Law. B.A. 1983, University of Pennsylvania; J.D. 1987, University of Virginia School of Law.

I would like to thank the following for their helpful comments and suggestions: Lawrence Baxter, Lloyd Cohen, Harold Demsetz, Einer Elhauge, Henry Hansmann, Bruce Kobayashi, Bill Kovacic, Aaron Krauss, Saul Levmore, Nelson Lund, Henry Manne, Richard McAdams, Timothy Muris, Jeffrey Parker, Larry Ribstein, Glen O. Robinson, Linda Schwartzstein, David Skeel, and Gordon Tullock. I would also like to thank the participants in the GMUSL brown bag lunch series for their helpful comments, the GMUSL library staff for their assistance in tracking down hard-to-find source materials, Wendy Payton for her assistance in creating the tables that appear in the text, and Melissa Austin for her research assistance. Finally, I wish to acknowledge the generous research funding provided by the John M. Olin and Sarah Scaife Foundations. 
V. Collective Decisionmakers Through a Wide-ANgle ArRovian Lens . 1287

A. Markets . . . . . . . . . . . . . . . . . . . . . . . 1287

B. Legislatures and Appellate Courts . . . . . . . . . . 1288

C. Agencies . . . . . . . . . . . . . . . . . . . . . . 1289

D. Summary . . . . . . . . . . . . . . . . . . . . . . 1290

TABLE 2. Collective Decisionmakers Through

a Wide-Angle Arrovian Lens . . . . . . . . . . . . . 1290

VI. Conclusion . . . . . . . . . . . . . . . . . . . . . . . . . 1291

VII. APPENDIX . . . . . . . . . . . . . . . . . . . . . . . . 1291

A. Arrow's Theorem Proof . . . . . . . . . . . . . . . . . 1291

B. Arrow's Theorem Explanation .................. 1292 


\section{INTRODUCTION}

\section{A. The Intellectual History of Social Choice}

In a world in which relatively few people were formally educated and fewer still could honestly describe themselves as intellectuals, it is perhaps not surprising that both Thomas Jefferson and James Madison were familiar with the noted French philosopher and mathematician, ${ }^{1}$ the Marquis de Condorcet. ${ }^{2}$ As Minister to France, Jefferson personally knew Condorcet. ${ }^{3}$ Jefferson owned several of Condorcet's works, including the famous Essai sur l'application de l'analyse à la probábilité des décisions rendues à la pluralité des voix written in 1785. ${ }^{4}$ The Essai describes what has become known as the "Condorcet Paradox," the seminal insight underlying what Condorcet described as "social mathematics" and what is presently known as social choice theory. ${ }^{6}$

The paradox is fairly straightforward. Consider the plight of three law firm associates, Alice, Bob, and Carole, who need to decide which flavor to order for an ice cream cake that they intend to serve at a party honoring their departing colleague Diane. Three flavors are available: coffee, chocolate, and

1. H.P. Young, Condorcet's Theory of Voting, 82 AM. POL. SCI. REv. 1231 (describing Condorcet as a "mathematician and social philosopher"); DUNCAN BLACK, THE THEORY OF COMMITTEES AND ELECTION 159 (1963) (describing Condorcet as a "mathematician, philosopher, economist and social scientist"). Describing the Marquis de Condorcet as a philosopher and mathematician is a bit misleading. In the late 18 th century, spheres of knowledge were not delineated with the precision that they are today. Instead, intellectuals of the day, including the three men identified in the text, were well versed across a wide variety of what we today call mathematics, philosophy, history, law, architecture, and the natural sciences.

2. See Iain McLean \& Annold B. Urken, Did Jefferson or Madison Understand Condorcet's Theory of Social Choice?, 73 PUB. CHOlce 445, 445, 453 (1992).

3. See 8-12 The Papers of Thomas JefFerson (Julian P. Boyd ed., 1950); Arnold B. Urken, The Condorcet-Jefferson Connection and the Origins of Social Choice Theory, 72 PuB. CHOICE 213, 215, 218 (1991).

4. McLean \& Urken, supra note 2, at 447 ("Jefferson owned a copy of Condorcet's 1785 Essai and several of Condorcet's other works in social choice."); Urken, supra note 3, at 215, 218.

5. McLean \& Urken, supra note 2, at 446 ("Condorcet's standing as the principal founder of social choice rests largely, but not entirely, on his Essai sur l'application de l'analyse à la probabilité des décisions rendues à la pluralité des voix of 1785 .... This work investigates the logical relationship between voting procedures and collective outcomes.").

6. The name social choice theory is derived from the title of Kenneth Arrow's famous book, Social Choice and Individual Values, for which, along with other works, he was awarded a Nobel Prize in 1972. See Noiman Macrae, Towards Smaller Government, ECONOMIST, Dec. 23, 1978, at 48 ("Professor Kenneth Arrow won a Nobel Prize in economics by trying to discover a 'social welfare function,' designed to be useful in guiding the planning authority for a society - and then discovering to his surprise and chagrin that it is logically impossible for any such function to exist."); KENNETH J. ARROW, SOCIAL CHOICE AND INDIVIDUAL VALUES (1951). Arrow initially set out to determine a method of aggregating collective welfare and instead proved mathematically that the Condorcet Paradox was an intractable problem in collective decisionmaking. See DenNis C. Mueller, Public Choice II 2-3 (1989).

The Marquis de Condorcet was not the first to identify the voting paradox that bears his name. Some fifteen years earlier, Jean Charles de Borda read a paper to the French Academy of Sciences demonstrating the paradox and proposing a different solution from that which Condorcet offered in his 1785 Essai. See Young, supra note 1, at 1236-39 (describing and evaluating Borda method); BLACK, supra note 1, at 17880 (describing relationship between the theories of Condorcet and Borda). See infra note 124 for a description of the Borda method. 
vanilla. Assume further that each announces his or her preferences in advance. Alice ranks her preferences "coffee, chocolate, vanilla;" Bob ranks his "chocolate, vanilla, coffee;" and Carole ranks hers "vanilla, coffee, chocolate." Bob suggests that they put the choice of flavor to a series of votes, two flavors at a time. Carole, amused by the suggestion, remains silent. In the first vote, vanilla versus coffee, vanilla prevails two to one, with Alice losing to Bob and Carole. In the second vote, vanilla versus chocolate, chocolate prevails two to one, with Carole losing to Alice and Bob. Carole explains that she truly dislikes chocolate and asks for one final vote, this time chocolate versus coffee. Alice and Bob, a bit surprised at the suggestion of their colleague, whom they had always considered to be quite bright, explain that the final vote is obviously unnecessary; given that chocolate prevailed over vanilla and that vanilla prevailed over coffee, chocolate would obviously prevail over coffee. Carole, who double majored in French and intellectual history before going to law school, asks her friends to indulge her. Much to the surprise of Alice and $\mathrm{Bob}$, in a final pairwise vote between chocolate and coffee, coffee prevails, with Bob losing to Alice and Carole. Carole then explains that if everyone voted sincerely in accordance with his or her preannounced set of preferences, there was no rational means of choosing a flavor through pairwise voting. ${ }^{7}$

This fundamental insight, that absent clear majority support for one of three or more options presented to a collective decisionmaking body there may be no rational means of aggregating individual preferences, contributed to what Condorcet hoped would become a social science, founded upon the laws of probability, no less rigorous than the natural sciences. ${ }^{8}$ While Madison did not know Condorcet personally, he received copies of the Essai from at least two independent sources, Thomas Jefferson and Philip Mazzei. ${ }^{9}$ In addition, in a

7. As shown in infra notes 223-24 and accompanying text, there may be other rational ways for Alice, Bob, and Carole to choose a flavor, including strategic voting and logrolling.

8. See KeITH M. BAKER, CONDORCET: From NATURAL PhILOSOPHY TO SOCIAL MATHEMatics 188 (1975) ("In this probabilistic philosophy, Condorcet found a model for social science that made it no less certain-no less susceptible of the precise and measured evaluation of mathematical calculation-than the physical sciences."); McLean \& Urken, supra note 2, at 445 ("Condorcet was the last of the Enlightenment philosophes. A dedicated liberal and the founder of what he called 'social mathematics', he believed that rigorous social science, founded on the laws of probability, was no less obtainable than rigorous natural science."); BLACK, supra note 1, at 184 ("The hope had sprung up to carry the methods of rigorous and mathematical thought beyond the physical and into the realms of the human sciences.").

In addition to describing the cycling phenomenon, Condorcet devised a partial solution. Assume that Carole's preferences are changed to "vanilla, chocolate, coffee," while her friends' preferences remain unchanged. Now, even though chocolate is not the first choice of a majority of voters, it prevails over any alternative flavor in a pairwise vote. Choosing the option that prevails over all other options in a series of pairwise votes, called the "Condorcet criterion" or the "Condorcet winner," see ARROW, supra note 6, at 94 , is only a partial solution to the voting paradox because such a winner will not always exist. See Saul Levmore, Parliamentary Law, Majority Decisionmaking, and the Voting Paradox, 75 VA. L. REv. 971, 99396 (1989). If the original orderings are left unchanged, for example, there is no Condorcet-winning flavor. The Condorcet-winner and non-Condorcet-winner paradigms are described in more detail in note 122.

9. See McLean \& Urken, supra note 2, at 453-54. McLean and Urken describe Mazzei, who resided in Virginia before relocating to Paris, as "an Italian adventurer," who although "vain and pompous" was "shrewd about French and American politics." Id. at 450; see also Urken, supra note 3, at 226 (providing 
direct but failed attempt to influence the drafting of the United States Constitution, Mazzei sent Madison a series of four "well-reasoned letters" in which he claimed that Condorcet's work provided mathematically sound support for a unicameral legislature, ${ }^{10}$ based upon principles of social choice.

While the historic evidence is not conclusive, Iain McLean and Arnold B. Urken recently reviewed all available primary sources and determined, first, that while Jefferson and Madison owned copies of the Essai, it is unlikely that either of them actually read the fairly short section that described the voting paradox; ${ }^{11}$ and, second, that no available evidence supports the claim that an understanding of the voting paradox influenced the drafting of the United States Constitution. ${ }^{12}$ In addition, McLean and Urken conclude that Madison,

historical background information on Mazzei).

10. Letter from Philip Mazzei to James Madison (Aug. 14, 1786), in 9 THE PAPERS OF JAMES MADISON 102-03 (Robert A. Rutland ed., 1975). Saul Levmore has recently argued, somewhat ironically, that bicameral legislatures are better suited to act on Condorcet winners than are unicameral legislatures with a supermajority consensus requirement. See Saul Levmore, Bicameralism: When Are Two Decisions Better than One?, 12 INT'L REV. L. \& ECON. 145, 156 (1992). Professor Levmore explains that a bicameral legislature with a simple majority rule in each house will produce "'strong-Condorcet' alternative[s]," defined as the simultaneous Condorcet winner in both houses, because the motion-and-amendment procedure within each house is conducive to yielding Condorcet-winning options. Id. In contrast, in any body that requires supermajority consensus, Levmore explains, a minority can block a Condorcet-winner. Id. For an explanation of how and why motion-and-amendment procedures yield Condorcet winners, see infra notes 169-87 and accompanying text. In contrast, other theorists have argued that bicameralism functions to prevent a minority from controlling the outcome of the legislative process. JAMES M. Buchanan \& GoRdon TUllock, The Calculus of CONSENT: LOGICAL Foundations of CONSTITUTIONAL DEMOCRACY 242 (1962) (showing that many more votes are needed to control a bicameral legislature than a unicameral one). Levmore explains that while both a unicameral legislature with supermajority rule and a bicameral legislature with majority rule can expand the base of support needed to pass ordinary legislation, only the latter is successful in producing legislation that satisfies the Condorcet criterion. Levmore, supra, at 156-58 ("Both bicameralism and supermajoritarianism can serve to stop legislation or special interests, but only bicameralism can at the same time preserve all strongCondorcet alternatives.").

11. See Urken, supra note 3, at 219 (observing that Jefferson's typical margin notes do not appear in the copies of the Essai that scholars believe he may have owned); McLean \& Urken, supra note 2, at 454 (positing that Madison's correspondence implies that the Essai passed only briefly across Madison's desk and that he probably did not read it).

12. See McLean \& Urken, supra note 2, at 455-56; see also Urken, supra note 3, at 222 (positing that Jefferson "seems not to have assimilated [Condorcet's] theoretical approach to the design of constitutions."). Dennis R. McGrath takes a contrary position in James Madison and Social Choice Theory: The Possibility of Republicanism (1983) (unpublished Ph.D. dissertation, University of Maryland). McGrath states: "Madison was aware of some of Condorcet's work [related to the voters' paradox] from the Encyclopedia Methodique and when he was writing Federalist 10 Condorcet's practical applications of these theories were fresh in his mind." Id. at 37; see also id. at 40 ("Madison ... had [] some knowledge of the Paradox of Voting."). While McGrath notes that Mazzei sent Madison the four "well-reasoned letters" referred to in the text, id. at 37, he produces no direct evidence that Madison read either the Encyclopedia Methodique or those letters. McGrath comments, for example, that "Madison reviewed this work just weeks before he wrote Federalist 10," $i d$. at 38, but admits in a footnote that "[t]he letter in which Madison commented on the book was written November 5, 1787; but it has been lost." Id. at 73 n.8 (citing PAPERS OF JAMES MADISON (Robert A. Rutland ed., 1975)). The only direct evidence McGrath produces conceming Madison's familiarity with Condorcet's letters is Madison's rather curt reply to Philip Mazzei: “If your plan of a single Legislature, as in Pennsylvania, \&c., were adopted, I sincerely believe that it would prove the most deadly blow ever given to Republicanism." Id. at 38 (citing Letter from James Madison to Philip Mazzei (Dec. 10, 1788), in 1 LeTTERS AND OTHER WRITINGS OF JAMES MADISON 444 (New York, Worthington 1884)). This reply does not demonstrate familiarity with the basis of Condorcet's theory for unicameralism. Indeed, McGrath hedges on Madison's familiarity with the voters' paradox, stating: 
who was strongly committed to creating a bicameral federal legislature, likely did not read the Condorcet letters attempting to prove the superiority of unicameralism. ${ }^{13}$ Duncan Black, a modern founder of social choice theory, along with Nobel laureate Kenneth Arrow, reached a similar conclusion, claiming that E.J. Nanson, who described the voting paradox in 1882 , was the first English speaker to understand Condorcet's insights on social choice. ${ }^{14}$

While Condorcet's efforts to influence the framing of the Constitution failed, his intellectual descendants have attempted to combine his insights with modern understandings of social choice to influence constitutional interpretation two hundred years later. In 1972, Kenneth Arrow won the Nobel Prize in large part for proving mathematically that no legislative process can simultaneously satisfy the five assumptions on legislative fairness set forth below and remain rational, where rationality is defined as the capability of aggregating individual preferences into transitive group orderings. ${ }^{15}$ Since then, literature in the field of social choice has proliferated. ${ }^{16}$ This proliferation has both influenced and been influenced by the law reviews. Although no court to date has expressly recognized the significance of Arrow's Impossibility Theorem on collective decisionmaking, social choice theory has had a very significant impact upon legal scholarship. ${ }^{17}$ Perhaps more

[I]t is not unlikely that a technician, busy attempting to construct something and thoroughly familiar with many similar attempts in the past, discovers empirically a problem not yet anticipated in theory. This, I maintain, is what happened to Madison. Busy trying to find a reason for republican failures of the past and the perceived failures of the 1780's in the new states of America, Madison developed an explanation of those failures which corresponds remarkably to the theoretical prediction of Kenneth Arrow. Id. at 3.

One reason why Jefferson and Madison may not have read Condorcet's work on social choice is that it was "buried in a few pages of the enormous Essai." McLean \& Urken, supra note 2, at 446. Jefferson, for example, catalogued the Essai under the heading, "Mathematics. Pure. Arithmetic," suggesting that he did not recognize its significance to collective decisionmaking. Id. at 449.

13. McLean \& Urken, supra note 2, at 455 (explaining that while Madison had been presented with letters containing Condorcet's theory of voting, "[t]here is no direct evidence that he had read it at all, and both it and the text encasing it put forward views to which Madison was strongly opposed").

14. See id.; see also BLACK, supra note 1, at 186-88.

15. See Michael E. Levine \& Charles R. Plott, Agenda Influence and Its Implications, 63 VA. L. REv. $561,561 \mathrm{n} .2$ (1977). In short, Arrow proved the intractability of a wide range of collective preference aggregation problems, including the Condorcet Paradox. Accord WILliaM H. RIKER, LiBERALISM AGAINST POPULISM: A CONFRONTATION BETWEen THE THEORY OF DEMOCRACY AND THE THEORY OF SOCIAL CHOICE 116 (1982) (explaining that Arrow's Theorem "is a generalization of the paradox of voting").

16. See Levine \& Plott, supra note 15 , at 562 n.2 (observing that "[a]n entire literature has grown out of [Arrow's] effort, consisting mostly of attempts to escape the rather depressing implications of this theorem and of attempts to identify the range of circumstances to which it applies" and adding that "attempts to sabotage the theory or to weaken its implications ... have not been nearly as successful as originally hoped"); Amartya Sen, Social Choice and Justice: A Review Article, 23 J. ECoN. LIT. 1764, 1765 n.7 (1985) (observing that the "number of books and papers published in formal social choice theory has now certainly exceeded a thousand, the bulk of it coming in the last decade and a half'); see also Levmore, supra note 8, at 985 ("The [voting] paradox is surely one of the best known insights or topics in the social sciences.") (footnote omitted). While this Article in no sense attempts to "sabotage the theory," it does provide a framework for assessing Atrow's Theorem's relevance in analyzing our constitutional collective decisionmaking bodies that may limit some of the theory's "depressing implications."

17. A recent LEXIS search in the law review data base using the query "Arrow's Theorem" yielded ninety-three articles. In contrast, not a single case in the Genfed or Allstate data bases mentions Arrow's 
astounding than the quantity of literature generated under the label "social choice" is the range of propositions that Condorcet's initial insight has been used to support in recent years.

\section{B. Social-Choice-Based Normative Proposals}

Scholars have used Arrow's Theorem to argue that legislative bodies are fundamentally incompetent, justifying significantly expanded judicial review. ${ }^{18}$ In addition, scholars have used Arrow's Theorem, often in

Theorem. One case, Branion v. Gramley, 855 F.2d 1256, 1264 (7th Cir. 1988), mentions Condorcet, but in a context that does not involve the voting paradox.

18. See, e.g., Lynn A. Stout, Strict Scrutiny and Social Choice: An Economic Inquiry into Fundamental Rights and Suspect Classifications, 80 GEO. L.J. 1787, 1822 (1992) ("Some of those who argue against substantive judicial review of legislative judgments believe democratic rule is inherently desirable. Arrow's Theorem cautions otherwise.") (footnote omitted); see also RIKER, supra note 15, at 137 (arguing that "the consequences of [Arrow's Theorem] are either that power is concentrated in society or that any system of voting can be manipulated to produce outcomes advantageous to the manipulators or at least different from outcomes in the absence of manipulation"); id. at 167 (concluding that "the meaning of social choices is quite obscure"); LAURENCE H. TRIBE, AMERICAN CONSTITUTIONAL LAW \$ 1-7, at 12 n.6 (2d ed. 1988) (positing that Arrow's Theorem "[a]t the least ... puts the burden of persuasion on those who assert that legislatures (or executives) deserve judicial deference as good aggregators of individual preference").

Stout's article is among the most notable examples of using social choice theory to advance farreaching claims for expanded judicial review. Professor Stout argues that social choice theory provides a strong basis for supporting several Supreme Court decisions applying strict scrutiny to invalidate statutes under the Fourteenth Amendment Due Process and Equal Protection Clauses and for attacking other Supreme Court decisions that have upheld statutes against similar constitutional challenges. This Article is not intended to demonstrate that the Supreme Court decided any of the particular cases that Stout describes correctly or incorrectly; it does, however, demonstrate that the theory of social choice fails to provide an independent basis with which to determine the outcome of these cases.

Stout argues, for example, that binary legislative voting fails to account for the intensity with which some persons are harmed by a wide range of privacy-infringing or discriminatory statutes. See Stout, supra, at 1789 ("When a legislature's majority voting rules fail to incorporate preference intensities or encourage rent seeking, the result may be legislative failure, statutes that diminish rather than increase citizens' average level of well-being.") (footnote omitted). Stout cites as examples laws that classify based upon immutable traits or that single out discrete and insular minorities for disparate treatment, id. at 1817 (discussing United States v. Carolene Products, 304 U.S. 144, 152 n.4 (1938)); laws that prohibit intimate homosexual acts, id. at 1827 (criticizing Bowers v. Hardwick, 478 U.S. 186 (1986)); and laws that prevent individuals from choosing to terminate life support equipment, $i d$. at 1802-04 (discussing Cruzan v. Director, Missouri Department of Health, 497 U.S. 261 (1990)). Stout argues that because legislative voting procedures are deficient, Arrow's Theorem justifies placing decisional authority over such issues in the Supreme Court. Id. at 1789 ("An independent judiciary that strictly scrutinizes these statutes can protect against the welfare losses that flow from legislative failure."). If this Article's thesis is correct, Stout's analysis is precisely backwards. Legislatures, because they condone logrolling and strategic voting, have a comparative advantage relative to appellate courts, including the Supreme Court, which base their decisions upon legal principles, in taking intensity of preferences into account in their decisional processes. See infra notes 213-36 and accompanying text (applying unanimity and independence criteria to Supreme Court and Congress to demonstrate that the latter institution is superior at taking intensity of preferences into account).

In fact, Stout appears to recognize at least some of the difficulty with her own thesis, see Stout, supra, at 1795 (acknowledging that legislators logroll); id. at 1826 n.164 (acknowledging that appellate courts, because they are collective decisionmakers, are subject to the tenets of Arrow's Theorem). Stout attempts to avoid these problems by proposing a regime in which courts themselves logroll. $1 d$. at $1826 \mathrm{n} .164$. Stout contends, somewhat oddly, that judges can logroll at lower cost than legislators if judges "act as representatives of different constituencies." Id. Recognizing however that appellate courts have often thwarted the very rights that she seeks to advance, Stout argues that this anomaly is due to the Article III appointments process. If judges were appointed with the goal of creating a "diverse judiciary" consisting 
combination with the more interest-group-oriented public choice literature, ${ }^{19}$ to support a wide variety of normative proposals for statutory interpretation. These proposals include, first, strictly honoring the terms of legislative bargains, eschewing the notion of collective intent; ${ }^{20}$ second, reading a publicregarding purpose into statutes to minimize the impact of special interest group

of judges "from a variety of ethnic, racial, and class backgrounds," Stout contends, then federal judges would find the process of achieving the necessary consensus to protect such rights easier to achieve. Id. at $1829 \&$ n.177. While I am certainly not opposed to increasing diversity within the federal judiciary (although I do oppose altering the constitutional appointments process to achieve this end), this Article demonstrates that Stout's analysis of the supposed benefits that diversity would provide, based upon social choice, is also backwards. Ironically, Stout's proposal for judicial reform, if adopted, would likely replicate in federal appellate courts the very causes of legislative cycling that Stout claims justify shifting decisional responsibility from legislatures to appellate courts in the first place. See infra note 90 and accompanying text (explaining that cycling problems are exacerbated when participants' preferences are multi-peaked and ameliorated when preferences are uni-peaked). This is not to suggest that individuals with diverse backgrounds cannot share like preferences; it does, however, cast substantial doubt on Professor Stout's thesis that increasing the diversity of substantive viewpoints in federal appellate courts, including the Supreme Court, will ease the process of achieving appellate court consensus, thus increasing judicial rationality and reducing social welfare losses.

19. Indeed, some of the scholars whose works are cited below, infra notes 20-24 and accompanying text, mention the insights from the social choice literature as merely one reason among many for departing from conventional methods of constitutional or statutory interpretation. See, e.g., Cass R. Sunstein, Interpreting Statutes in the Regulatory State, 103 HARV. L. REV. 405, 410 (1989) (citing social choice literature in support of proposition that "those who emphasize the findings of public choice theory would treat statutes as lacking coherent normative underpinnings") (footnote omitted); William N. Eskridge, Jr., Politics Without Romance: Implications of Public Choice Theory for Statutory Interpretation, 74 VA. L. REV. 275, 284 (1988) (positing that Arrow's Theorem demonstrates that "results achieved under 'democratic' voting rules are arbitrary. The mere fact that Decision 1 is adopted may mean nothing more than that Legislator $A$ controls the agenda (e.g., holds the chair during the proceedings).") (footnote omitted). Specifically, these authors and others combine the axiomatic social choice literature with the public choice interest group literature. This Article will focus primarily on social choice, although it will draw on some public choice literature where necessary to explain relevant social choice concepts. See infra notes 193-201 and accompanying text.

20. In Frank H. Easterbrook, Statutes' Domains, 50 U. CHI. L. REV. 533, 547 (1983), the author argues based upon Arrow's Theorem that "[a]lthough legislators have individual lists of desires, priorities, and preferences, it turns out to be difficult, sometimes impossible, to aggregate these lists into a coherent collective choice." (footnote omitted). After explaining that agenda control renders the process of determining even an individual legislator's preferences difficult and that logrolling provides a potentially misleading appearance of unanimity among legislators as a whole, id. at $547-48$, Easterbrook goes on to state:

In practice, the order of decisions and logrolling are not total bars to judicial understanding. But they are so integral to the legislative process that judicial predictions of how the legislature would have decided issues it did not in fact decide are bound to be little more than wild guesses, and thus to lack the legitimacy that might be accorded to astute guesses. Moreover, because control of the agenda and logrolling are accepted parts of the legislative process, a court has no justification for deciding cases as it thinks the legislature would in their absence. It might as well try to decide how the legislature would have acted were there no threat of veto or no need to cater to constituents.

Id. at 548; see also Frank H. Easterbrook, The Supreme Court, 1983 Term-Fonward: The Court and the Economic System, 98 HARV. L. REV. 4, 51 (1984) ("Interest-group legislation requires adherence to the terms of the compromise. The court cannot 'improve' on a pact that has no content other than the exact bargain among the competing interests, because the pact has no purpose."); Richard A. Posner, Economics, Politics, and the Reading of Statutes and the Constitution, 49 U. CHI. L. REV. 263, 270-72 (1982). But see Richard A. Posner, Legal Formalism, Legal Realism, and the Interpretation of Statutes and the Constitution, 37 CASE W. RES. L. REV. 179, $195-96$ (1986) (arguing that "[a] document can manifest a single purpose even though those who drafted and approved it had a variety of private motives and expectations."); RICHARD A. POSNER, THE FEDERAL COURTS 286-93 (1985) (arguing for "imaginative reconstruction" of statutes). 
influence; ${ }^{21}$ and third, varying levels of judicial scrutiny according to the extent and malignancy of interest group involvement. ${ }^{22}$ Ironically, perhaps, given Condorcet's alleged commitment to liberalism, ${ }^{23}$ the theorem has even been used to support imbuing our legislative processes with a modified republican hue. ${ }^{24}$

21. See, e.g., Jonathan R. Macey, Promoting Public-Regarding Legislation Through Statutory Interpretation: An Interest Group Model, 86 CoLUM. L. REv. 223, $250-56$ (1986). Macey explains:

When the legislature has passed a statute that claims to be in the public interest but in fact benefits an interest group, that interest group may meet with frustration in the courts when it tries to enforce the statute. The statute is unlikely to serve the ends it claims to serve and at the same time enrich a particular group. When the court interprets the statute so as to serve the public, the court may ... inadvertently invalidate a legislative bargain. But when this happens it is all to the common good.

Id. at 254. After reviewing Easterbrook's application of Arrow's Theorem to the Supreme Court, Macey goes on to state, "the inconsistency of Supreme Court decisions ought not to be viewed as an unmitigated evil. While inconsistency is detrimental when it leads to the misapplication of public interest statutes, it is beneficial when it results in nullification or misapplication of special interest group bargains." Id. at 259-60.

22. See, e.g., Sunstein, supra note 19, at 448 (" $[\mathrm{F}]$ ar from having a good constitutional pedigree, the pluralist understanding [that courts should recognize legislation as codified deals among special interests and enforce them as such] runs afoul of the fundamental constitutional norm against naked interest-group transfers."); Cass Sunstein, Naked Preferences and the Constitution, 84 ColuM. L. REv. 1689, 1698-1704 (1984) (positing that statutes enacting "naked preferences" should be narrowly construed); Eskridge, supra note 19, at 319-37 (noting that courts, in interpreting statutes, should vary the level of scrutiny depending upon the combination of benefits conferred and costs imposed).

23. See McLean \& Urken, supra note 2, at 445 (describing Condorcet as a "dedicated liberal"). Notwithstanding this characterization, Condorcet's views reflect the influence of Jean-Jacques Rousseau's republican writings. See Young, supra note 1, at 1231 (discussing and comparing views of Condorcet and Rousseau). For example, in the Essai, Condorcet premised his assertion that legislators, in choosing among options before them, should not be influenced by options that may be introduced in the future on the notion that legislators seek to determine what is objectively best for society. Id. The concept is strikingly similar to Rousseau's republican concept of the general will. See generally JEAN-JACQUES ROUSSEAU, THE SOCIAL CONTRACT (Maurice Cranston trans., 1968).

24. See Daniel A. FARber \& Philip B. FRICKEY, LAW AND Public Cholce: A CRIMcal INTRODUCTION (1991). The authors explain:

To the extent that recent advocates of republicanism have rejected total pluralism, public choice supports them. . . . We are skeptical of the more utopian strands of neo-republican thought. A careful reading of the public choice literature does support, however, a more modest version of republicanism, in which concern about the public interest and legislative deliberation play a role in politics.

Id. at 61 (citations omitted). The authors further state:

Democracy cannot be equated with pure majority rule, because pure majority rule is incoherent. Rather, a viable democracy requires that preferences be shaped by public discourse and processed by political institutions so that meaningful decisions can emerge. Given this richer understanding of democracy, Arrow's Theorem holds fewer terrors.

Id. at 61-62.

In his recent book advocating federal term limits, George Will made a similar, albeit more direct, plea for classical republicanism, although his argument is not based upon Arrow's Theorem. See GEORGE F. WILL, RESTORATION: CONGRESS, TERM LIMITS AND THE RECOVERY OF DELIBERATIVE DEMOCRACY (1992). The author states:

[T]erm limitation is an idea nourished by two intellectual streams. One is the Founders' understanding of the institutional prerequisites for deliberative democracy .... [The other] is the idea of classical republicanism. That idea had a larger role in the American founding, and hence has a larger relevance to contemporary American governance, than most Americans realize.

Id. at 151. While the term limit debate is beyond the scope of the present discussion, the Article does demonstrate that without the need to infuse a classic republican mindset into our political actors, Arrow's Theorem does not render our system of govemance inherently irrational. 
This Article demonstrates that this social choice renaissance, at least its renaissance in the legal literature, has been largely misguided. The purpose of this Article is certainly not to undermine the relevance of social choice. The theory has made and continues to make significant contributions to an understanding of our collective decisionmaking institutions. ${ }^{25}$ Social choice has made impressive contributions to political and economic theory. ${ }^{26}$ In fact, this Article relies upon social choice theory to explain decisional processes in the Supreme Court and in Congress that absent a social choice framework appear counterintuitive. ${ }^{27}$ In addition, the Article draws upon insights from other scholárs who have used social choice to argue against several of the normative proposals outlined above, especially those that call for greater judicial intervention in lawmaking processes. In short, the objective of this Article is twofold: (1) to demonstrate that social choice theory does not compel the vast majority of normative proposals outlined above; and (2) to provide a framework for social choice theory that renders it more useful in analyzing our constitutionally established lawmaking bodies.

Frank Easterbrook and others, for example, have observed that appellate courts, including the Supreme Court, are collective decisionmakers subject to the tenets of social choice. ${ }^{28}$ This insight undermines arguments for expanded judicial review that are premised on the ground that legislatures are uniquely susceptible of cycling. In addition, Daniel A. Farber and Philip P. Frickey have recently counseled against adopting far-reaching normative proposals for legislative reform based upon social choice, claiming that sophisticated mathematical models demonstrate that legislatures are more stable and rational than early social choice theorists thought possible. ${ }^{29}$ Finally, some have taken

25. See, e.g., Levmore, supra note 8 (developing evolutionary hypothesis, based upon Arrow's Theorem, that demonstrates that various rules of parliamentary procedure are similar where they are capable of yielding Condorcet winners and are dissimilar where they are not).

26. A complete listing of the numerous sources that could be cited for this proposition is impossible, see Sen, supra note 16, at $1765 \mathrm{n} .7$ (compiling partial bibliography and describing proliferation of social choice literature in the last several years). A preliminary list of citations would include ARRow, supra note 6; BLACK, supra note 1; MUELLER, supra note 6; RIKER, supra note 15.

27. This Article differs from the social-choice-based legal scholarship thus far in that it provides an explanation as to why legislative voting processes are better suited to identify and to act upon Condorcet winners than are appellate courts. This explanation, as demonstrated below, has significant implications for a wide range of modern jurisprudential theories.

28. See, e.g., Frank H. Easterbrook, Ways of Criticizing the Court, 95 HARv. L. Rev. 802 (1982); see also Lewis A. Kornhauser, Modeling Collegial Courts. II. Legal Doctrine, 8 J.L. ECON. \& ORGANIZATION 441 (1992); Levine \& Plott, supra note 15, at 563 ("Decisionmaking by multi-judge appellate courts . . . [and other collective decisionmakers] display[s] features that may make them vuinerable to similar theoretical criticism [based on social choice]."); Lewis A. Kornhauser \& Lawrence G. Sager, Unpacking the Court, 96 YALE L.J. 82 (1986). While these authors have recognized that appellate courts are subject to Arrow's Theorem in some form, this Article demonstrates that these authors have misunderstood the theorem's significance for appellate court decisionmaking. In addition, these authors and others have misunderstood the theorem's significance when assessing both legislatures and appellate courts, given that these institutions operate in conjunction with, rather than in isolation from, each other.

29. See FARBER \& FRICKEY, supra note 24, at 50-51, 54 \& n.45 ("The 'sense of the legislature' or the legislative center of gravity comesponds to the solution sets (yolk, strong point, uncovered set or whatever) of recent formal models."); Daniel A. Farber \& Philip P. Frickey, Legislative Intent and Public 
an altogether different tack, namely, attempting to prove the theorem wrong, or at least, irrelevant, by challenging the underlying assumptions and definitions, especially Arrow's definition of rationality. ${ }^{30}$

\section{The Nirvana, Isolation, and Composition Fallacies}

While this Article draws on much of this literature, it takes a substantially different approach in criticizing social-choice-based normative proposals that seek to tinker with our constitutional scheme. More importantly, the Article devises a rigorous framework with which to assess all future social-choicebased normative proposals. The Article's thesis applies with equal force to normative proposals that seek to modify judicial review ${ }^{31}$ and those that seek to modify legislative practices. ${ }^{32}$ Underlying most, if not all, social-choicebased normative proposals, is one or more of three fundamental flaws. First, through the "nirvana fallacy," scholars erroneously compare real-world institutions with some abstract or ideal institution, even if the ideal institution

Choice, 74 VA. L. REv. 423, 432-33 (1988). Farber and Frickey, in arguing that legislatures are more rational than Arrow's Theorem suggests, however, merge two concepts that are critically distinct in social choice theory. In characterizing and responding to an argument by Judge Easterbrook, for example, Farber and Frickey state:

Although Judge Easterbrook acknowledges the importance of agendas in legislatures, he seems to view them as an additional source of arbitrariness and unpredictability. On the contrary, the recent public choice literature suggests that agenda rules make outcomes more predictable and therefore more understandable.

Id. at 431 (footnote citing Easterbrook, Statutes' Domains, supra note 20, at 547-48, omitted).

The authors' contention that legislative processes are predictable and understandable does not undermine Judge Easterbrook's argument, based upon social choice theory, that the results of those processes are arbitrary in their failure to refiect the majority's preferences. Indeed, a wholly irrational process may be quite predictable and understandable, for example, vesting substantial agenda control in a person whose preferences, although shared by no other legislator, are well-known. For a simple illustration, consider a rule that allows only two pairwise votes for three options, vanilla, chocolate, and coffee. As demonstrated infra note $\mathbf{2 0 0}$ and accompanying text, the choice of flavor is fully within the control of the person given the power to set the agenda. Indeed, the person who controls the agenda, with this rule in place, can achieve any desired outcome. Assuming that the preferences are known in advance, the outcome of the process, while admittedly predictable and understandable, remains arbitrary and irrational if the procedure is intended to reflect the preferences of a majority of the participants. As shown infra notes 22831, however, social choice theory can be used to strengthen the argument advanced by Farber and Frickey that agenda control, if understood and anticipated by legislators, can enhance both legislative predictability and rationality.

30. See, e.g., Richard H. Pildes \& Elizabeth S. Anderson, Slinging Arrows at Democracy: Social Choice Theory, Value Pluralism, and Democratic Politics, 90 CoLUM. L. REV. 2121, 2146-58, 2192 (1990). The authors criticize the rationality assumption on the ground that it fails to consider that numerous fundamental values are inherently diverse (or plural) and incommensurable. As shown below, this criticism misconceives Arrow's definition of rationality. See infra note 115; see also Herbert Hovenkamp, Arrow's Theorem: Ordinalism and Republican Government, 75 IOWA L. REV. 949 (1990) (arguing that formal assumptions of Arrow's Theorem's rarely hold).

31. See supra notes 18-22 and accompanying text.

32. See, e.g., FARBER \& FRICKEY, supra note 24, at 55 (arguing for germaneness and single-subject rules based on social choice theory); Pildes \& Anderson, supra note 30, at 2201 n.211 (arguing that social choice theory, unlike the authors' proposed participatory democracy model, operates from the erroneous premise that majoritarian preferences as such have an independent and legitimate value, and claiming instead that "preferences must be backed up by publicly acceptable reasons"). 
has never existed or, as in this case, has been proven impossible to devise. ${ }^{33}$ Indeed, Arrow's Theorem proves that it is impossible to devise a collective decisionmaking institution that simultaneously satisfies five specified fairness assumptions and the condition of rationality (or transitivity). ${ }^{34}$ Beginning with the premise that our constitutionally created collective decisionmaking institutions do function, the relevant inquiry is which assumptions must be relaxed to render those institutions functional. In other words, the Arrovian criteria should be used as an ideal, or norm, against which to assess divergences within real-world institutions. Second, through the "isolation fallacy," scholars fail to consider that the collective decisionmaking bodies they are studying have never operated, and were never intended to operate, in isolation, but rather were intended to operate in an inherently complementary fashion with other collective decisionmaking institutions. Finally, through the closely related "fallacy of composition," 35 scholars fail to recognize that even

33. For an excellent discussion of the "nirvana fallacy," coincidentally directed at an article by Kenneth Arrow (albeit in a different context), see Harold Demsetz, Information and Efficiency: Another Viewpoint, 12 J.L. \& ECON. 1 (1969). Demsetz explains the fallacy as follows:

The view that now pervades much public policy economics implicitly presents the relevant choice as between an ideal norm and an existing "imperfect" institutional arrangement. This nirvana approach differs considerably from a comparative institution approach in which the relevant choice is between alternative real institutional arrangements. In practice, those who adopt the nirvana viewpoint seek to discover discrepancies between the ideal and the real and if discrepancies are found, they deduce that the real is inefficient. Users of the comparative institution approach attempt to assess which alternative real institutional arrangement seems best able to cope with the economic problem; practitioners of this approach may use an ideal norm to provide standards from which divergences are assessed for all practical alternatives of interest and select as efficient that alternative which seems most likely to minimize the divergence.

Id. at 1 . In short, Demsetz maintains that markets are not superior at resource allocation because they are maximally efficient, but because they are less inefficient than any alternative. While an omniscient being might be able to increase aggregate utility by altering the allocation of resources resulting from a series of market transactions, that does not undermine the claim that the market remains a superior resource allocator to an alternative regulatory regime, given that regulators are neither omniscient beings nor capable of cardinalizing preferences with market precision.

Ronald Coase, in criticizing scholarly works that study a world with zero transactions costs, has made a similar argument illustrating the nirvana fallacy:

[W] hile consideration of what would happen in a world of zero transaction costs can give us valuable insights, these insights are, in my view, without value except as steps on the way to the analysis of the real world of positive transactions costs. We do not do well to devote ourselves to a detailed study of the world of zero transaction costs, like augurs divining the future by the minute inspection of the entrails of a goose.

R.H. Coase, The Coase Theorem and the Empty Core: A Comment, 24 J.L. \& ECoN. 183, 187 (1981) [hereinafter Coase, The Empty Core]; see also R.H. Coase, The Problem of Social Cost, 3 J.L. \& ECON. 1, 43 (1960) [hereinafter Coase, The Problem of Social Cost] ("Actually very little analysis is required to show that an ideal world is better than a state of laissez faire .... But the whole discussion is largely irrelevant . . . since whatever we may have in mind as our ideal world, . . . we have not yet discovered how to get to it from where we are.").

34. See discussion infra Part III; cf. Demsetz, supra note 33, at 1 . The analysis considers one additional criterion: the ability of a collective decisionmaker to act upon a Condorcet winner, when one is available.

35. The isolation and composition fallacies are closely related but distinct. The isolation fallacy is the failure to recognize that a particular institution that cycles might not cycle if it works in conjunction with another institution. The fallacy of composition is the failure to recognize that, even if two separate institutions cycle, collectively they may reduce cycling. The two remain distinct because (1) the decisionmaker that prevents a given institution from cycling may be a single person, thus implicating the 
if two or more collective decisionmaking institutions are susceptible of cycling, working together they avoid cycling unless they happen to cycle in the same manner and in response to the same factual phenomena. ${ }^{36}$ To understand the implications of Arrow's Theorem for our constitutional division of lawmaking responsibility it is essential to analyze each of these analytical errors.

Avoiding the "nirvana fallacy" requires a novel Arrow's Theorem analysis of our collective decisionmaking bodies. This Article begins with the seemingly obvious premise that Arrow's Theorem is correct insofar as it is an axiomatic proof. ${ }^{37}$ The theorem proves that five assumptions, each associated with fair collective decisionmaking, cannot coexist in an institution that renders rational decisions, where rationality is defined as the ability to aggregate individually ranked preferences into transitive group orderings. ${ }^{38}$ The five assumptions are: (1) "range," allowing all participants to rank all available choices; (2) "universal domain," allowing all aggregate rankings regardless of individual rankings; (3) "unanimity," proceeding with any proposal that leaves at least one person better off and no person worse off; ;9 "nondictatorship," disallowing any one participant to impose her preferences on the group; and (5) "independence of irrelevant alternatives," disallowing choices that may be presented in the future to influence decisions in any given pairwise vote. ${ }^{40}$

This Article departs from existing work in the significance it attaches to the theorem. Given that Congress and the Supreme Court actually function ${ }^{4}$-meaning simply that Congress passes bills for the President to

isolation fallacy, but not the composition fallacy; and (2) there may be circumstances in which two institutions cycle in the same manner and in response to the same factual phenomena, thus preventing the institutions from having a positive synergistic effect in reducing cycling when operating together. Both fallacies come into play when the two decisional bodies each have multiple members, such that are capable of cycling, and when the factual phenomena that cause one to cycle do not cause the other to cycle.

36. See, e.g., FARBER \& FRICKEY, supra note 24, at 55 ("In a sense, the Riker/Easterbrook thesis [demonstrating the susceptibility of legislatures to cycling] proves too much. If chaos and incoherence are the inevitable outcomes of majority voting, then appellate courts (which invariably have multiple members and majority voting rules) and even the 1787 Constitutional Convention are equally bankrupt. As a result the Riker/Easterbrook thesis is bereft of any implications for public law, since it tells us to be equally suspicious of all sources of law. If we accept the thesis as to legislatures, we are left with nowhere to turn."); cf. Hovenkamp, supra note 30, at 972 (arguing that "Arrow's theorem is not a constraint on 'distributive' legislation as opposed to 'efficiency' legislation. ... Arrow's theorem suggests that all legislative solutions, whether efficient or otherwise, are inherently unstable and cannot yield determinative social welfare functions.").

37. Cf. John Craven, Social Choice: A Framework for Collective DeCisions and INDividual JUDGMENTS I (1992) ("If Arrow's result were not true, we could then stop.").

38. See RIKER, supra note 15, at 116 ('The essence of Arrow's theorem is that no method of amalgamating individual judgments can simultaneously satisfy some reasonable conditions of fairness on the method and a condition of logicality on the result.").

39. This is simply a restatement of the Pareto optimality criterion. See CRAVEN, supra note 37, at 3435 (describing relationship between Arrovian unanimity requirement and Pareto optimality criterion).

40. See Easterbrook, supra note 28, at 823 (listing conditions of Arrow's Theorem); see also discussion infra Part III.A (providing more detailed explanation of Arrow's Theorem assumptions).

41. Much of the analysis in this Article applies equally to other appellate courts and legislatures. For clarity of presentation, the Article focuses largely on Congress and the Supreme Court and points out differences where necessary. 
sign or veto and that the Supreme Court issues opinions that resolve cases before $i^{42}$-at least one of the five fairness assumptions or the requirement of rationality must not hold, in practice, for each of these institutions. It is in that respect that Arrow's Theorem is axiomatic. Deriving the theorem's real significance, then, for comparative purposes, requires the following three-step process: $:^{43}$ first, identifying which assumption(s) is relaxed for each institution; second, analyzing how relaxing each assumption affects the relevant institution's ability to render meaningful collective decisions; and, third, comparing the ability of a given institution to which collective decisionmaking responsibility has been assigned under the Constitution to issue a rational collective decision, with the ability of an alternative institution for which decisionmaking responsibility is proposed after applying the first two parts of this analysis to the alternative institution. This three-step process for avoiding the nirvana fallacy explains the Article's overall structure and methodology: it uses the Arrovian criteria as an ideal against which to measure, then compare, collective decisionmaking bodies. ${ }^{44}$

The analysis also exposes the "isolation fallacy," demonstrating that Congress and the Supreme Court operate together to achieve a greater level of rationality than each would if it operated alone. ${ }^{45}$ Finally, the analysis exposes the "fallacy of composition," demonstrating that multiple collective decisionmaking bodies, even if each is independently susceptible of cycling, can operate together to reduce cycling when each cycles in a different manner and in response to different factual phenomena. The analysis of the isolation and composition fallacies demonstrates that the prevalence of cycling across institutions is substantially less cause for alarm than it first appears. ${ }^{46}$

Part II uses three hypotheticals involving markets and lawmaking bodies to define and to illustrate, first, the isolation and composition fallacies; second, the game-theoretical problem of the empty core, which provides a deeper understanding of Arrow's Theorem; and, third, the differences in factual

42. This Article considers the extent to which, these activities notwithstanding, these institutions remain dysfunctional. See discussion infra Part IV.

43. Cf. Demsetz, supra note 33, at 1 (distinguishing comparative institutional analysis of economic institutions from nirvana analysis).

44. See discussion infra Parts III ("Defining the "Ideal' Norm") and IV ("The Supreme Court and Congress Through an Arrovian Lens").

45. The Article also places appellate courts and legislatures within a broader framework of collective decisionmaking institutions, including markets and agencies. See discussion infra Part V. Widening the Arrovian lens not only demonstrates how multiple collective decisionmakers may work better together than alone, but also demonstrates that each institution, most notably markets, is subject to a version of the Condorcet Paradox. See discussion infra Parts II and V.

46. See, e.g., FARBER \& FRICKEY, supra note 24, at 55 (explaining that because Arrow's Theorem presumably applies to both appellate courts and to legislatures, arguments that legislatures are inherently chaotic and incoherent, in effect, "tell[] us to be equally suspicious of all sources of law. If we accept the thesis as to legislatures, we are left with no where to turn."); Pildes \& Anderson, supra note 30, at 2139-40 (explaining that if the Court were to abandon the attempt to reason from legislative outcomes, as Judge Easterbrook and others have suggested, "[r]ather than curing legislative irrationality, ... judicial irrationality [would] merely coexist[] alongside it"). 
phenomena that give rise to market and legislative cycling. Part III revisits Arrow's Theorem to demonstrate the similarities between the Condorcet Paradox and the problem of the empty core. This Part also describes and illustrates the concept of a Condorcet winner, which is essential to understanding the differences between congressional and Supreme Court decisional processes. Both the Arrow's Theorem assumptions and the Condorcet criterion provide the ideal norm or benchmark against which to assess departures for purposes of evaluating the relative competence of any collective decisionmaking body. Part IV describes how Congress and the Supreme Court depart from the Arrovian ideal in different ways. ${ }^{47}$ This Part also demonstrates how these two institutions, working together, behave in a substantially more rational manner than each would working alone and suggests that several normative proposals based upon social choice would undermine, rather than enhance, the collective rationality of those institutions. Perhaps most importantly, Part IV demonstrates why legislatures are better equipped than appellate courts to identify Condorcet winners, those options that prevail over all alternatives in pairwise contests. Finally, Part V draws and expands upon the thesis advanced in the prior parts by placing legislatures and appellate courts within a broader framework of collective decisionmaking institutions, including markets and agencies.

\section{MARKETS, LeGISLATURES, AND THE EMPTY CORE}

To illustrate the isolation and composition fallacies, this Part presents three hypothetical case studies that involve the interplay between markets and legislatures and that demonstrate the different circumstances that lead to market and legislative cycling. The first case study was presented in a 1981 article by Varouj A. Aivazian and Jeffrey L. Callen. ${ }^{48}$ Their article intended to establish that the Coase Theorem, "which states that in the absence of transaction costs resource allocation is neutral with respect to liability rules,"49 is sometimes indeterminate with more than two participants. ${ }^{50}$ For present purposes, the more important analysis is offered in Ronald Coase's response. He demonstrates that while an empty core, as explained below, can in fact render the Coase Theorem indeterminate, contract damage rules may restore determinacy. ${ }^{51}$ The second case study, based on the recent Supreme Court

47. As indicated above, supra note 41 , this discussion is intended to apply generally to appellate courts and legislatures.

48. Varouj A. Aivazian \& Jeffrey L. Callen, The Coase Theorem and the Empty Core, 24 J.L. \& ECON. 175 (1981) (arguing that Coase Theorem is indeterminate in three-person game with empty core).

49. Id. at 175; see also Coase, The Problem of Social Cost, supra note 33, at 6 (demonstrating Coase Theorem in two-participant context).

50. Aivazian \& Callen, supra note 48 , at 175 ("[W]ith more than two participants the Coase theorem cannot always be demonstrated.").

51. Coase, The Empty Core, supra note 33, at 187. 
decision, New York v. United States, ${ }^{52}$ illustrates the difference in factual circumstances that lead to market and legislative cycling. The third case study, which involves intestacy law, further illustrates that off-the-rack legal rules can restore stability among private decisionmakers negotiating in the absence of a core.

\section{A. The Case of the Polluting Firms}

In the 1950's, at the same time that social choice theory was reemerging in economic theory, economists discovered a phenomenon nearly identical to the Condorcet paradox within private markets. ${ }^{53}$ The problem, known as the "empty core," demonstrates that in certain circumstances, participants in private markets may be unable to arrive at any conclusive set of contractual arrangements and may therefore cycle indefinitely. ${ }^{55}$ The only significant difference between this phenomenon and the Condorcet Paradox, is that the "empty core" takes place among private market participants rather than among lawmakers. The 1981 Aivazian and Callen article ${ }^{56}$ presents a hypothetical which is particularly helpful for present purposes.

Two factories, $A$ and $B$, pollute a river to the detriment of a large laundry, C. If $\mathrm{A}, \mathrm{B}$, and $\mathrm{C}$ operate independently and do not negotiate with each other, the profits per day for each company, noted as $\mathrm{V}(\mathrm{A}, \mathrm{B}$, or $\mathrm{C})$, are as follows: $\mathrm{V}(\mathrm{A})=\$ 3000 ; \mathrm{V}(\mathrm{B})=\$ 8000 ;$ and $\mathrm{V}(\mathrm{C})=\$ 24,000$. If any two companies form a coalition, their joint profits increase ${ }^{57}$ as follows: $V(A, B)^{58}=$ $\$ 15,000 ; V(A, C)=\$ 31,000 ;$ and $V(B, C)=\$ 36,000$. These two-party coalitions do not affect the profits of the remaining party. Finally, a grand coalition of all three companies would yield aggregate profits of $\mathrm{V}(\mathrm{A}, \mathrm{B}, \mathrm{C})=\$ 40,000 .^{59}$ Assume that in any coalition that includes the launderer, $\mathrm{C}$, the other participant(s) agree to close down, leaving $\mathrm{C}$ to operate with reduced (or in the

52. 112 S. Ct. 2408 (1992).

53. See John S. Wiley Jr., Antitrust and Core Theory, 54 U. CHI. L. Rev. 556, 557 n.10 (1987) (explaining that while "[t]he core has precursors in the last century, . . . it was introduced as such in 1953 by Gillies and by Shapely [sic: Shapley] in unpublished works. The idea surfaced in specialized publications later in the 1950's.").

54. For a thorough analysis of core theory, see generally LESTER G. TELSER, ECONOMIC THEORY AND THE CORE (1978). While this Part will present a formal definition of the term empty core, after providing an illustration, the concept can briefly be described as follows: The core is the set of stable outcomes that can be predicted using the standard tools of economic analysis. An "empty core" means that no such predictable and stable outcomes exist. The more formal definition, infra note 68 and accompanying text, will be easier to understand in light of the example provided in the text.

55. Because no one really knows what happens in the absence of a core, a more accurate statement may be that economic theory cannot be used to predict what will happen in the absence of a core.

56. Aivazian \& Callen, supra note 48 .

57. The authors explain that "[i]n the merger literature this phenomenon is known as synergy. In the game-theory literature the characteristic function $\mathrm{V}$ is said to be superadditive." Id. at 177.

58. $V(A, B)$ means the profits of both $A$ and $B$ if $A$ and $B$ create a coalition.

59. Aivazian \& Callen, supra note 48 , at 176. 
case of the grand coalition, with no) pollution. This means that if A and B both stop polluting, ${ }^{60} \mathrm{C}$ 's profits would increase from $\$ 24,000$ to $\$ 40,000$.

Any combination that includes a two-party coalition generates greater aggregate profits than does the status quo in which $\mathrm{A}, \mathrm{B}$, and $\mathrm{C}$ operate independently. ${ }^{61}$ For example, if $\mathrm{A}$ and $\mathrm{B}$ form a coalition, their joint profits become $\$ 15,000$, as opposed to $\$ 11,000$. Because C's profits remain unchanged with the coalition (A,B), aggregate profits increase by $\$ 4000$ for all three companies through that coalition. ${ }^{62}$ The grand coalition $(A, B, C)$ yields the maximum possible profits, $\$ 40,000$. To see why, consider the coalition $(A, B)$ with $C$ operating independently. Because $V(A, B)=\$ 15,000$ and $V(C)$ $=\$ 24,000$, the profits total $\$ 39,000 .^{63}$ Thus, if $\mathrm{A}, \mathrm{B}$, and $\mathrm{C}$ operate with no coalitions, maximum profits are $\$ 35,000$. Any combination that includes a twoparty coalition yields maximum profits among all three parties of $\$ 39,000$, $\$ 1,000$ less than the grand coalition profits of $\$ 40,000$.

Aivazian and Callen demonstrate that in this hypothetical, the Coase Theorem is indeterminate because the bargaining lacks a core. As a result, the presence or absence of a pollution liability rule may affect which coalitions form and thus whether $A$ and $B$ continue to operate. ${ }^{64}$ Assume, first, for example, that the polluters, $A$ and $B$, are liable for all pollution damages that they cause $C$. In that case, the core is not empty and the grand coalition is stable. $C$ will operate without pollution and $A$ and $B$ will close because $A$ and $B$ cannot generate sufficient profits independently or in the coalition $(A, B)$ to bribe $C$ into letting them operate. ${ }^{65}$ Because no party or group of parties can bribe $\mathrm{C}$ into changing the status quo, the game, with a pollution liability rule in place, has a core.

Complications arise when there is no pollution liability rule. While it is obvious that the grand coalition is the most efficient, it is not obvious that the grand coalition will form. The critical point, however, is that whether the parties are likely to achieve a grand coalition, thus causing $A$ and $B$ to close, depends upon whether there is a liability rule for breach of contract. Any two parties can increase their aggregate profits relative to the status quo by forming a coalition, and all three parties can increase their aggregate profits relative to

60. This assumes that there are no polluting firms other than $A$ and $B$.

61. To simplify matters, assume that if A and B form a coalition, their profits increase through economies of scale.

62. The reader can confirm that the same holds true for coalitions $(A, C)$ and $(B, C)$.

63. Similarly, a combination that includes the two-party coalition $(A, C)$, with $V(A, C)=\$ 31,000$ and $V(B)=\$ 8000$, yields total profits of $\$ 39,000$, as does a combination that includes the two-party coalition $(B, C)$, with $V(B, C)=\$ 36,000$ and $V(A)=\$ 3000$.

64. This is directly contrary to the Coase Theorem, which provides that, absent transactions costs and with perfect information, liability rules do not affect resource allocation. See Coase, The Problem of Social Cost, supra note 33 , at 6.

65. $C$ earns $\$ 16,000$ more without $A$ and $B$ operating than with $A$ and $B$ operating. The maximum profits $A$ and $B$ can generate is $\$ 15,000, V(A, B)=\$ 15,000$, which is therefore insufficient to bribe $C$ into letting them continue to operate. 
any combination that includes a two-party coalition by forming the grand coalition. The difficulty is that no coalition, including the grand coalition, is stable because the bargaining lacks a core.

To see why, consider either of two alternatives: first, an initial decision by two parties, $A$ and $C$, to enter into a coalition without $B ;{ }^{66}$ and second, a decision by $\mathrm{A}, \mathrm{B}$, and $\mathrm{C}$ to enter into the grand coalition. If $\mathrm{A}$ and $\mathrm{C}$ form a coalition, their joint profits are $\$ 31,000$. As stated above, all of the profits are earned by $\mathrm{C}$, which means that $\mathrm{A}$ is required to close down. If $\mathrm{A}$ and $\mathrm{C}$ operated independently, A would earn $\$ 3000$ and $C$ would earn $\$ 24,000$, for a total of $\$ 27,000$. The two-party coalition increases the profits of $A$ and $C$ by $\$ 4000$. To induce $A$ to join coalition (A,C), $C$ must bribe $A$ to close down with at least $\$ 3000$, the amount $A$ would earn by operating independently. To simplify the analysis without changing it, assume that $\mathrm{A}$ is a good negotiator and requires that $C$ split the $\$ 4000$ superadditive surplus. A now earns $\$ 5000$ $(\$ 3000$ plus $\$ 2000$ ) and $C$ earns $\$ 26,000$ ( $\$ 24,000$ plus $\$ 2000$ ). Is the coalition (A,C) stable? No.

$B$ can now lure either $A$ or $C$ to form coalitions $(A, B)$ or $(B, C)$, thus increasing the profits for the (defector, $B$ ) coalition. For example, if $A$ defects to form coalition $(A, B), A$ and $B$ earn joint profits of $\$ 15,000$. In the new coalition, the superadditive surplus is again $\$ 4000$. This time, however, $A$ earns $\$ 3000$ from operating. If $B$ will give $A$ more than the $\$ 2000$ coalition surplus that $C$ gave to $A, A$ has an incentive to defect from $(A, C)$ to form $(A, B)$. Assume that $A$ is again savvy and requires that $B$ split the difference between the surplus that $C$ was willing to pay, $\$ 2000$, and the total additional profits generated by the new $(A, B)$ coalition, $\$ 4000$, such that $A$ now earns an additional $\$ 3000$ and $B$ earns an additional $\$ 1000$. Is the coalition $(A, B)$ stable? No.

Now $C$ has an incentive to bribe either $A$ or $B$ to defect. $C$ can again earn $\$ 4000$ more by forming coalition $(B, C)$, and $B$ will defect to form that coalition if $C$ pays $B$ more than the $\$ 1000$ surplus that $B$ earned in coalition $(A, B)$. Similarly, A will defect to form $(A, C)$ if $C$ pays A more than the $\$ 3000$ surplus that it earned in coalition $(A, B)$. In short, no two-party coalition is stable because there is always an alternative (defector,excluded party) coalition that can improve the lot of its members.

The same phenomenon arises if all three parties agree to form the grand coalition $(A, B, C)$. Assume that they divide the $\$ 5000$ superadditive profits evenly, $\$ 1666$ each. Now A earns $\$ 4666$, B earns $\$ 9666$, and C earns $\$ 25,666$. Any two of the three can now increase their profits by defecting to create a two-party coalition. Thus, A and B can increase their joint profits from $\$ 14,332$ to $\$ 15,000$ by defecting; $A$ and $C$ can increase their joint profits from

66. The reader is free to confirm that the same analysis applies with the remaining two-party coalitions, $(A, B)$ and $(B, C)$. 
$\$ 30,332$ to $\$ 31,000$ by defecting; and $B$ and $C$ can increase their joint profits from $\$ 35,332$ to $\$ 36,000$ by defecting. Of course, once two parties defect to form a coalition, the above analysis demonstrating the instability of two-party coalitions holds. In short, assuming no contractual damages and zero transactions costs, no two-party or three-party coalition is stable in this hypothetical because the core is empty. ${ }^{67}$

With this illustration in mind, John Shepard Wiley Jr.'s general description of the empty core phenomenon is quite helpful:

The core of a game is the set of solutions that leaves no coalition in a position to improve the payoffs to all of that coalition's members. A solution ... in the core thus offers no possible subset of players an option to defect to a different coalition and do better on their own. If some group can improve its collective lot by playing in a different way, then that subset will reconstitute itself as a new coalition that will play the game in a different way and, hence, distribute the game's proceeds differently. Because the new coalition will block the first round's result from emerging as the stable or permanent resolution of the game, the first round solution is said to be outside the core. If some new coalition of players can block all possible solutions of a game, no solution is within the core. Synonymously, any such game has an empty core. ${ }^{68}$

67. One interesting potential solution to the cycling problem is vertical integration. This may not, however, provide a means with which to avoid the cycling problem, but may, instead, simply create a new outlet for cycling. Presumably a fourth company, D, or even one of the present companies, could engage in the necessary takeovers to "internalize" the superadditive gains in the example. The problem is that if we assume perfect information and zero transactions costs, each time a prospective takeover bid is anticipated, the excluded party or the object of the bid could make a new bid aimed at forming a different combination or a bid aimed at forming the same combination at a higher price. Given the superadditivities, the result might be a "bidding war" that becomes merely another outlet for endless cycling. It may instead, as Coase suggests, see Coase, The Empty Core, supra note 33, at 186-87, reach a conclusion if the gains from the continuous bids and counterbids asymptotically approach the potential gains available from forming the maximally integrated firm, which merges all of A, B, and C. See infra text accompanying note 73. In short, the same indeterminacy from cycling results whether the participants attempt to form coalitions or to vertically integrate.

68. Wiley, supra note 53, at 558. In other words, the core is empty when there is no Nash equilibrium. See Herbert Hovenkamp, Rationality in Law and Economics, 60 GEO. WASH. L. REV. 293, 312 (1992) ("A Nash equilibrium is a set of choices such that no player has any incentive to deviate from the set, given the options available to the opponent."); see also Keith N. Hylton, Efficiency and Labor Law, 87 Nw. U. L. REv. 471, 502 (1993) ("The equilibrium of a game is in the core if it is 'coalition-proof' in the sense that no subgroup has an incentive to form a coalition in order to change the existing coalition."); Telser, supra note 54. While defaulting to the status quo may be the outcome of the hypothetical in the text, that outcome is not stable. Given the superadditivities, the parties will always have an incentive to depart from the status quo to form coalitions, just as they will always have an incentive to depart from any particular coalition that is formed. This is why it is impossible to predict a stable outcome.

Wiley criticizes George Bittlingmayer's thesis that core theory may provide a basis for exempting some industries from the per se prohibition on horizontal price-fixing announced in United States v. Addyston Pipe \& Steel Co., 85 F. 271 (6th Cir. 1898), aff'd, 175 U.S. 211 (1899). Wiley, supra note 53, at 580-87. Bittlingmayer, relying upon the analysis of Lester Telser, attempts to demonstrate that some horizontal price-fixing may be a necessary means to enhance output among multiple market participants competing in the absence of a core. See generally George Bittlingmayer, Decreasing Average Cost and Competition: A New Look at the Addyston Pipe Case, 25 J.L. \& ECON. 201 (1982). While an analysis of the antitrust implications of core theory is well beyond the scope of this Article, Wiley's response to 
In an insightful, albeit mixed, metaphor, Wiley goes on to state: "A finding that a market situation has no core upsets theorists because they cannot state that the situation has a tendency to align individual conduct with social advantage; the Invisible Hand lurches off on a random walk."

The empty core problem is a generalization of the Condorcet Paradox. ${ }^{70}$ In the ice cream cake hypothetical, for example, ${ }^{71}$ if the coalition (Alice,Bob) decides that it will impose chocolate upon the group, Carole can lure Alice away and make the new coalition (Alice,Carole) better off by selecting coffee. Then Bob can lure Carole away to form the coalition (Bob,Carole) in favor of vanilla. This time Alice lures Bob away to reform the coalition (Alice,Bob) in favor of chocolate. While the group has completed its first cycle, there is no means to predict the outcome precisely because the hypothetical, which exemplifies the Condorcet Paradox, has an empty core.

In response to Aivazian and Callen, Ronald Coase demonstrated that contract rules could render the market substantially more determinate even in the absence of a pollution liability rule. ${ }^{72}$ Assume an expectancy damages rule for breach of contract. Further assume the grand coalition, with profits divided evenly as outlined above: A earns $\$ 4666$, B earns $\$ 9666$, and C earns $\$ 25,666$. While it remains true that any two parties can increase their profits by defecting, the contract damages rule consumes these profits and thus removes

Bittlingmayer's argument is noteworthy. Wiley asserts, remarkably, that judges "should wholly ignore core theory's implications for antitrust." Wiley, supra note 53, at 557. He bases his categorical response on the following insight: "Telser's idea [of exempting from the Addyston per se rule those industries that, based upon core theory, engage in benign horizontal price-fixing] is worth pursuing only if the costs it saves outweigh these losses from cartelization." Id. at 578 . Wiley adds: "But when we ask just how costly empty cores are likely to be, the rather surprising answer is that, to date, the theory of the core hasn't a clue." Id. at 578-79. While Wiley is certainly correct that the costs and benefits should be assessed before proceeding with any proposal, such analysis is most often used to attack proposed regulatory regimes. Wiley instead uses the analysis to support sustaining a regulatory regime, namely the Addyston Pipe prohibition on horizontal price-fixing. The same analysis, however, can be readily turned against Wiley: Given the uncertain costs associated with prohibiting horizontal price-fixing, in light of core theory, do the benefits of the per se prohibition necessarily outweigh the costs?

69. Wiley, supra note 53, at 579 . This may explain a phenomenon which, although based upon anecdotal evidence, I have observed on repeated occasions. Persons who describe themselves as conservative often tend to gravitate toward law and economics until they stumble across game theory, at which point they immediately become uncomfortable. In contrast, persons who describe themselves as liberal tend to find law and economics relatively unattractive until they discover game theory. In part, this Article is intended to demonstrate that while game theory is helpful in explaining how some of our legal institutions operate, it should be less influential in affecting the prior status quo between these two groups.

In contrast with games involving three or more persons, the outcomes of two-person games are not susceptible to cycling because no move from a given outcome can improve the situation of one player without leaving the other player worse off. See Aivazian \& Callen, supra note 48, at 176 (explaining that in "the two-participant case ... the core is always nonempty"). In other words, two-person games, unlike games with three or more persons, always have Nash equilibria.

70. See Lynn A. Baker, Direct Democracy and Discrimination: A Public Choice Perspective, 67 CHI.Kent L. REv. 707, $726 \mathrm{n.63}$ (1991) ("The core of the game is identical with the Condorcet Paradox."); Hovenkamp, supra note 68, at 332-33 ("In short, the intransitivity problem shows up in exactly the same fashion as it does in the legislative situation.").

71. See supra p. 1221.

72. Recall that if a pollution liability rule is present, there is no empty core problem. See supra notes 64-65 and accompanying text; Coase, The Empty Core, supra note 33, at 186-87. 
the incentive to defect. While any two parties can defect and increase their joint profits by $\$ 668$, they will face a $\$ 1666$ penalty for breach of contract. In short, the contract damages rule renders the grand coalition stable. It remains unclear whether the parties will cycle endlessly in negotiations before they formally enter into a coalition, grand or two-party. As Coase points out, however, they should quickly realize, assuming they consistently divide the superadditive gains, that their maximum joint profits from repeated two-party negotiations and defections will asymptotically approach $\$ 39,000$, while the grand coalition will yield $\$ 40,000 .^{73}$ If the parties know that contract damages will eat up any superadditive profits from defection, the grand coalition may become an attractive alternative to negotiation and defection. ${ }^{74}$

This hypothetical illustrates an important aspect of this Article's central thesis. ${ }^{75}$ While an empty core may render the market susceptible to cycling, an appropriate legal regime will reduce this tendency (at least postcontractually). ${ }^{76}$ Of course, markets are not the only collective decisionmaking institutions that cycle. How can the legal system, then, help reduce market cycling when the legislature, and indeed appellate courts, also cycle? ${ }^{77}$ The answer is twofold.

73. Coase, The Empty Core, supra note 33, at 186-87.

74. See id. at 184-87.

75. Of course, both courts and legislatures will presumably respond to the factual phenomena giving rise to the empty core in this hypothetical differently than do market participants. While this example presents a state law issue, the same analysis is readily extended to cover bankruptcy questions arising under federal law. Assume no federal or state bankruptcy rules or other rules on creditors' remedies. Further assume that company $A$ has $\$ 10$ in assets and owes $\$ 50$ each to companies $B$ and $C$, and that a majority vote (here two out of three companies) will determine how A's assets will be divided. The reader is free to confirm that the result will be endless cycling because the hypothetical lacks a core. In other words, given the superadditivities, no two- or three-party coalition is stable. While this may explain why Congress or state legislatures are better suited than the participants themselves to create off-the-rack bargaining rules, in the form of bankruptcy laws, it is also consistent with recent "chameleon equity" proposals. See generally Barry E. Adler, Financial and Political Theories of American Corporate Bankruptcy, 45 STAN. L. REv. 311, 362-63 (1993) (outlining chameleon equity proposal); Michael Bradley \& Michael Rosenzweig, The Untenable Case for Chapter 11, 101 YALE L.J. 1043, 1079 (1992) (outlining contingent equity proposal); see also Robert $\mathrm{K}$. Rasmussen, Debtor's Choice: A Menu Approach to Corporate Bankruptcy, 71 TEX. L. REv. 51, 100-07 (1992) (advocating alternative menu approach). For a critical review of these and other bankruptcy proposals, see David A. Skeel, Jr., Markets, Courts, and the Brave New World of Bankruptcy Theory, 1993 WIS. L. REv. 465. In other words, provided that the parties foresee the potential for cycling in the event that company A becomes insolvent, and that they iron out an agreement ex ante as to how to proceed in that event, the legal system maximizes all parties' utility only if it allows the parties to substitute their preferred rules for legislatively created off-the-rack rules. See infra p. 1244. Indeed, even under existing federal bankruptcy rules, which require that creditors in the same class be treated in a like manner, similar cycling problems can arise among the equity holders and the various classes of creditors.

76. While ex ante legal rules reduce the tendency of markets to cycle, they also violate the formal dictates of Arrow's Theorem by giving decisional authority to nonparticipants. One caveat, however, is essential. Given that no solution to the cycling problem is, or can be, perfect, this partial solution appears justifiable on the ground that ex ante legal rules are a "less bad" proxy than any alternative for what the market participants would have chosen had they thought about the cycling problem and hammered out an agreement.

77. For a discussion of how legislatures and courts cycle, see infra Parts II.B (describing legislative cycling) and IV.A (describing appellate court cycling). 
First, the difference between the creation of legal rules in legislatures and courts on the one hand and market negotiations by private parties on the other is that legal rules are created ex ante, before the facts arise that lead to cycling, while negotiations occur ex post, after the facts arise that lead to cycling. While A, B, and C, left to their own devices, may be unable to avoid cycling in a game in which every repeat defection yields a gain, that does not mean that a legislature or court, empowered to create prospective rules-even if that lawmaking body tends to cycle - cannot reach a meaningful consensus. Indeed, even if $\mathrm{A}, \mathrm{B}$, and $\mathrm{C}$ were the only participants in the legislative process, for example at a town meeting with three citizens, they might well agree on an efficient expectancy damages rule for breach of contract before an actual set of facts arises creating the empty core problem outlined above. ${ }^{78}$ Of course, many more people than the participants in any particular game are involved in, and affected by, the enactment of ex ante legal rules. Thus, even if $A, B$, and $C$ actually enjoyed endless negotiations and defections that lead nowhere, it is unlikely that the community in which they live would agree to indulge them in this costly regime, precisely because such a regime may prevent that community from avoiding costly cycling in the future. ${ }^{79}$ Instead, the citizenry at large will prefer a set of contractual rules that allows economic actors to assume that when parties breach their contractual obligations, nonbreaching parties can obtain appropriate sanctions so that they may continue to rely upon the benefits associated with contracting.

\section{B. Location of Toxic-Waste Disposal Facility}

Now consider a situation in which the legislature is likely to cycle. Assume that a federal statute requires states to become self-sufficient in radioactive waste disposal by creating disposal facilities in-state. ${ }^{80}$ Assume

78. Expectancy damages is, in fact, the majority rule. See JOHN D. CALAMARI \& JOSEPH M. PERILLO, CONTRACTS $\$ 14-4$, at 591-92 (3d ed. 1987).

79. This is not to suggest that the government itself should enforce the contracts that are formed and then breached or that the legislature should choose to prevent the parties from contracting around the offthe-rack rules that it establishes. The point remains, however, that individuals benefit by assuming that offthe-rack rules are in place to punish breaches.

80. This hypothetical is based upon an adaptation of the facts in New York v. United States, $112 \mathrm{~S}$. Ct. 2408 (1992). In New York, the Court held the take-title provisions of the Low-Level Radioactive Waste Policy Amendments Act of 1985 unconstitutional because the amendments penalized states that failed either to enter into regional pacts for low-level radioactive waste disposal or otherwise to become self-sufficent within a preset time frame. Id. at 2427-28. Justice O'Connor, writing for the Court, held that the 1985 amendments exceeded Congress' delegated powers under Art. I, $\S$, because Congress did not have the power to "commandeer" the states into legislating and because the amendments did not leave the states with the power to do nothing. Id. at 2420,2428-29. The opinion also suggested that the holding was compelled by the Tenth Amendment, which O'Connor stated was the "mirror image[]" of the delegation of congressional powers. Id. at 2417; see also id. at 2419 ("In the end, just as a cup may be half empty or half full, it makes no difference whether one views the question at issue in this case as one of ascertaining the limits of the power delegated to the Federal Government under the affirmative provisions of the Constitution or one of discerning the core of sovereignty retained by the States under the Tenth Amendment."). 
that New York determines that the statute requires it to create one waste facility and identifies three possible sites that satisfy the environmental criteria for such a facility. Assume further that each proposed site is located in the center of one of three triangular shaped districts, $A, B$, and $C$, such that $A$ is to the north, $B$ is to the southeast, and $C$ is to the southwest. Each district is adjacent to the other two such that all three form a point in the middle. Figure 1 illustrates this hypothetical.

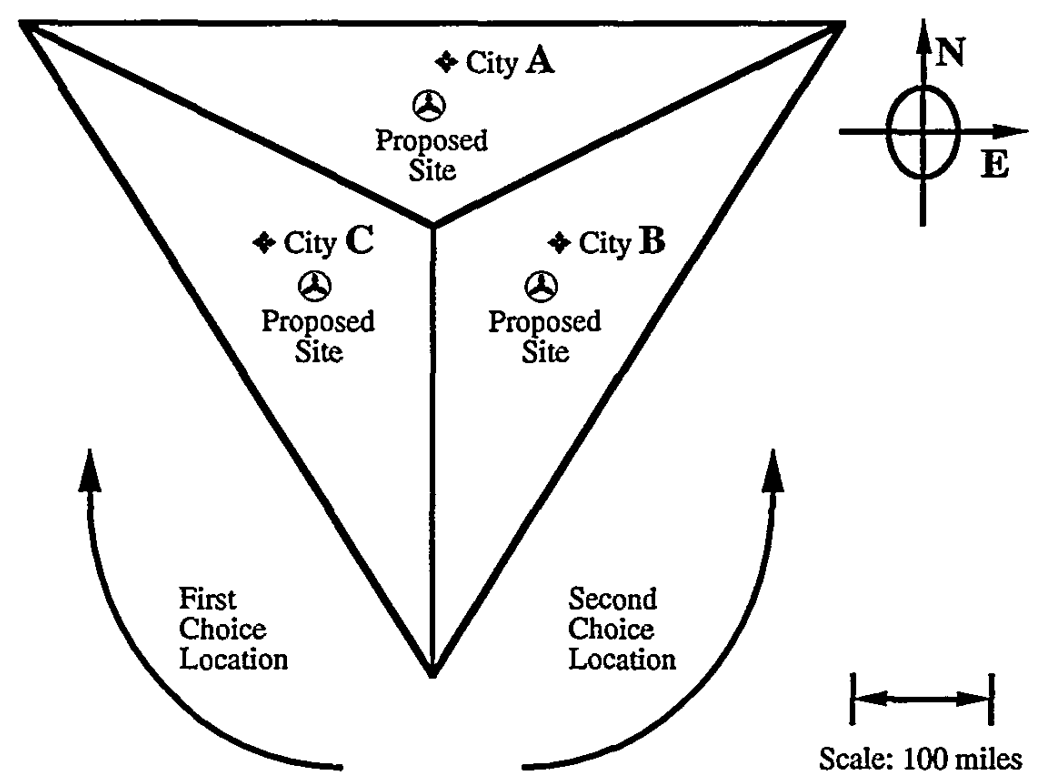

FIGURE 1. Proposed Locations of Toxic Waste Dump

Each district contains a significant residential area within 100 miles of the proposed site. Finally, assume, that a substantial majority of the voters in each district consider a facility in their district the worst option; that they consider a facility in the district situated counterclockwise from them the second worst option; and thus they prefer that New York build the facility in the district

The case has been cited as partly restoring the Supreme Court's Tenth Amendment jurisprudence in the aftermath of Garcia v. San Antonio Metropolitan Transit Authority, 469 U.S. 528 (1985) (holding that the Tenth Amendment does not prevent the application of minimum wage laws to municipalities and reversing the contrary holding in National League of Cities v. Usery, 426 U.S. 833 (1976)). See, e.g., Ira C. Lupu, Statutes Revolving in Constitutional Law Orbits, 79 VA. L. REv. 1, 57 (1993) ("New York v. United States has in a limited way restored the state sovereignty barrier erected in National League of Cities v. Usery and demolished in Garcia v. San Antonio Metropolitan Transit Authority a decade later ....") (footnotes omitted). 
located clockwise from their home district. The districts' preferences are then as follows: ${ }^{81}$

District A: B, C, A

District B: C, A, B

District C: A, B, C

A quick comparison will demonstrate that these preferences are identical to those in the ice cream cake hypothetical. Indeed, this is the non-Condorcet winning paradigm case which leads to cycling because there is an empty core. $^{82}$

Why in this hypothetical does the legislature cycle when in creating the ex ante rule for contract damages it does not? The answer is critical to understanding both the isolation fallacy and the fallacy of composition. In the waste storage hypothetical, New York has, as a result of the federal statute, suffered the equivalent of a capital loss. ${ }^{83}$ The issue facing the legislature, then, is how to allocate that loss. There is no core because the victim-district of any coalition formed to impose the loss on that district can lure away a coalition participant to form a (victim, defector) coalition that makes the new coalition members better off. ${ }^{84}$ This phenomenon is therefore identical with the market cycling phenomenon that occurs in the absence of a core. In contrast, in creating ex ante legal rules, the legislature is not allocating the burden of a capital loss. Instead, it is determining how a market should best operate to facilitate private transactions. Assuming participants legislate without knowing how the rules they devise will affect particular constituents in future transactions, all parties then have an interest in selecting efficient, utility-maximizing rules. ${ }^{85}$

81. To simplify the analysis without changing it, assume either that the remainder of the legislators are evenly divided among the same sets of preferences or, to make the analysis even easier, that these are the only legislators.

82. The New York case arose precisely because the state of New York did not create a mandated waste facility. $112 \mathrm{~S}$. Ct. at 2416-17 (explaining that after the state identified five potential sites, residents in two of the counties in which sites were proposed, and the state, brought suit against the United States). This suggests that inaction is at least one viable response to legislative cycling.

83. As shown in the next example, infra Part II.C, the same cycling phenomenon arises in attempting to divide the benefits of a capital gain.

84. Thus, if the representatives from Districts $B$ and $C$ form a coalition to place the waste site in District $A$, the representative from District $A$ can lure his colleague in District $B$ away to form a new coalition (District A, District B) to place the site in District C, leaving Districts A and B better off. The same analysis holds for any other two-party coalition.

85. Indeed, legislatures may be able to create rational ex ante rules even when a majority is not formed around a single option. See infra note 90 and accompanying text (describing decisionmaking with unipeaked preferences). The analysis in the text differs significantly from that offered by Herbert Hovenkamp. Hovenkamp states:

The implications of [Arrow's Theorem indeterminacy] should not be overlooked: Arrow's theorem is not a constraint on "distributive" legislation as opposed to "efficiency" legislation. It does not suggest that pork barrel legislation is prone to cycling while efficient legislation designed to correct market failures will yield stable social welfare functions. Arrow's theorem suggests that all legislative solutions, whether efficient or otherwise, are inherently unstable and 
This demonstrates the isolation and composition fallacies. Because the market and the legislature, in the context of devising prospective bargaining rules, do not work in isolation, and because the legislature does not cycle in response to the same phenomena that cause the market participants to cycle, the two institutions can reduce cycling when working in conjunction. This holds true even though in a different context, for example, in dividing the burdens of a capital loss, the legislature itself cycles.

While the foregoing discussion was obviously not an exhaustive analysis of the empty core problem or of the interplay between legislatures and courts, on the one hand, and markets, on the other, it did illustrate several important points. First, it demonstrated that markets have a comparative disadvantage relative to legislatures, or other lawmaking bodies, in devising off-the-rack ex ante rules designed to govern negotiations in the absence of a core, at least after the facts take place giving rise to the empty core. ${ }^{86}$ This is not to suggest that private market participants are unable to devise rules to govern future negotiations. But when negotiating begins after the facts arise that create an empty core, the legislature and the courts have a comparative advantage relative to the market participants themselves in devising facilitating rules. In this respect, the empty core problem is precisely analogous to the negotiating problems that arise when parties are forced into an unexpected market relationship or when an unanticipated contingency arises requiring postcontractual negotiations. ${ }^{87}$ In both sets of circumstances, the lawmaking body has a comparative advantage in devising facilitating rules because, unlike the market participants themselves, it behaves as if those underlying facts had not yet taken place. ${ }^{88}$

cannot yield determinative social welfare functions.

Hovenkamp, supra note 30 , at 972 . Hovenkamp adds: "As a result, one cannot use Arrow's theorem as a basis for dividing the territory between types of legislation and suggest that legislatures confine themselves to correcting market failures." Id, at 972-73. While this Article does not advocate limiting legislative action to "correcting market failures," the analysis offered in the text, contrary to that offered by Hovenkamp, does demonstrate that the legislature may have a comparative advantage, relative to market participants, in correcting certain kinds of market failures and may lack that comparative advantage when engaging in certain kinds of distributive legislation. See infra notes 86-87 and accompanying text.

86. As Herbert Hovenkamp has suggested, legislatures and courts may also have a comparative advantage relative to market participants in providing rules designed to facilitate, or to obviate the need for, postcontractual negotiations or negotiations arising when parties are forced into an unanticipated market relationship. Like negotiations in the absence of a core, post contractual negotiations can break down. See Hovenkamp, supra note 68, at 297 (providing examples of difficult negotiating circumstances resulting from markets that are not competitive). The two situations are analogous in that standard economic analysis cannot be used to predict, with any reasonable degree of certainty, the negotiated outcome. Lawmaking institutions, whether courts or legislatures, have a comparative advantage in designing off-the-rack rules in these circumstances because they behave as if the operative facts giving rise to the difficult negotiating circumstances had not yet taken place. Moreover, in the course of designing such rules, they reduce market transactions costs by defining postcontractual obligations ex ante, provided they allow the market participants to accept the legal regime's rules or to contract around those rules.

87. See, e.g., Hovenkamp, supra note 68, at 297.

88. The positive synergy between markets and legislatures may work in both directions. Not only can the legislature reduce market cycling by creating appropriate facilitating legal rules, but the market may be able, by responding differently to the same factual phenomena, to reduce the effects of an inefficient 
In short, the analysis demonstrates that core theory has much the same relevance as does the Coase Theorem in a world of positive transactions costs. To the extent that transacting is expensive, lawmaking bodies, in devising offthe-rack rules, do well only to the extent that they are successful in replicating what the parties would have agreed to had they thought about the problem giving rise to the particular difficult negotiating circumstance and hammered out a negotiated agreement. Otherwise, the parties may be stuck with a legal regime that they would not have chosen and be prevented from achieving their preferred negotiated outcome by virtue of the transactions costs. This perpetuates inefficient outcomes. Thus core theory suggests that, as with the Coase Theorem, the legal regime should attempt, where possible, to reach the solution to problems that the parties did not consider and provide for in terms. In the pollution example, that meant providing a contract damages rule. But while the legal regime attempts to achieve the postcontractual solution that the parties would have achieved in the case of the Coase Theorem, the legal regime attempts, in the case of the empty core, to establish background rules that avoid cycling.

While custom may suffice as a substitute for off-the-rack legal rules when little is at stake, ${ }^{89}$ the Coase Theorem and empty core problems both call for default legal rules in more serious cases. In addition, the tendency of both markets and legislatures to cycle does not necessarily mean that the two will

regulatory rule. While prohibitions on insider trading have the effect of reducing market efficiency by preventing insiders from moving the price of stock more quickly toward the market clearing price than in the absence of a prohibition, see generally HENRY MANNE, INSIDER TRADING AND THE STOCK MARKET (1966), diversification of market portfolios may ameliorate this inefficiency by reducing its financial impact for most people who hold securities. See Robert G. Hansen \& John R. Lott, Jr., Externalities and Corporate Objectives in a World with Diversified Shareholder Consumers (unpublished draft 1993). In short, if some companies' stock prices are effectively understated as a result of the prohibition on insider trading and other companies' stock prices are effectively overstated as a result of the prohibition on insider trading, a consumer can significantly reduce the risk of holding either category of stock by diversifying her portfolio. While this does not cure the inefficiency resulting from the insider trading prohibition, it significantly reduces the significance of that market imperfection for diversified investors.

89. Daniel A. Farber and Philip B. Frickey have argued that equal division based upon simple faimess may provide a stable "value solution," in at least some empty-core games. See Farber \& Frickey, supra note 29, at 434. The authors explain:

[T]his solution is a sort of equilibrium. It is true that any player could offer an amendment that would beat this outcome-but what would be the point of doing so and thereby setting off a round of endless cycling? In a sense, the existence of massive cycling provides the basis for a new form of equilibrium adopted precisely to avoid the cycles.

Id. (footnote omitted); see also MARTIN SHUBIK, GAME THEORY IN THE SOCIAL SCIENCES: CONCEPTS AND SOLUTIONS 179-216 (4th ed. 1987) (describing value solutions to empty-core games). Shubik cautions: "while there is a growing economic literature on fairness [as a value solution to empty-core games] ... [it] is only tangentially related to game theory." Id. at 413 . In other words, the merits of the Farber and Frickey contention that fairness provides a proxy for a core remains an empirical question, the foundations of which lie outside formal game theory. Moreover, while fairness may dictate the outcome of some emptycore games, e.g., when parties anticipate future games with the same players; when other factors, like familial relationships, dictate fairness; and where the stakes are small, the fact remains that faimess cannot be expected to dictate the outcome in all circumstances. When there is an empty core and when faimess cannot be relied upon to provide a proxy for a core, legal institutions can restore stability by providing appropriate legal rules. 
cycle when operating in conjunction, if they do not cycle in the same manner and in response to the same factual phenomena. Finally, the legislature may not have a comparative advantage in avoiding cycling when it is attempting to allocate the burdens of a capital loss (or, for that matter, the benefits of a capital gain) in the absence of a core.

To reiterate, the examples illustrated first the "isolation" fallacy, namely that market participants negotiating in the absence of a core will not endlessly cycle, at least postcontractually, if the market works in conjunction with an appropriate legal regime that punishes breach; and second, the "fallacy of composition," namely that multiple collective decisionmaking bodies, even when each is susceptible of cycling, will not cycle when working together if they do not cycle in the same manner and in response to the same factual phenomena. In short, using the language of game theory, multiple collective decisionmaking institutions have a superadditive effect in reducing cycling. The next Part will apply the same analysis to the Supreme Court and Congress.

These two examples further illustrate that commonality of preferences among decisionmakers increases the likelihood that the collective decisionmaking body will reach rational decisions. In the language of social choice, the above example illustrates the distinction between uni-peaked and multi-peaked preferences. In the waste disposal hypothetical, the legislature cycled because the legislators' preferences could not be aggregated along a single dimension. In contrast, when legislators are not attempting to allocate the losses imposed by a federal statute or trying to divide the gains of a federal grant, but instead are attempting to establish ex ante rules to facilitate market transactions, it is more likely that they will share common preferences, e.g., for utility maximization. In the language of social choice, it is more likely that their preferences will be uni-peaked. ${ }^{90}$ Uni-peakedness is one means to avoid

90. See Levmore, supra note 8, at 985-87 \& n.47, $1002-03$ (explaining how uni-peaked preferences function and how they operate to avoid Arrow's Theorem aggregation problems). Imagine, for example, that legislators $A, B, C, D$, and $E$ need to determine how much money to spend on a particular project and the choices are, in increments of $\$ 100,000,1,2,3,4$, or 5 . Using a motion-and-amendment procedure will not lead to cycling, even if each of five legislators has a different preference among the five options, because the preferences are uni-peaked. In fact, if you drew a graph with the legislators on one axis and the allocations on another, you could create a single peaked curve, sloping downward, from the legislator favoring the maximum expenditure to the legislator favoring the minimum expenditure. Given the unipeaked preferences, it does not matter whether the motion-and-amendment process starts from the highest proposal and works down or the reverse because as the votes move toward the center, for each increment, the proposal picks up one additional voter. A majority is achieved at 3 , regardless of procedure. See id. at 1002-03.

William H. Riker explains that "single-peakedness implies transitivity and hence ensures the existence of a Condorcet winner." RIKER, supra note 15, at 126. Riker further states:

Single-peakedness is important because it has an obvious political interpretation. Assuming a single political dimension, the fact that a profile ... is single-peaked means the voters have a common view of the political situation, although they may differ widely on their judgments.

Id. In contrast, Riker explains: "This kind of agreement is precisely what is lacking in a cycle, where voters disagree not only about the merits of alternatives but even about where alternatives are on the political dimension." Id. at 128. 
cycling, even when a majority of a collective decisionmaking body does not favor one of three or more options. ${ }^{91}$

\section{Alice, Bob, and Carole as Siblings}

To demonstrate the pervasiveness of the empty-core problem, this next example takes place in a context that does not involve business actors. Consider the plight of three siblings who have just inherited $\$ 180,000$ with no background law and no instructions. They decide on only one governing rule; they will divide based upon the decision of a majority, which in this case is two out of three. Otherwise, they are entirely free to decide how to divide the money. ${ }^{92}$ An obvious solution, based upon simple fairness, is for each to take $\$ 60,000 .^{93}$ It should be obvious that this result, and for that matter any other, is unstable. ${ }^{94}$ The core is empty and the cycles may continue indefinitely in the absence of some default legal rule.

Now assume that a legislature is devising an inheritance law governing the allocation of an intestate estate. Ex ante, there is no obvious reason for the legislature to prefer any one sibling over any other, e.g., based upon birth order or sex, ${ }^{95}$ and thus the obvious legal solution is an even division among siblings. Indeed this is the rule in virtually all jurisdictions today. ${ }^{96}$ Again,

One interesting implication of this analysis is that appellate courts may turn out to be quite rational in line-drawing situations, which are often touted as breeding grounds for judicial abuse. Line drawing by an appellate court may be rational because it is in that situation that the preferences of the court's members are most likely to be uni-peaked.

91. This analysis is directly contrary to that of Professor Stout, who has argued that increasing diversity among federal appellate judges, including Supreme Court Justices, will ease the task of invalidating statutes that create social welfare losses. See Stout, supra note 18 , at $1829 \mathrm{n} .177$. In fact, the above analysis, see supra note 90 , demonstrates the opposite: increasing commonality of outlook increases the likelihood of rational decisions while increasing diversity of outlooks increases the likelihood that the collective decisionmaking body will cycle. Cf. Einer R. Elhauge, Does Interest Group Theory Justify More Intrusive Judicial Review?, 101 YALE L.J. 31, 106 (1991) (positing that relaxing restraints on judicial range may exacerbate Arrovian cycling problems). Again, the Article is not intended to suggest that increasing diversity among federal judges is undesirable. It does suggest, however, that the justification for such a proposal must lie outside social choice theory.

92. The following analysis would also apply, for example, to state legislators attempting to divide the proceeds of a federal grant.

93. For a discussion of the (lack of) game-theoretical foundations for such fairness solutions, see supra note 89.

94. With equal division, for example, if Alice and Bob choose to defect and keep all the money for themselves, they stand to gain $\$ 60,000$. If they decide to split the gain evenly, they each take $\$ 90,000$. Carole then has an incentive to enter a coalition with either Alice or Bob and to pay either more than $\$ 90,000$ for defecting. If Alice defects and insists upon splitting the superadditive gains evenly with Carole, then Alice receives $\$ 135,000$ and Carole receives $\$ 45,000$. Of course, Bob now has an incentive to bribe Alice or Carole to defect. The cycling result is the same as in the pollution game.

95. Of course, the decedent may well have had reasons to favor one child over another. For this reason, virtually all jurisdictions allow bequests to supersede the off-the-rack rule. See WILLIAM M. MCGOVERN ET AL., WILLS, TRUSTS AND ESTATES: INCLUDING TAXATION AND FUTURE INTERESTS $\S 1.4$, at 21 (1988) (observing that wills allow decedents to supersede rules of intestacy through which, for example, "a wealthy or unloving child is treated the same as a needy and devoted one").

96. See id. $\S 1.2$, at $3-4$ (explaining that after spouse takes intestate share, "the issue shar[e] the balance"). 
even though private collective decisionmakers and legislatures may cycle on their own, when working in conjunction, the two institutions may not cycle.

While the frequency of empty core problems and the ways they are resolved remain empirical questions, ${ }^{97}$ the point remains that any analysis of how collective decisionmakers respond when faced with an empty core is incomplete without first determining whether the institution in which collective decisionmakers operate was intended to, and in fact does, operate in isolation. Only by considering the market mechanisms, for example, in conjunction with the legal regime can one meaningfully predict the ultimate outcome of negotiations in the absence of a core. ${ }^{98}$

\section{DEFINING THE "IDEAL" NORM}

Before demonstrating how the isolation fallacy and the fallacy of composition apply to congressional and Supreme Court decisionmaking, it is first necessary to revisit Arrow's Impossibility Theorem and to consider the Condorcet criterion, a partial solution to the Condorcet or voters' Paradox. As stated above, the Arrow's Theorem criteria and the Condorcet criterion provide the ideal, or benchmark, for judging the relative competence of real-world decisionmaking bodies. ${ }^{99}$

\section{A. The Arrow's Theorem Criteria}

Arrow's Theorem proves that five assumptions, seemingly necessary for fair collective decisionmaking, cannot coexist with a process that is capable of aggregating individual preferences into transitive group orderings. The following analysis considers each of the underlying assumptions and the rationality criterion in turn. ${ }^{100}$

1) Range: "Range" requires that participants in the decisionmaking process not be limited in their ability to choose from available options. Limiting individuals in their choice of options presented to the decisionmaking

97. See Aivazian \& Callen, supra note 48, at 181. The authors note: "Examples of negotiations where the core does not exist are easy to concoct and may be quite common in practice." Id.

98. This discussion is consistent with the intuition that markets remain superior at resource allocations, assuming preexisting resource endowments and zero transaction costs. But markets have a comparative disadvantage relative to legislatures in enacting ex ante rules that are necessary to guide market participants in negotiations in the absence of a core after the facts arise that create an empty core.

99. See supra note 33 (describing "nirvana fallacy"). While the Arrovian criteria provide the most obvious basis for defining the "ideal" collective decisionmaking institution, as shown below, the Condorcet criterion provides an additional, almost universally accepted, benchmark against which to measure the soundness and rationality of any collective decisionmaking institution.

100. These terms are universally used in the social choice literature. Mueller attributes these terms, which differ from those initially used by Kenneth Arrow, to William Vickrey, Utility, Strategy, and Social Decision Rules, 74 Q.J. ECON. 507 (1960). MUELLER, supra note 6, at 385. The definitions that follow are my best attempt to synthesize many variations on the same set of definitions that recur in the literature, including those offered by Vickrey, into a simple and usable form. 
body would substitute democratic form over substance by presenting a number of options and then requiring that everyone vote only for some of those options.

2) Universal Domain: "Universal domain" is essentially the flipside of "range." In aggregating individually ranked preferences, no particular aggregate ordering is off limits. Again, this insures that the decisional process is democratic in substance rather than merely in form. If certain aggregate orderings are off limits before the votes are cast, then the votes of some individuals will count for more than the votes of others; persons who voted for proscribed outcomes will have effectively thrown their votes away.

3) Unanimity: The oddly named "unanimity" assumption ${ }^{101}$ is really a substitute for the Pareto optimality requirement of welfare economics. Unanimity in this context means that if a proposal benefits at least one person and leaves no other person worse off, the institution must proceed with the proposal. While this might seem to suggest that one person can control the process, that is not the case. A proposal that benefits one person will not proceed unless no one else is harmed, which means that at the very least everyone else is indifferent to whether the proposal carries. ${ }^{102}$ In standard economic analysis, proceeding with such proposals is a requirement of efficiency. ${ }^{103}$ The term "unanimity" is best understood by considering the limited category of proposals that a collective decisionmaking body would be willing to commit to adopting unanimously ex ante, before those proposals are formally presented to it for consideration. Presumably, any collective decisionmaking body would agree unanimously ex ante to approve automatically any proposal satisfying the Pareto optimality criterion, because such proposals always increase aggregate utility without harming anyone. ${ }^{104}$

101. See Vickrey, supra note 100, at 508 (defining unanimity as follows: "If an individual preference is unopposed by any contrary preference of any other individual, this preference shall be preserved in the resulting social ordering. (This is, of course, the principle of Pareto optimality.)").

102. For those who have studied microeconomics, this principle is well illustrated by considering the Edgeworth box in which two persons have concave preference curves. The contract curve is the set of points satisfying the criterion that any future trade would leave at least one party worse off. In contrast, all points off the contract curve are inefficient in that through a trade that moves onto the contract curve, at least one party will be made better off while the other party will not be made worse off. Unanimity simply requires that all legislative outcomes be on the contract curve when possible.

One caveat is essential here. The traditional Edgeworth analysis involves two players. This is easily modified, however, to satisfy the Arrow's Theorem requirement. Assume that one side is the preference curve of the individual favoring the proposal and that the other side is the aggregate preference curve for all the players who are indifferent. Unanimity simply requires that the players, one of whom favors the proposal and the second of whom is defined as the indifferent remainder of the group, agree to move onto the contract curve whenever possible.

103. One of the major benefits of market decisionmaking as a means of allocating resources, setting aside the problems of externalities and initial endowments, is that market transactions satisfy the Arrovian unanimity criterion. All market participants agree to the transactions in which they engage. See Levmore, supra note 10 , at 150 ("Every market transaction can be seen as the equivalent of a unanimous decision (leaving aside the problems of externalities and disparate endowments), because only voluntary transactions take place.").

104. See generally BuCHANAN \& TULLOCK, supra note 10, at 171-74 (describing Pareto criterion). For 
4) Nondictatorship: The "nondictatorship" assumption, while the most obvious for any democratic collective decisionmaking process, ironically turns out to be quite problematic. Nondictatorship requires that no one person's set of preferences control the group. This may at first blush sound like a restatement of the requirement of universal domain, but there is a critical difference. Universal domain holds that the group will not precommit to exclude any set of aggregate preferences; nondictatorship holds that the group will not precommit to exclude the preferences of all individuals but one. In other words, the first prevents a predetermined set of preferences from controlling; the second prevents a predetermined individual from controlling. The difficulty, as demonstrated in the Arrow's Theorem proof presented in the Appendix, is that nondictatorship is ultimately inconsistent with the concept of rationality, defined below. ${ }^{105}$

The nondictatorship criterion turns out to be extremely controversial in yet another respect. The criterion essentially prevents the institution from placing greater weight on the relative ordering of one person than on the relative ordering of a second person. Put differently, the criterion provides that every person's rankings receive equal weight regardless of the intensity with which any individual may hold her relative ordering. Even if Carole only slightly prefers vanilla to coffee, for example, but greatly prefers coffee to chocolate, the group cannot provide less weight to the first relative preference, vanilla to coffee, than to the second, coffee to chocolate, in a series of pairwise votes. To do so would allow Carole's votes to be weighted more heavily than those of her colleagues. This requirement stems from the economic tradition of refusing to engage in interpersonal utility comparisons. ${ }^{106}$

5) Independence of Irrelevant Alternatives: The "independence" requirement is, along with the requirement of rationality, among the theorem's most debated assumptions. ${ }^{107}$ Independence requires that individuals remain true to their ranked sets of preferences in all pairwise votes, without trying to

an analysis of whether increasing one person's tangible benefits without decreasing any other person's tangible benefits may still leave the latter person worse off, see Richard H. McAdams, Relative Preferences, 102 YALE L.J. 1 (1992). The textual explanation of unanimity uses an ex ante perspective because after the facts take place that would allow a Pareto move that benefits one person and harms no persons, those not harmed may still prevent the Pareto move by engaging in opportunistic behavior.

105. See infra notes 111-16 (defining Arrovian rationality criterion). While it is not necessary to understand the Arrow's Theorem proof for the discussion that follows, the Appendix presents interested readers with a very simplified proof and cites more thorough presentations.

106. While some scholars have attempted to demonstrate that this ironclad requirement of economic analysis is wrongheaded, see, e.g., Stout, supra note 18, at 1800 (contending that the "argument against interpersonal utility comparisons essentially is an offshoot of the skeptic's argument against the existence of other minds"), this Article instead relies on standard economic analysis, eschewing interpersonal utility comparisons. It does so for two reasons: first, I remain unconvinced that institutions are capable of engaging in meaningful interpersonal utility comparisons; and second, it is not necessary to modify this standard assumption of economic analysis to pursue the analysis to follow.

107. See RIKER, supra note 15, at 101 (explaining that while independence "seems a fundamental requirement of consistency and faimess to prevent the rigging of elections and the unequal treatment of voters ... it has nevertheless been seriously disputed") (footnote omitted). 
anticipate the future agenda. ${ }^{108}$ To use the ice cream cake example by way of illustration, Carole-who, you may recall, truly disliked chocolate-could have ensured that her second choice, coffee, prevailed by voting for coffee instead of vanilla (her first choice) in the first pairwise vote, vanilla versus coffee. While Carole prefers vanilla to coffee, if she knew the voting agenda in advance, and if she was not able to convince her friends to provide the final pairwise vote between chocolate and coffee, then this strategy would have been entirely rational on her part. ${ }^{109}$ This strategy would also violate independence. ${ }^{110}$

6) Rationality: Finally, Arrow's Theorem holds that the above five fairness assumptions cannot hold in an institution that is rational. ${ }^{111}$ Rationality has a specific definition in the theorem: it means that the institution must be capable of aggregating individual preferences into transitive group

108. While independence is critical to both Condorcet's and Arrow's analyses, each applies it for somewhat different reasons. Condorcet, echoing Rousseau's concept of the "general will," believed that the collective decisionmaking body's function was to identify an objectively "best" answer. See Young, supra note 1, at 1231-32 ("For Condorcet, as for Rousseau, the object of voting is not merely to balance subjective opinions; rather, it is a collective quest for truth."); see also BAKER, supra note 8, at 230:

All men, Rousseau and Condorcet agreed, have the right to follow their own opinion. But reason dictates that on entering political society, they consent to submit to the general will-or, in Condorcet's phrase, 'the common reason'-those of their actions that must be governed for all according to the same principles.

If the body's goal is to find the objectively "best" option, then each voter must try to identify, among competing pairs, the option that is "better," until the body as a whole agrees upon that option which is "best."

Arrovian independence is based upon a different intuition. While the collective decisionmaking body is not charged with attempting to identify the ultimate truth, it is charged as a condition of faimess with providing equal weight to each vote. See RIKER, supra note 15, at 101 (explaining that Arrovian independence "prevent[s] the rigging of elections and the unequal treatment of voters") (footnote omitted). Independence ensures that no one voter's relative ranking weighs more heavily in the body as a whole than another voter's relative ranking. See $i d$. Indeed, such processes as strategic voting and logrolling violate the independence criterion, enabling voters to cardinalize, or place different weights upon, their preferences. See infra notes 223-24 and accompanying text.

Condorcet's rationale for independence may provide a better explanation than does Arrow's for why the criterion applies in the Supreme Court. As demonstrated below, infra notes 153 and 215 and accompanying text, because the Supreme Court engages in judgment, not preference, aggregation, see Kornhauser \& Sager, supra note 28, at 89 ("[W]e . . . strongly lean toward a view of adjudication as an exercise in judgment aggregation; indeed we understand most plausible schools of jurisprudence to embrace this view.") (footnote omitted), independence ensures that in choosing among competing alternatives, each voter attempts to identify the better option so that the institution as a whole can render the best decision. In other words, independence ensures that individual Justices will not be influenced by irrelevant options or issues when deciding issues within an actual case.

109. As set forth below, infra notes 223-27 and accompanying text, relaxing the independence criterion in Congress marks a critical difference between the collective rationality of Congress versus that of the Supreme Court.

110. See RIKER, supra note 15 , at 143 (explaining that strategic voting "violate[s] Arrow's independence criterion in that, for a given profile, the social choice might be $x$ with one chance selection and $y$ with another.").

111. It is worth noting that while the theorem provides that the five assumptions cannot coexist with rationality, the order in which the theorem is presented is itself somewhat arbitrary. For example, Herbert Hovenkamp has pointed out that the theorem could just as accurately be stated as follows: "If one wishes to have a rational (transitive) and democratic (nondictatorial) process for state policymaking, judgments about social welfare must be based on some criterion other than purely ordinal rankings of preferences." Hovenkamp, supra note 30 , at 973. 
orderings. ${ }^{112}$ While not stated as a formal assumption, individual rationality is implicit in the theorem. ${ }^{113}$ If we assume, for example, that Carole prefers vanilla to coffee and coffee to chocolate, we must conclude that Carole prefers vanilla to chocolate. ${ }^{114}$ This requirement, also known as "transitivity," is a standard and essential economic assumption. ${ }^{115}$

112. As Kenneth Arrow has observed, one of the benefits of transitive rationality is that it ensures "the independence of the final choice from the path to it." ARROW, supra note 6, at 120; see also RIKER, supra note 15 , at 132 .

113. Bruce Chapman has recently argued that this definition of individual rationality does not always hold. See Bruce Chapman, The Rational and the Reasonable: A Comparison of Social Choice Theory and Legal Adjudication, 61 U. CHI. L. REV. 41 (1994). Professor Chapman uses the following hypothetical to illustrate his point. Assume that an individual, Donor, must choose from among $A, B$, or $C$ to be the recipient of a financial grant to be used for a good purpose. Further, assume that as between $A$ and $B$, Donor knows that $A$ will do more good and that as between $B$ and $C$, Donor knows that $B$ will do more good. Applying the Arrovian definition of rationality, this means that Donor prefers A to B and B to C. We would thus infer that Donor prefers $A$ to $C$. Chapman goes on to explain, however, that if Donor chooses $A$ over $B$ in the first pairwise contest, and B over $C$ in the second, that should not necessarily imply that Donor is irrational if she chooses $C$ over $A$ in a final pairwise contest. To illustrate the point he offers the following insight; if in the contest between $A$ and $C$, Donor learns that $A$ owes money to $C$ and will repay the debt rather than use the money for some good purpose, then Donor might find it disquieting to give the money to $\mathrm{A}$ when $\mathrm{C}$ is present in the final pairwise contest. Id. at 24-26.

In fact, this example does not prove that Donor is simultaneously rational and intransitive. Instead, it shows that as Donor acquires additional information, her ordinal rankings may change. Assume that Donor had full information in the first two pairwise votes. She would not then have preferred $A$ to $B$. While she probably would have preferred $B$ to $C$, as she did initially, instead of preferring $A$ to $B$, she would have preferred B, who will use the money for "the good," to A, who will use it to repay the debt to $C$. In fact, the choice between $A$ and $C$ becomes irrelevant; $B$ prevails against either. In short, assuming that Donor has the same knowledge in all rounds of voting, her preferences will be both transitive and rational in the Chapman example.

114. This does not, of course, mean that Carole is irrational if she sometimes prefers the flavor that is generally her second choice to the flavor that is generally her first choice. If, for example, Carole generally prefers vanilla to coffee but occasionally orders coffee even when vanilla is available, it simply means that she favors variety over sameness. Contrary to the assertion of Pildes \& Anderson, supra note 30 , at 2161, this insight does not demonstrate an "ambiguity in the notion of "preference"" in social choice theory. Carole remains rational if on those occasions when she prefers vanilla to coffee and coffee to chocolate, she prefers vanilla to chocolate, and if on those occasions when she prefers coffee to vanilla and vanilla to chocolate, she prefers coffee to chocolate. This combined group of orderings is consistent with both the social choice definition of rationality and with the statement: "Carole generally prefers vanilla to coffee, but on occasion she chooses coffee over vanilla because she would become bored if she invariably chose the same flavor."

115. In Pildes \& Anderson, supra note 30, the authors, in attempting to disprove Arrow's Theorem - or at least its relevance in evaluating democratic decisionmaking processes-take issue primarily with the above definition of individual and group rationality. Id. at 2142 ("[W] argue that the theory of rationality presupposed by social choice is wholly inadequate for evaluating democratic institutions."). The authors contend that individuals simultaneously hold numerous, often abstract, values. The authors suggest that Arrow's Theorem demands that individuals be able to rank abstract, and hierarchically and radically incommensurable, values ordinally when in fact most people are unable to do so. $I d$. at 2145-66. For a similar argument based on the independence, rather than the rationality, criterion, see McGrath, supra note 12. Pildes and Anderson explain:

All complex democratic lawmaking institutions are structured to embody diverse, incommensurable political values and to provide distinct settings that facilitate their rational expression. Whether the structure of any particular set of democratic institutions does so in ways appropriate to the values and substantive aims of particular societies can be judged only after critical reflection and political debate on numerous, substantive grounds. But social choice theory provides no way even to commence such reflection or debate because it misconceives the nature of rationality, and hence some of the central functions of democratic institutions highlighted here. Rationality is not a given property of individuals, but a social and political achievement that requires appropriate institutional design. 
Arrow's Theorem proves that it is impossible for any collective decisionmaking body to satisfy simultaneously the above six criteria. ${ }^{116}$ This simply means that in any collective decisionmaking body that actually reaches collective decisions, at least one of these criteria must be relaxed. Before analyzing which criteria are relaxed in the Supreme Court and Congress, however, it is necessary to consider one additional criterion for evaluating collective decisionmaking bodies, the ability to yield a Condorcet winner.

\section{B. The Condorcet-Winner Criterion}

Saul Levmore has recently analyzed multiple rules of order, including Robert's Rules of Order, and has developed an extremely valuable evolutionary hypothesis, based upon Arrow's Theorem, designed to explain where those rules are consistent and where they diverge. ${ }^{117}$ Professor Levmore found that where rules could be devised that were capable of yielding a Condorcet

$I d$. at 2183 . In addition to rejecting the social choice definition of rationality, the authors further reject the notion that majoritarian preferences have any value per se in democratic decisionmaking processes: "Indeed, preferences as such have no weight in the public arena, for one cannot stand up and say 'I want' without more and expect anyone to listen; preferences must be backed up by publicly acceptable reasons." Id. at 2201 n.211.

The Pildes and Anderson critique of social choice miscomprehends the Arrow's Theorem rationality requirement. The theorem does not require as a condition of rationality that individuals (or groups) be able to rank abstract values ordinally. Nor does the theory disclaim that democratic processes can assist in the process of filtering abstract values to achieve concrete political decisions. The authors' contention that because democratic processes allow individuals to participate in fora in which hicrarchical and incommensurable values are aired and ultimately resolved in response to real-world situations, those processes are far more rational than they first appear, see $i d$. at 2201-03, is thus not an indictment of Arrow's Theorem. Nor does the authors' suggestion that a particular individual may rationally be satisfied with democratic decisionmaking processes even if the end result of those processes places different weights on abstract values than did that participant, see id. at 2207, prove the irrelevance of Arrow's Theorem in evaluating our democratic institutions.

Obviously, many, if not most, individuals would be rendered irrational under a test that requires ordinal and transitive ranking of abstract values. The rationality requirement is much more modest; when presented with three or more concrete options, whether they be ice cream flavors or legislative proposals concerning the proposed situs of a toxic waste dump, an individual must be able to rank those options ordinally and the individual's ranking must satisfy the requirement of transitivity. In doing so, individuals may apply numerous hierarchical and incommensurable values. In addition, they may attach different weights to those values when presented with different legislative issues because those issues may implicate the same values in different ways. But faced with concrete legislative options $A, B$, and $C$, it would be irrational for an individual to prefer $A$ to $B$ and $B$ to $C$, but $C$ to $A$. By the same token, however, the same individual when ranking options $E, F$, and $G$, may well apply different weights to some of the same values that entered into her ranking: A preferred to B preferred to $C$.

In short, while Superman might generally rank his hierarchical preferences: (1) truth; (2) justice; (3) the American way, he might be willing to deceive, if necessary, to prevent a deadly encounter, plotted by an archvillain, with the dreaded kryptonite, on the ground that his foe's planned injustice is sufficiently great to warrant departing from strict adherence to truth. Superman's rationality remains intact, however, if he prefers a plan that allows him to foil his foe's plot without deception to an alternative plan that requires deception.

116. Recall that the rationality requirement can be stated as a criterion of legislative decisionmaking. See supra note 111. For a simplified version of the Arrow's Theorem proof, and citations to other proofs, see the Appendix.

117. See generally Levmore, supra note 8. 
winner, the rules tended to be similar, while they tended to vary greatly where they could not yield such a winner. ${ }^{118}$

A Condorcet winner-so named because Condorcet posited that whenever such a winner is available, it should prevail ${ }^{119}$-is an option that beats all other options in pairwise contests. ${ }^{120}$ Holding aside the problems associated with the Condorcet criterion, ${ }^{121}$ the Condorcet criterion remains only a partial solution to the voting paradox. In the ice cream cake hypothetical, for example, there is no Condorcet winner and, as a result, for any chosen flavor, there is always another flavor that could beat it in a pairwise contest. There is no Condorcet winner because the hypothetical has an empty core. In contrast, by modifying the preferences slightly, a Condorcet winner emerges. Assume, for example, the following, slightly modified, preferences:

1) Alice: coffee, chocolate, vanilla

2) Bob: chocolate, vanilla, coffee

3) Carole: vanilla, chocolate, coffee

The only preference changed from the original hypothetical is Carole's; instead of "vanilla, coffee, chocolate" she now prefers "vanilla, chocolate, coffee." Now assume a series of pairwise votes. In the first vote, chocolate versus coffee, chocolate wins, with Alice losing to Bob and Carole. In the second vote, chocolate versus vanilla, chocolate also wins, this time with Carole losing to Alice and Bob. There is obviously no need for a final vote, vanilla versus coffee, because whichever flavor emerges the winner, chocolate, the Condorcet winner, will beat it in a pairwise contest. ${ }^{122}$ It is worth noting that the Condorcet winner is not the first choice of a majority of the voters. ${ }^{123}$

118. See id. at $992-96,1018,1019$ n.134, and 1034-35.

119. See Young, supra note I, at 1239 ("Condorcet proposed that whenever a candidate obtains a simple majority over every other candidate, then that candidate is presumptively the 'best.' This decision rule is now known as 'Condorcet's criterion,' and such a candidate (if it exists) is a 'Condorcet winner' or a 'majority candidate."') (citation omitted).

120. See id.; see also Levmore, supra note 8, at $989 \mathrm{n.55}$ ("A Condorcet winner is an alternative which beats all alternatives in one-on-one comparisons.").

121. These problems are described infra at notes $129-33$ and accompanying text.

122. This illustrates the two contrasting paradigms. In the first non-Condorcet-winner paradigm, below, the result of unlimited pairwise votes is endless cycling.

Person 1: A, B, C

Person 2: B, C, A

Person 3: C, A, B

The second Condorcet-winner paradigm, below, in contrast, does not lead to endless cycling with unlimited pairwise votes; instead, the Condorcet winner, in this case B, prevails.

Person 1: A. B, C

Person 2: B, C, A

Person 3: C, B, A

123. Indeed, as shown infra notes $\mathbf{1 2 5 - 2 7}$ and accompanying text, the Condorcet winner need not be anyone's first choice. 
Nonetheless, the Condorcet criterion is attractive when it exists because it will prevail in a pairwise contest against any choice. ${ }^{124}$

Professor Levmore posits that rules of order are similar where they are capable of producing Condorcet winners because Condorcet-producing rules prevent avoidable dissatisfaction. ${ }^{125}$ To see why, assume five voters choosing among five options A, B, C, D, and E. The voters have the following sets of preferences:

1) $\mathrm{A}, \mathrm{B}, \mathrm{C}, \mathrm{D}, \mathrm{E}$

2) A, B, C, E, D

3) $\mathrm{C}, \mathrm{B}, \mathrm{D}, \mathrm{E}, \mathrm{A}$

4) C, B, E, A, D

5) $\mathrm{E}, \mathrm{D}, \mathrm{B}, \mathrm{C}, \mathrm{A}$

Assume that the voting procedure is a plurality with a runoff; each person votes for her first choice and the two options that receive the highest number of votes are pitted against each other in a final pairwise vote. In the first ballot, $A$ and $C$ each get two votes and $\mathrm{E}$ gets one vote. In the runoff between $A$ and $C, C$ beats $A$ three to two. After the meeting, however, voters 1,2, and 5 realize that while option $C$ prevailed, each of them preferred option $B$ to option $C$ and that their three votes should have been sufficient under majority rule to enact outcome B instead of outcome $C$. They would presumably be dissatisfied with this voting procedure because it failed to yield an option that a majority preferred.

Assume, now, that at the next meeting voters 1,2 , and 5 impose a new voting regime, motion and amendment. Under this regime, someone moves to vote for a particular legislative option, and, upon motion, a majority can vote

124. Chevalier Jean Charles de Borda offered an alternative method for resolving intransitivities in collective preferences in a paper 15 years prior to Condorcet's Essai. For general descriptions of the Borda method, see BLACK, supra note 1, at 59-64; RIKER, supra note 15, at 30-35; Young, supra note 1, at 1236. Assume that each voter ranks her preferences as follows: (1) A,B,C; (2) B,C,A (3) C,B,A. This ranking is the Condorcet-winner paradigm. See supra note 122. Each preference that is lowest on a given list receives a zero score for that list, the next highest preference receives a one, and the next highest then receives a two. The votes for all three options are then tallied as follows: A receives $2(2,0,0)$; B receives $4(1,2,1)$; and $C$ receives $3(0,1,2)$. In this hypothetical, the outcomes of the Borda and Condorcet methods are the same; option B wins.

Now consider the following modified preferences: (1) A,B,C,D,E,F; (2) B,C,A,E,D,F (3) C,D,E,F,B,A. Options D, E, and F are "irrelevant alternatives" in that none of them would prevail against $A, B$, or $C$ based upon either the Condorcet or Borda vote-counting methods. Assume, therefore, that the only motions involve options A, B, and C. Using the Condorcet method, which entails pairwise contests among any two of the three relevant options, option $B$ prevails, just as it prevailed without including the irrelevant options D, E, and F. Using the Borda method, however, option $C$ beats options $A$ and $B$. In this example, the first choice receives five points, the second choice four, and so on, down to zero for the last choice. The scores are as follows: A receives $8(5,3,0)$; $B$ receives $10(4,5,1)$; and $C$ receives $12(3,4,5)$. Thus, if this collective decisionmaking body adopted the Borda method, option $\mathrm{C}$ would prevail even though a majority of the body preferred option $B$ to option $C$. This illustrates a critical problem with the Borda method: it violates Arrovian independence. See also RIKER, supra note 15, at 105 (demonstrating that Borda-count method violates Arrovian independence).

125. Levmore, supra note 8, at 994. 
to substitute an alternative motion. This process can be repeated. ${ }^{126}$ Assume the same sets of preferences. Now assume that voter 5 moves for a vote to approve plan $\mathrm{E}$, her first choice. Voter 4 , who has ranked $\mathrm{E}$ third, moves to substitute option $C$, her first choice. Voters 1 through 4 prefer $C$ to $E$ and thus approve the motion. Now voter 1 moves to substitute her second choice, B, for C. Voters 1,2 , and 5, who prefer $B$ to $C$, approve the motion. Thus far, two options have not been moved, namely options $A$ and $D$. A review of the ranked preferences, however, will reveal that neither $A$ nor $D$ can defeat option B. Thus option B, the Condorcet winner, is the stable outcome that emerges from the motion-and-amendment procedure.

The Condorcet winner, as in this example, need not be anyone's first choice. It is, to restate, simply an option that prevails over all others in pairwise contests. ${ }^{127}$ For that very reason, theorists generally favor procedures that yield Condorcet winners. ${ }^{128}$

Not surprisingly, the Condorcet criterion suffers its own limitations. ${ }^{129}$ Foremost, it fails to account for intensity of interest in any particular voter. ${ }^{130}$ Thus, while $B$ is the Condorcet winner in the given example, voters 1 and 2 may be close to indifferent as between $B$ and $C$ while voters 3 and 4 may greatly prefer $\mathrm{C}$ to $\mathrm{B}$. In that case, notwithstanding the Condorcet criterion, the $\mathrm{B}$ outcome does not appear to be utility maximizing. In addition, there are times when preferences cannot be ranked ordinally to yield a Condorcet

126. Limiting the permitted number of motions to less than the number of options changes the analysis. See infra note 171 .

127. A motion-and-amendment procedure is not the only device that yields Condorcet winners. Roundrobin voting and sometimes logrolling will also yield such a winner when one is available. In describing procedures that yield Condorcet winners, William Riker explains:

There are many rules that utilize paired comparisons of alternatives to discover a Condorcet winner. If a Condorcet winner exists, then all these methods come out the same way. If a Condorcet winner does not exist, however, these rules typically produce different results, no one of which, in my opinion, seems more defensible than another.

RIKER, supra note 15, at 69. Logrolling, as demonstrated infra notes 223-24 and accompanying text, sometimes achieves a result that, although inconsistent with the Condorcet criterion, nonetheless satisfies Pareto optimality because logrolling processes allow participants to cardinalize their preferences rather than to merely treat their preferences as ordinal rankings.

128. See, e.g., BLACK, supra note 1, at 58 ("[The Condorcet criterion] appeals, perhaps via mathematical symmetry, to our sense of justice. . . Our own position is that our faith in the Condorcet criterion is stronger than in any other, but it is not an unqualified faith."); Levmore, supra note 8, at 995 n.69 ("Most writers accept almost as a given that the ability not to miss a Condorcet winner is a basic test when evaluating a voting procedure."); $i d$. at $994-95$ ("II]t is reasonable to proceed, as does virtually the entire collective choice literature, under the assumption that a Condorcet winner is very desirable.") (footnote omitted); RIKER, supra note 15, at 100 ("This notion [that the Condorcet winner, when available, should prevail] is closely related to the notion of equality and 'one man, one vote,' in the sense that, when an alternative opposed by a majority wins, quite clearly the votes of some people are not being counted the same as other people's votes.").

129. Accord Levmore, supra note 8, at 995 n.69 ("The Condorcet concept has at least two well-known defects: Preferences do not necessarily, or even usually, deliver a Condorcet winner [meaning that, at best, the Condorcet criterion is only a partial solution], and the concept does not take into account intensity of preference.").

130. See id. In fact, Arrovian independence assumes pure ordinalization of preferences as well. 
winner. ${ }^{131}$ Setting aside these problems, and the fact that collective preferences will not always yield a Condorcet winner in any event, ${ }^{132}$ the ability to yield a Condorcet winner when one is available is often viewed as a form of Arrovian efficiency. ${ }^{133}$

One of the fundamental distinctions between Congress and the Supreme Court, as shown below, ${ }^{134}$ is that congressional voting procedures, and even the process of logrolling, ${ }^{135}$ are better at identifying Condorcet winners than are Supreme Court voting procedures. Consider, for example, the case of Kassel v. Consolidated Freightways Corp. ${ }^{136}$ In Kassel, the Supreme Court issued three opinions: a plurality, a concurrence, and a dissent. To demonstrate the Condorcet winner it will be helpful to treat the case as if there were only three votes, any two of which are sufficient to rule on a given issue. ${ }^{137}$

In Kassel, the Supreme Court held that an Iowa statute prohibiting, with exceptions, intrastate use of sixty-five foot twin trailers, violated the dormant commerce clause. ${ }^{138}$ The Court considered two underlying issues: first, whether to apply a balancing test first announced in Raymond Motor Transportation, Inc. v. Rice ${ }^{139}$ or a rational basis test; and second, whether to allow the court below to consider only evidence used in support of the statute by the state legislature or instead to also allow the court to consider evidence submitted at trial by the state's attorneys. ${ }^{140}$ In his plurality opinion, which, because it was the narrowest basis for decision became the rule of the case, ${ }^{141}$ Justice Powell held, first, that the appropriate test was the Raymond

131. The following example is taken from ROBERT SUGDEN, THE POLITICAL ECONOMY of PubliC CHOICE: AN INTRODUCTION TO WELFARE ECONOMICS 183 (1981); see also Baker, supra note 70, at 725-26 (discussing Sugden hypothetical). Assume, for example, a vote on whether to grant a liquor permit in either or both of two adjacent towns, $\mathrm{A}$ and $\mathrm{B}$, and that a particular voter opposes both on temperance grounds. Assume further that the same voter is more concerned about drinking and driving than about temperance, however, and thus would prefer to approve both facilities to just one if either facility is approved. This will prevent intoxicated persons from having to drive home across town. Even though the voter prefers not to allow either bar to open, she will change her vote in the second town ballot based upon the outcome of the first. Moreover, this switch in voting is rational. Another way to state this is that the preferences are 'endogenous,' meaning that the outcome of one vote affects the preferences in the second vote. By definition, therefore, endogenous preferences cannot satisfy the independence criterion.

132. See supra note 122 (outlining two paradigm cases).

133. See supra note 128 and sources cited therein. This term is simply intended to demonstrate the universality with which the ability of a collective decisionmaking body to yield Condorcet winners is accepted as a benchmark of institutional competence among social choice theorists.

134. See infra Parts IV.B and C.

135. See supra note 127 (explaining relationship between logrolling and Condorcet criterion).

136. 450 U.S. 662 (1981).

137. This does not change the analysis because the Court had three camps: (1) the Powell group with four members; (2) the Brennan group with two members; and (3) the Rehnquist group with three members. Any two-group combination contains the requisite five votes for a majority.

138. 450 U.S. at 671.

139. 434 U.S. 429 (1978).

140. 450 U.S. at $672-74$.

141. See Marks v. United States, 430 U.S. 188, 193 (1977) ("When a fragmented Court decides a case and no single rationale explaining the result enjoys the assent of five Justices, 'the holding of the Court may be viewed as that position taken by those Members who concurred in the judgments on the narrowest grounds.....") (citation omitted). 
balancing test and, second, that the court below could consider evidence admitted at trial..$^{142}$

Both Justice Brennan in concurrence and Justice Rehnquist in dissent voted to apply the rational basis test. ${ }^{143}$ While Justice Brennan voted to consider only evidence that the legislature considered when enacting the statute, however, Justice Rehnquist agreed with Justice Powell that the court below could consider trial evidence. ${ }^{144}$

To see the Condorcet winner, consider the following separate votes on each issue: (1) Justices Brennan and Rehnquist prevail two to one over Justice Powell in concluding that the appropriate test is the rational basis test; and (2) Justices Powell and Rehnquist prevail two to one over Justice Brennan in concluding that the court may consider trial evidence. In pairwise voting, therefore, for each issue presented, the positions taken by Justice Rehnquist would have prevailed, when in fact, he voted in dissent. ${ }^{145}$ Thus Supreme Court voting procedures did not identify the Condorcet winner in this case.

Given the value associated with the Condorcet-winner criterion in social choice theory, any comparative analysis of Congress and the Supreme Court must explain why congressional voting procedures are better equipped to identify Condorcet winners than are Supreme Court voting procedures. ${ }^{146}$ The next Part will provide such an explanation.

\section{THE SUPREME COURT AND CONGRESS THROUGH AN ARROVIAN LENS}

As indicated above, Arrow's Theorem can be stated as follows: No collective decisionmaking body can simultaneously satisfy the following six conditions: (1) range; (2) universal domain; (3) unanimity; (4) nondictatorship; (5) independence of irrelevant alternatives; and (6) rationality. ${ }^{147}$ The theorem says nothing, however, about which assumptions will be relaxed in any given institution. What is absolutely clear, however, is that no real-world institution can be held to the standard of an abstract institution that satisfies all six Arrovian criteria, because the theorem proves that the latter institution is impossible to devise. Thus, to avoid committing the "nirvana" fallacy, namely comparing a real-world institution with an institution that does not exist, or in this case, that has been proven impossible to create, it is essential to analyze

142. 450 U.S. at $678-79$.

143. Id. at 680-81 (Brennan, J., concurring); id. at 689-9l (Rehnquist, J., dissenting).

144. Id. at 681 (Brennan, J., concurring); id. at 702 (Rehnquist, J., dissenting).

145. For other examples of "shifting majority cases," see John M. Rogers, "I Vote This Way Because I'm Wrong": The Supreme Court Justice as Epimenides, 79 KY. L.J. 439, 456-58 (1990-91) (collecting cases to illustrate thesis that individual Justices should not switch votes to achieve a majority ruling in three-remedy cases). The three-remedy problem is discussed infra note 176.

146. As shown below, this distinction generally holds true for all legislatures and appellate courts.

147. Each of these terms is defined in Part III.A supra. 
each institution under review based on the Arrovian criteria. ${ }^{148}$ Once the Arrovian deficiencies in each institution are properly exposed (and bear in mind that the theorem proves that each institution must have at least one Arrovian deficiency), the two institutions can then be studied together to determine, first, whether each is better suited to perform its assigned tasks than the other would be if the tasks were transferred to the latter institution; and, second, whether and to what extent the deficiencies within each institution are ameliorated when the institutions work in conjunction.

This Part will first analyze both the Supreme Court and Congress based upon each of the six Arrovian criteria. In the process, it will explain why congressional voting practices are better equipped to yield Condorcet winners than are Supreme Court voting practices. This Part will then demonstrate that the two institutions, by working in conjunction, can ameliorate some of the Arrovian deficiencies that are exposed. ${ }^{149}$

\section{A. Range}

Perhaps the most notable distinction between legislative bodies, including Congress, and appellate courts, including the Supreme Court, at least under traditional theory, involves range. State legislatures have general authority to deal with virtually any issue except to the extent that the proposed legislation violates the United States Constitution, other federal laws, or the state constitution. In that sense, the restraint on state legislatures is that of a ceiling (barring infringement on higher law) without a floor (requiring no particular delegation to create a legislative enactment). ${ }^{150}$ In contrast, Congress is bounded by both a floor and a ceiling. Congress cannot legislate unless it has a specific constitutional grant, based upon Article I, $\S 8$, for general legislation. In addition, it cannot legislate when doing so will violate independent provisions of the United States Constitution.

Within these restraints, legislatures generally, and Congress in particular, have complete range. State legislatures are free, for example, to choose any option that does not exceed the relevant ceilings, and Congress is free to choose any option that is between the relevant ceiling and the relevant floor. This means that Congress, for example, can take multiple bites at the same policy apple, whether the Supreme Court held the first bite forbidden or Congress subsequently determined the first bite unwise, provided the second

148. This avoids the "nirvana fallacy" by assessing relative departures across institutions from the ideal norm. See supra note 33 (discussing "nirvana fallacy").

149. Table 1 , infra p. 1286, summarizes the analysis to follow.

150. See, e.g., James E. Castello, The Limits of Popular Sovereignty: Using the Initiative Power To Control Legislative Procedure, 74 CAL. L. REv. 491, 553 n.329, 554 (1986) (distinguishing restrained legislative powers under California Constitution from delegated legislative powers under United States Constitution). 
bite falls within its sphere of authority. Included in this legislative range is the power to do nothing in response to any proposal. ${ }^{151}$ Doing nothing, of course, allows the status quo to prevail over any other option. As shown below, this element of range, the power to do nothing, proves to be the single most important Arrovian difference between Congress and the Supreme Court. It explains the most critical distinction in their decisional processes, namely, why congressional voting processes are better equipped to yield Condorcet winners than are Supreme Court voting processes. ${ }^{152}$

The Supreme Court's range is far more circumscribed, at least under traditional jurisprudential theories. ${ }^{153}$ When exercising its power of judicial

151. Indeed, for state legislatures, New York v. United States, 112 S. Ct. 2408 (1992), strongly suggests that the power to do nothing as an element of state legislative range is guaranteed by the Tenth Amendment. Id. at 2428-29. Thus in criticizing Respondent's argument that the Low-Level Radioactive Waste Policy Amendments Acts of 1985 provide states with substantial leeway for implementation, Justice O'Connor stated for the Court: "This line of reasoning, however, only underscores the critical alternative a State lacks: A State may not decline to administer the federal program. No matter which path the State chooses, it must follow the direction of Congress." Id. Justice O'Connor hedged a bit in basing the Court's decision on the Tenth Amendment, providing an alternative basis upon which to invalidate the 1985 amendments-that Congress lacked the power to provide the states with this choice under Art. I, $\$ 8$. Thus, Justice O'Connor stated:

In the end, just as a cup may be half empty or half full, it makes no difference whether one views the question at issue in this case as one of ascertaining the limits of the power delegated to the Federal Government under the affirmative provisions of the Constitution or one of discerning the core of sovereignty retained by the States under the Tenth Amendment. Id. at 2429.

152. See infra notes $156-88$ and accompanying text. As shown below, this Article offers a substantially different explanation of the differences between Supreme Court and congressional decisional processes than has been previously offered in the literature.

153. Accord Kornhauser \& Sager, supra note 28, at 89 (positing that "most plausible schools of jurisprudence" embrace the view that judges exercise judgment based upon legal doctrine rather than express policy preferences in deciding cases). One practice that illustrates the difference between judgment aggregation in appellate courts, which means that an appellate court aggregates the judgments of individual judges into a single collective outcome by the court as a whole, and preference aggregation in legislatures is the contrast between judicial dicta and statements on the floor of the legislature. Because judges are engaged in judgment aggregation, their dicta are reasonable indicators as to how they are likely to proceed in the future when faced with similar issues. Legislators making statements on the floor of the legislature, on the other hand, may do so for any number of reasons, which may or may not include a principled commitment to the position taken. As a result, statements on the floor of the legislature are less informative indicators of future legislative conduct than is dicta of future judicial conduct.

The Senate Judiciary Committee hearings for the nomination of Ruth Bader Ginsburg to the Supreme Court recently illustrated this point. See Litmus Tests, WASH. POST, July 23, 1993, at A22; see also Joan Biskupic, Ginsburg Deplores Bias Against Gays: Senators Find Nominee Harder To Pin Down on Death Penalty Issue, WASH. POST, July 23, 1993, at A1. Judge Ginsburg had refused to respond to a series of questions by Senator Orrin Hatch about the death penalty, on the grounds that she had not written in the area and that she may have to decide future cases addressing the issue. After Senator Hatch stated: "It appears that your willingness to discuss the established principles of constitutional law may depend somewhat on whether your answer might solicit a favorable response from the committee," Litmus Tests, supra, Chairman Joe Biden read back an excerpt from the confirmation hearings of then-Judge David Souter in which Senator Hatch "urged the nominee to 'stand your ground' in refusing to give 'answers which you clearly cannot provide," and "warned against the Senate's imposing 'indirect litmus tests on specific issues or cases."' Id. (quoting Senator Hatch). In a candid follow-up, however, that illustrates the distinction between judgment and preference aggregation, Senator Biden then "graciously acknowledged that he might not like to have all his earlier statements read back to him." Id. In contrast, statements contained in an appellate judge's published opinions, whether holding or dictum, are always fair game because they are intended to reflect the judge's assessment of results compelled by law. 
review for a federal statute, the Court is limited to determining whether Congress has acted within its proper range. When exercising that function for a state statute, the Court is limited to determining whether the state legislature has exceeded the relevant part of its range that implicates federal law, including the Constitution, on the ground that federal law is superior under the constitutional scheme. ${ }^{154}$ This power is in essence a negative check; the Court is empowered to invalidate only those federal statutes that infringe upon the Constitution and those state laws that infringe upon federal law, including the Constitution.

There are two critical restrictions on the Supreme Court's range. The first restriction, the inability to invalidate federal laws that do not violate the Constitution or state laws that do not violate federal law, will be considered in the following parts. ${ }^{155}$ The second restriction, which is more important for present purposes, is the inability to do nothing. ${ }^{156}$ Unlike Congress, which can let bills die without any formal action by the institution as a whole, the Supreme Court, for any case properly before it, must formally resolve the case as an institution. In other words, judicial, unlike legislative range, does not include inaction.

At first glance, justiciability doctrines, which allow courts to preserve the legal status quo, may appear inconsistent with this analysis. While an extended treatment of justiciability doctrines would be inappropriate here, a preliminary analysis demonstrates that these doctrines, and in particular standing, are consistent with the distinction that judicial range does not include inaction while legislative range does. Standing enables the Supreme Court to satisfy two functions simultaneously: (1) institutionally resolving the case before it; and (2) doing so in a manner that minimizes the extent to which it infringes upon legislative range. ${ }^{157}$ Indeed, social choice appears to provide a strong functionalist explanation for the emergence of justiciability doctrines; without them, the legislature's power not to act would be undermined because the

154. U.S. CONST, art. VI (Supremacy Clause).

155. See infra notes $245-50$, and accompanying text. Under the preemption and dormant commerce clause doctrines, the Supreme Court can invalidate state laws even when there is no express federal law on the subject if the Court determines (in the case of preemption) that Congress has chosen to exclusively occupy the field, see generally JOHN E. NOWAK \& RONALD D. ROTUNDA, CONSTITUTIONAL LAW, \$\$ 9.19.5 (4th ed. 1991), or presumes (in the case of the Commerce Clause) without congressional action, that federal law exclusively occupies the field. Id. $\$ 8.1$.

156. The Supreme Court can decline to grant certiorari. When it does so, however, it simply imposes the obligation to resolve the pending dispute and to resolve the legal issues raised in that dispute onto lower courts, which, unlike the Supreme Court, lack the power to decline the case. Moreover, the point remains that whenever the Court does take a case, it must dispose of it through some means of formal action. In contrast, Congress need not dispose of each proposal through some means of formal action. It can let bills die.

157. But cf. Lujan v. Defenders of Wildlife, 112 S. Ct. 2130 (1992) (delineating Article III limits on congressional grants of standing). For critical analyses demonstrating that the Lujan result is not compelled by Article III case or controversy concerns or by prior standing precedents, see Gene R. Nichol, Jr., Justice Scalia, Standing, and Public Law Litigation, 42 DUKE L.J. 1141 (1993); Cass R. Sunstein, What's Standing After Lujan? Of Citizen Suits, "Injuries," and Article III, 91 MICH. L. REV. 163 (1992). 
judiciary, which is obligated to decide cases, would invariably select an option from within the legislature's permissible range when the legislature itself has failed to choose. Sometimes the legislature's failure to choose from available legislative options, thus preserving the legal status quo, will be the product of an advertent collective choice; other times it will be the product of cycling. ${ }^{158}$ In appellate courts, in contrast, the decision to preserve the legal

158. The point is best illustrated by comparing three cases: Marbury v. Madison, 5 U.S. (1 Cranch) 137 (1803), which established the doctrine of judicial review; Allen v. Wright, 468 U.S. 737 (1984), a noted standing case; and Weeks v. United States, 232 U.S. 383 (1914), a criminal procedure case. In Marbury, the Court held that (1) when Congress engages in a collective action, in the form of a statute, and (2) when that statute violates the Constitution, the Court will, in a properly presented case, invalidate that collective legislative action. In other words, the Court will hold that collective action off limits and in violation of Congress's permissible legislative range. In contrast, in Allen, the parents of black school children sought to invalidate an IRS policy granting tax exemptions for private schools that allegedly discriminated against black school children as a violation of the Fourteenth Amendment's Equal Protection Clause. The Court dismissed the case for lack of standing, reasoning that Congress-not the Court-is the proper branch to monitor executive agency action. Id. at 760. "Carried to its logical end, [respondent's] approach would have the federal courts as virtually continuing monitors of the wisdom and soundness of Executive action; such a role is appropriate for the Congress acting through its committees and the "power of the purse'; it is not the role of the judiciary ...." Id. (quoting Laird v. Tatum, 408 U.S. 1, 15 (1972)); see also id. ("A federal court . . . is not the proper forum to press' general complaints about the way in which government [namely, the executive branch] goes about its business.") (quoting, in part, Los-Angeles v. Lyons, 461 U.S. 95, 112 (1983)). While the Allen Court obviously did not use social choice terminology, one could translate its holding to mean that Congress has a range of legislative options available for monitoring the IRS and other executive agencies and the Supreme Court is generally unwilling to choose a single option from within that permissible legislative range.

While choosing an option from within Congress' legislative range would arguably have vindicated the claimants' constitutional right not to have the government support racially discriminatory schools through a tax exemption, it might also have effectively foreclosed Congress from choosing a different, and perhaps more effective, option from within its permissible legislative range. Unlike Marbury, therefore, which stands for the proposition that the Court will invalidate congressional action that violates the Constitution, Allen can be translated as follows: (1) where Congress fails to act, and (2) where that failure to act leads to an arguably unconstitutional result, the Court will not invalidate that congressional inaction by choosing an option for it. Of course, that alone does not solve the problem that the Supreme Court as an institution must resolve the Allen case. But the requirement that the Court resolve all cases properly before it, coupled with the desire to preserve legislative range, per Allen, may well explain the emergence of justiciability doctrines. Standing, for example, simultaneously allowed the Allen Court to resolve the case as an institution while, at the same time, preserving the power of Congress to choose from within its range to resolve the issues presented in that case in the future.

A critical exception to the Court's disinclination to invalidate legislative inaction arises in the criminal procedure context. For example, in Weeks, which established the exclusionary rule, see also Mapp v. Ohio, 367 U.S. 643 (1961) (applying exclusionary rule to the states), the Court did in fact choose from Congress' permissible range to prevent an outcome in violation of the Constitution where Congress had been silent. The exclusionary rule was not constitutionally compelled; it was, however, consistent with the Constitution. See also Miranda v. Arizona, 384 U.S. 436 (1966) (requiring that an arresting officer provide Miranda warnings, a remedy that is consistent with the Fifth Amendment, but not constitutionally compelled). That simply means that had Congress chosen the exclusionary rule as the remedy for illegally obtained evidence, that remedy would have fallen within its permissible range. The question then arises why the Court was willing to choose a single remedy from within Congress' permissible range in Weeks when it was not willing to do so in Allen. One plausible explanation is that in Weeks, the consequences of the constitutional violation to the actual defendant would have been severe had the Court not chosen a single remedy from within Congress' permissible range to vindicate the defendant's constitutional right. The Court reasoned in Allen, however, that the "links in the chain of causation" were sufficiently tenuous that even if the Court granted the requested relief, there might be no "significant effect on the ability of public school students to receive a desegregated education." 468 U.S. at 759; see also Simon v. Eastern Ky. Welfare Rights Org., 426 U.S. 26 (1976) (denying standing based upon similar causal chain analysis). Together, these three cases stand for the proposition that the Court will employ justiciability doctrines to preserve Congress' legislative 
status quo, e.g., by deciding that a case is nonjusticiable, is always the product of an advertent collective choice.

This distinction, that legislative range includes inaction while judicial range does not, proves critical because it explains why Supreme Court decisional processes sometimes miss available Condorcet winners. Consider, for example, two 1982 Supreme Court cases, issued on the same day, Washington v. Seattle School District No. $1^{159}$ and Crawford v. Board of Education. ${ }^{160}$ In Seattle School District, Washington voters used a statewide initiative to prevent a school board from continuing mandatory busing for purposes of integration, except for nonracial reasons, or unless a court determines that the state or federal constitution requires such busing. ${ }^{161}$ To implement integrative busing not constitutionally compelled, the referendum required either another superseding referendum or, after two years, a new statute. ${ }^{162}$ In Crawford, an amendment to the California Constitution prevented state courts from interpreting the state constitution to compel busing for purposes of racial integration unless a federal court would so order to remedy a federal constitutional violation. ${ }^{163}$ The effect was to require another state constitutional amendment as a precondition to mandating busing not required by a federal court order. In short, the Seattle initiative equated state desegregation law with both state and federal constitutional law, ${ }^{164}$ while the Crawford amendment equated state desegregation law with the requirements of the federal Constitution. ${ }^{165}$

range, except when it is necessary to choose from within that range to prevent a concrete harm to an actual litigant. In all cases, however, the Court will employ a voting rule that allows it collectively to decide the case.

159. 458 U.S. 457 (1982).

160. 458 U.S. 527 (1982).

161. Seattle Sch. Dist., 458 U.S. at 462-63; see also id. at $490 \mathrm{n.3}$ (Powell, J., dissenting) (explaining that unlike the Crawford constitutional amendment, the Seattle initiative allowed court-ordered desegregation based upon a violation of the state constitution).

162. Id. at 462 n.4 (explaining that the Washington Constitution only allows the state legislature to modify successful citizen initiatives less than two years after adoption through a two-thirds majority vote); $i d$. at 474 ("Those favoring the elimination of de facto school segregation now must seek relief from the state legislature, or from the statewide electorate.").

163. Crawford, 458 U.S. at 529. The California Supreme Court had previously interpreted the California Constitution to prohibit de facto segregation and to require that reasonable steps be taken to alleviate it. Id. at 530 n.2.

164. Seattle, 458 U.S. at 490; see also id. at 488 (Powell, J., dissenting) (observing that while Initiative 350 is "binding on local school districts ... [it] in no way affects the authority of state or federal courts to order school transportation to remedy violations of the Fourteenth Amendment"); id. at 490 n.3 ("Unlike the constitutional amendment at issue in Crawford... Initiative 350 places no limits on the state courts in their interpretation of the State Constitution.").

165. Crawford, 458 U.S. at 532, 535. In striking down the Seattle initiative, the Court relied on Hunter v. Erickson, 393 U.S. 385 (1969) (invalidating ordinance that required proponents of fair housing legislation to seek approval of both the city council and a majority of citywide voters), for the proposition that the state cannot restructure its political processes in a manner that imposes a unique burden on a protected minority seeking favorable legislation. Seattle, 458 U.S. at 470.

One conceivable basis on which to distinguish the two cases is that the initial law requiring busing in Seattle was local, 458 U.S. at 474 (noting that while those favoring elimination of de facto segregation must seek a change in state law, "authority over all other student assignment decisions, as well as over 
The Seattle Court held that the Washington initiative violated the Equal Protection Clause while the Crawford Court upheld the California constitutional amendment against an equal protection challenge. Despite the efforts of some commentators to reconcile the two cases, ${ }^{166}$ they appear indistinguishable as a matter of constitutional law. In fact, for purposes of the present analysis, it does not matter whether the cases are or are not distinguishable. To see why, consider the following breakdown of votes in each case:

\begin{tabular}{|c|c|c|}
\hline \multirow{7}{*}{$\begin{array}{l}\text { Majority } \\
\text { Blackmun } \\
\text { Marshall** } \\
\text { Brennan } \\
\text { White } \\
\text { Stevens }\end{array}$} & \multicolumn{2}{|l|}{ Seattle } \\
\hline & & Dissent \\
\hline & & Powell* \\
\hline & & Burger* \\
\hline & & Rehnquist: \\
\hline & & O'Connor* \\
\hline & & \\
\hline & Crawford & \\
\hline Majority & Concurrence & Dissent \\
\hline Powell"* & Blackmun & Marshall* \\
\hline Burger*: & & \\
\hline Rehnquist* & & \\
\hline O'Connor* & & \\
\hline White & & \\
\hline Stevens & & \\
\hline
\end{tabular}

The asterisks identify those Justices who made clear that they believed the two cases were indistinguishable and who voting accordingly. ${ }^{167}$ Chief Justice

most other areas of educational policy, remains vested in the local school board"); $i d$. at 477 ("And until the passage of Initiative 350, Washington law in fact had established the local school board, rather than the State, as the entity charged with making decisions of the type at issue here."), while the initial law requiring busing in Crawford, based upon an interpretation by the California Supreme Court, affected the entire state. This distinction, however, would prevent states from addressing an issue like busing at a statewide level, e.g., by equating state law with federal law on desegregation, once a local community has acted more ambitiously with respect to desegregation. See Seattle, 458 U.S. at 495 (Powell, J., dissenting) ("It is a strange notion-alien to our system-that local governmental bodies can forever pre-empt the ability of a State-the sovereign power-to address a matter of compelling concern to the State."); $i d$. at 498 n.14 ("Under its holding the people of the State of Washington apparently are forever barred from developing a different policy on mandatory busing where a school district previously has adopted one of its own."); id. at 499 n.14 ("After today's decision it is unclear whether the State may set policy in any area of race relations where a local governmental body arguably has done 'more' than the Fourteenth Amendment requires."). In any event, for purposes of the analysis to follow it does not matter whether the cases can be distinguished, although I remain unconvinced that they can be.

166. See, e.g., Julian N. Eule, Judicial Review of Direct Democracy, 99 YALE L.J. 1503, 1566 (1990) (arguing that the Court may have correctly inferred a more illicit motive in Seattle than in Crawford because passing a constitutional amendment "reflected an augmented rather than truncated version of lawmaking" but admitting that "none of this is explicit in the two opinions"); see also Baker, supra note 70 , at 762 n.220 (observing that "[s]cholars and judges have made many creative attempts to reconcile Crawford and Seatle").

167. In Seattle, Justice Powell, joined in dissent by Chief Justice Burger and Justices Rehnquist and $O^{\prime}$ Connor, suggested that the only relevant distinction between the two cases provided a stronger basis for 
Burger and Justices Powell, Rehnquist, and O'Connor voted to uphold both the Seattle initiative and the Crawford state constitutional amendment. Justice Marshall voted to strike down both laws as unconstitutional.

Three relevant majorities thus emerge from these two cases. The first majority would invalidate the Seattle initiative. The second majority would uphold the Crawford state constitutional amendment. The third majority, composed of Chief Justice Burger and Justices Powell, Rehnquist, O'Connor, and Marshall, would insist that the cases be decided consistently such that the Seattle initiative and the Crawford amendment are either both upheld or both struck down. ${ }^{168}$

Now assume that the Court, instead of using case-by-case resolution, uses a motion-and-amendment procedure, which identifies Condorcet winners. ${ }^{169}$ If the first motion is to announce a ruling that upholds the Seattle initiative, a majority would succeed in a motion to amend that requires that the two cases be decided consistently. The end result might appear to be (Seattle, notCrawford), where each entry denotes the Court's ultimate ruling relative to the actual case holding under the new procedure. ${ }^{170} \mathrm{~A}$ second motion to amend, this time to substitute the Crawford rule for the not-Crawford rule, would also pass, given the position of the six Justices who voted for the outcome in Crawford. A third motion to amend, again requiring consistency, this time with the outcome (not-Seattle, Crawford), would also pass because of the majority that favors consistency. A fourth motion to amend to substitute Seattle for notSeattle, thus creating (Seattle, Crawford), would also pass by a majority. A final motion, based upon consistency, to substitute not-Crawford for Crawford would pass as well, resulting in (Seattle, not-Crawford). While the Court has now come full circle, there is no predictable point at which the cycling will stop. ${ }^{171}$ This is because the preference patterns of the Justices lack a core;

upholding Initiative 350 than the California initiative. Justice Powell observed that unlike the California initiative, which limited court-ordered affirmative action to that required by the Fourteenth Amendment, Initiative 350 did not prevent court-ordered desegregation based on a violation of the Washington Constitution. Seattle, 458 U.S. at 490 n.3 (Powell, J., dissenting). To the extent that this distinction matters at all, it would have compelled deciding the cases in precisely the opposite manner, namely upholding the law that provides the broader basis for court-ordered desegregation. Moreover, Justice Powell, along with the three other Justices who joined his Seattle dissent, voted to uphold both state laws, which suggests that those Justices believed the two cases constitutionally indistinguishable. Justice Marshall (who voted with the majority in Seattle, and dissented alone in Crawford) expressly stated that he believed the two cases indistinguishable. Crawford, 458 U.S. at 547-58 (Marshall, J., dissenting).

168. The positions are summarized as follows:

1) Seattle majority: $\quad$ Blackmun, Marshall, Brennan, White, Stevens

2) Crawford majority: Powell, Burger, Rehnquist, O'Connor, White, Stevens

3) Consistency Rule: Powell, Burger, Rehnquist, O'Connor, Marshall

169. Another name for this procedure is issue-by-issue resolution. Each issue is presented in turn for a vote and a majority, upon motion, may substitute consideration of a different issue.

170. In other words, the Court would have decided to uphold both the Seattle initiative and the Crawford amendment. The symbol "not-Crawford" simply indicates that the new ruling is the opposite of that which the Court actually announced in Crawford.

171. Accord William H. Riker, The Paradox of Voting and Congressional Rules for Voting on Amendments, 52 AM. POL. SCl. REV. 349 (1958). Riker explains that if collective orderings for alternative 
unlimited motion-and-amendment voting procedure is therefore incapable of yielding a result.

The problem is that unlike the legislature, the Court lacks the option to simply walk away and leave the status quo. ${ }^{172}$ Instead, the Court must somehow resolve these two cases. ${ }^{173}$ This is not to suggest that the Supreme

motions are intransitive, as they are in the example offered in the text, and if the collective decisionmaking body "require[s] for the passage of a motion that [the motion] defeat each alternative to it, then no action can be taken." Id. at 353. The author adds that "the paradox results in a stalemate, in which, with no decision whatsoever, it is impossible to decide irrationally." Id. This analysis assumes there is no rule limiting the number of votes to be taken with respect to pending motions.

If, on the other hand, the collective decisionmaking body limits the number of motions on a given issue to less than the number of pending alternatives, then the intransitivity will not be revealed and the body will not endlessly cycle. See id. at 354 . In such cases, however, the outcome will be path dependent and thus arbitrary. Id. To see why, consider a three-person body with the paradigmatic non-Condorcetwinner preferences: (1) A,B,C; (2) B,C,A; (3) C,A,B. While the preferences are intransitive and there is no Condorcet winner, revealing the intransitivity requires three votes: (1) A v. B; (2) B v. C; and (3) C v. A. With only two of these three votes, taken in any order, the body will come to a conclusion but the conclusion will fail to satisfy the Condorcet criterion. For example if the two votes are A v. B (A wins) followed by $C$ v. A ( $C$ wins), then $C$ will be chosen. If, instead, the two votes are $B$ v. $C$ ( $B$ wins) followed by $A$ v. $B$ ( $A$ wins), then $A$ wins. Finally, if the two votes are $C$ v. $A$ ( $C$ wins) followed by $B$ v. $C$ (B wins), then $B$ wins. With only two votes and three alternatives, therefore, the body reaches a conclusion and fails to reveal the presence of a cycle. Indeed, with two votes on three issues, the agenda setter fully controls the outcome. See infra note 200 and accompanying text. In each case, the final pairwise vote reveals the cycle. Thus, in the first case $B$ v. $C$ reveals a cycle demonstrating that $C$ should not prevail; in the second case, $A$ v. $C$ reveals a cycle demonstrating that $A$ should not prevail; and in the third case, $A$ v. B reveals a cycle demonstrating that $B$ should not prevail.

Congressional voting practices that limit the number of votes relative to the number of pending motions may hide intransitivities and produce enactments that a majority disfavors. Id. at 355-56 (identifying circumstances that may arise under congressional voting procedures that fail to reveal intransitivities). While allowing the same number of votes as pending motions reveals intransitivities, there is no ready means with which to resolve such revealed intransitivities. See id. at 364 ("Even if both houses [of Congress] were to provide this method of discover[ing collective intransitivities], they would still need a procedure for resolving the intransitivities discovered. . . But, as Arrow has shown, an intransitivity, once in existence, cannot be eliminated simply by juggling the techniques of counting.").

172. There is, of course, a school of thought that takes the position that "not to decide is to decide," and thus that the very failure to reach a decision is no different than an advertent collective choice. Professor Sunstein argues that the theoretical basis of the Lochner era, namely the desire to leave markets unregulated in the name of vindicating the right to due process, was flawed because allowing market forces to operate is itself a deliberate governmental decision. Sunstein, supra note 22, at 1697,1718 . Sunstein goes on to state that once it is recognized that the status quo is the product of government action, there is no theoretical basis with which to hold regulation of the market off limits. Id.

One obvious difficulty with this analysis as applied to Lochner and its progeny is that if everything is the product of government action, then regulation and deregulation become the same thing. Both are then governmental choices concerning the extent to which outcomes will be determined by the marketplace or through nonmarket means. At the very least, defining "regulation" and "deregulation" to mean the same thing is cumbersome because it makes conversing about the Lochner era virtually impossible. In other words, to speak intelligently about any policy that involves legislative intrusion into the market place, it is essential to agree upon certain benchmarks. The most commonly accepted benchmark, and one I find most meaningful, is to accept that moves away from market decisionmaking are called "regulation," and that moves toward market decisionmaking are called "deregulation." Defining these terms as such says nothing necessarily about the merits of any particular proposal but only when these terms are properly defined and understood, is it possible to discuss the merits of such a proposal.

173. In criticizing a proposed solution to the voting paradox in the context of elections offered by Dodgson, Kenneth Arrow makes an analogous argument:

Dodgson accepts fully the Condorcet criterion, so much so that he comes to the conclusion that if a cyclical majority persists, then there should be "no election." This position is rather curious. Indeed Dodgson elsewhere shrewdly points out that "no election," if it is an allowable alternative, should be considered on a par with all the candidates. This seems quite inconsistent 
Court cannot issue a decision that has the effect of preserving the status quo. The distinction is more subtle. This Article demonstrates that there are two methods of preserving the status quo. One method is by failing to act formally and collectively. That can result from cycling. This method of preserving the status quo is not within the permissible range of the Supreme Court and other appellate courts. The second method is through a formal and collective decision that preserves the status quo. That method is within the permissible judicial range. In contrast, both methods are within the permissible range of Congress and other legislatures. ${ }^{174}$ Because appellate courts must act collectively in each case, and because Condorcet-producing rules would not allow them to satisfy that requirement, appellate courts employ voting procedures that do not satisfy the Condorcet criterion. A motion-andamendment procedure will not allow the Court to meet its obligation to collectively decide each case, ${ }^{175}$ while an alternative rule allowing each Justice to vote on the binary choice of outcome in each case does, albeit inconsistently. ${ }^{176}$ Moreover, the latter rule-unlike the motion-and-

with the previous statement. It does point, however, to an important empirical truth, especially about legislative matters rather than the choice of candidates: The status quo does have a builtin edge over all alternative proposals.

ARRow, supra note 6 , at 95 . As demonstrated in the text, however, the choice of voting rules across collective decisionmaking bodies is not explained by whether the status quo is a favored option in those bodies, but rather by whether the status quo is a permissible option in those bodies.

Saul Levmore has also considered why legislative bodies use motion-and-amendment procedures, which are conducive to identifying available Condorcet winners, while general elections use plurality voting or plurality voting with a runoff, both of which can miss available Condorcet winners. Levmore posits that a weak explanation for this difference is the desire for a genuine majority winner (or at least the appearance of such a winner after all other options are eliminated through pairwise voting) in crafting legislation, and that a stronger explanation is that replicating a motion-and-amendment procedure, or adopting round-robin voting, in general elections would substantially increase transactions costs. Levmore, supra note 8, at 101517. Levmore rules out round-robin elections on the additional grounds that "the importance and bias of order is too obvious," meaning that a candidate who awaits the outcome of all prior pairwise contests before campaigning against the finalist has an unfair advantage. Id. at 1031.

The explanation offered in this Article for why Supreme Court voting procedures are not designed to always yield available Condorcet winners, while congressional voting procedures are better suited to identify such winners, also explains the choice of procedure in legislative versus electoral voting. While the status quo is within the permissible range of legislative options, it is not within the permissible range of electoral options. Elections require results; some candidate must actually prevail. Legislatures, however, need not always produce results; the status quo can prevail. Procedures that guarantee available Condorcet winners, as demonstrated in the text, do not always guarantee an outcome. See BLACK, supra note 1, at 57 ("The main weakness of the Condorcet criterion is that when there is no majority candidate it leaves the election undecided."). Plurality voting or plurality voting with a run-off, in contrast, always guarantees a winner, but the winner will sometimes fail to satisfy the Condorcet criterion.

174. The statement that appellate courts, including the Supreme Court, must act collectively, however, does not imply that they must decide the issues in the manner that the litigants present those issues. That, the courts can, and often do, avoid. But appellate courts must make the (most often) binary choice to affirm or reverse as a collective institution.

175. This analysis at least holds true for a motion-and-amendment procedure that does not limit the number of motions based upon the number of issues. Such a limitation, while allowing for resolution of cases, would render the outcome of underlying issues path dependent. See supra note 171 and infra note 200 and accompanying text.

176. One narrow exception arises in cases involving three or more remedies, none of which has majority support among the Justices. One solution, offered by Justice White in such a case, Pennsylvania v. Union Gas Co., 491 U.S. 1, 56-57 (1989), is to switch a vote to achieve the necessary majority for one 
amendment procedure-will sometimes, as in Kassel, miss a Condorcet winner. ${ }^{177}$

In addition, by making a few minor assumptions we can demonstrate that an alternative decisional format, designed to avoid the doctrinal incoherence resulting from the requirement that the Court decide all cases, will still lead the Court into endless cycling. Under this decisional format individual Justices rank, then vote upon, packages of resolved issues. This procedure ensures that the same majority of the Court supports the outcome for each issue that the Court decides, thus avoiding the shifting majority problem. ${ }^{178}$ This part will apply the new decisional framework first to Seattle and Crawford and then to Kassel.

Assume that the Court is now faced with the following issues to resolve: (1) whether to uphold the Seattle initiative; (2) whether to uphold the Crawford amendment; and (3) whether to decide the cases consistently. These issues present each member of the Court with the following options: ${ }^{179}$

remedy to resolve the case. Justice Kennedy also followed this course. See Arizona v. Fulminante, $111 \mathrm{~S}$. Ct. 1246, 1266-67 (1991). For a critical analysis of the votes cast by Justices White and Kennedy in these cases, see Rogers, supra note 145 , at $439-42,475$ n.124. Adopting a procedure that identifies Condorcet winners would not remedy the problem posed by triple-remedy cases that lack majority support for one remedy, while adopting such Condorcet-producing procedures would create additional indeterminacy problems in shifting majority cases, as demonstrated in the text.

177. See supra text accompanying notes 139-46; $c f$. Kornhauser, supra note 28, at 457. Professor Kornhauser offers two altemative reasons why courts engage in case-by-case instead of issue-by-issue decisionmaking. First, he contends that issue-by-issue resolution requires that cases "hav[e] a perspicuous structure," meaning that the world of disputes must be susceptible to division into issues that can be "resolved acontextually." Id. at 455 . Kornhauser adds "[w]e may doubt that [legal] doctrine has this property." Id. He then argues:

If we believe that individual judges more accurately appraise issues than cases as a whole, we may be inclined to issue-by-issue adjudication. If, on the other hand, we believe that individual appraisals of cases are more accurate than appraisals of issues, we might be inclined to adopt case-by-case adjudication.

Id. He then conflates the two arguments, stating: "A view of the relative competence of judges between issue and case appraisal will depend on an assessment of doctrinal success in dividing disputes into discrete issues over which it is likely that judges have separable preferences." Id.

Kornhauser's argument suffers from two difficulties. First, there is no reason to assume judges are more competent at either case-by-case or issue-by-issue resolution. Second, both forms of case resolution lead to some form of doctrinal incoherence. Issue-by-issue resolution potentially leads to cycling, as shown in the Seattle and Crawford examples. Case-by-case resolution leads to rulings inconsistent with the preferences of a majority of the Court's members on particular issues or, in other words, misses Condorcet winners, as seen in Kassel.

But there is one critical difference between these two methods of decisionmaking. Case-by-case resolution guarantees outcomes in all cases, except the narrow category involving three or more remedies, none of which has majority support. See supra note 176 . That narrow category remains indeterminate regardless of the decisional rule. See id. Using issue-by-issue resolution, however, the Court cannot guarantee outcomes in all cases. Because the range of judicial, as opposed to legislative, decisionmaking does not include the power to default to the status quo through institutional inaction, the need to formally and institutionally resolve each case better explains the choice of case-by-case over issue-by-issue resolution in appellate courts.

178. In Kassel, for example, two separate majorities each supported the dissent's resolution of the two major issues in the case, thus creating a decision inconsistent with the Condorcet-winner criterion. For a fuller reconsideration of Kassel, see infra notes 186-87, and accompanying text. For other shifting-majority decisions, see Rogers, supra note 145, at 456-58.

179. There is a fourth option, "not-Crawford, not-Seattle." Adding this option only exacerbates the 


\section{A: Crawford, Seattle \\ B: Crawford, not-Seattle $e^{180}$ \\ C: not-Crawford, Seattle}

Each option A through $\mathrm{C}$ represents a package that resolves each of the three issues presented above but does so in a manner that avoids the shiftingmajority problem. By merging the three issues presented in these two cases and by requiring that the same majority support the outcome of all three issues, the decisional format ensures doctrinal coherence. Each Justice votes based upon the package that resolves the above three issues most favorably. The end result should be a ruling that is consistent across both cases and issues. ${ }^{181}$

By choosing, for example, option $B$, a Justice chooses to decide the cases consistently $^{182}$ and to uphold both the Seattle initiative and the Crawford amendment. A Justice choosing option $\mathrm{C}$ also chooses to decide the cases consistently, except that he has decided to strike both laws. Option A represents the actual case outcomes, namely a choice to decide the cases inconsistently by upholding the California constitutional amendment while striking the Washington initiative.

To simplify the analysis, assume that there are only three voters, any two of whom can decide for the Court. ${ }^{183}$ Assume further that while Justice Marshall states that he favors consistency, he would actually prefer a partly favorable inconsistent result to a fully adverse consistent result. ${ }^{184}$ Assume that Chief Justice Burger genuinely favors consistency over inconsistency, even if the consistent result is adverse. Finally, assume that Justice White believes that the cases should not be decided the same way based upon a distinction not shared by the other Justices. Assume further that Justice White has some reservation about striking the Washington initiative, given that a majority of the Court does not accept his basis for distinguishing the two cases but feels firmly that the California constitutional amendment is constitutionally valid. If Justice White must uphold or strike both the California amendment and the Washington initiative, he would prefer upholding both to striking both on the grounds that he disfavors striking a law that he firmly believes is constitutional

cycling problem.

180. See supra note $\mathbf{1 7 0}$ for an explanation of the term "not-Seattle."

181. This is not to suggest that the two cases will necessarily be decided the same way. Rather, they will be decided the same way if a majority believes that they should be decided the same way, and they will be decided differently if a majority decides that they should be decided differently.

182. Consistency has two meanings in this example. Some Justices believe that failing to uphold or to strike both state laws is inconsistent. Others disagree. The Court as an institution, in contrast, is inconsistent if a majority favors treating the cases in the same way, but the Court nonetheless treats the cases differently.

183. This assumption does not change the analysis because the Court had three camps: (1) the Burger group, with four members; (2) the White group, also with four members; (3) and Marshall. Any two-group combination contains the requisite five votes for a majority.

184. By modifying the above assumptions, the hypothetical also works if one assumes that Burger actually prefers inconsistency to an adverse consistent result. 
more than he disfavors upholding a law that is arguably but not clearly unconstitutional.

The following are the preference orderings for the three Justices based on the above assumptions:

$\begin{array}{ll}\text { Burger: } & \text { B, C, A } \\ \text { Marshall: } & \text { C, A, B } \\ \text { White: } & \text { A, B, C }\end{array}$

Chief Justice Burger's first choice, for example, is the position he actually voted for, deciding the cases in the same manner and upholding both state laws, which is position B. His second choice is the opposite consistent position, C. His third choice is the actual case outcomes. Justice Marshall's first choice is option $\mathrm{C}$, deciding the cases in the same manner and striking both laws. He then ranks option $A$, the actual case outcomes, which although inconsistent is partly favorable, ahead of option $B$, which although consistent, is adverse. Justice White's first choice is option A, the actual case outcomes. He then chooses option B, deciding the cases in the same way by upholding both laws, ahead of option $\mathrm{C}$, the opposite, for the reasons stated above. These rankings correspond with the non-Condorcet-winner paradigm. ${ }^{185}$ The result may therefore be endless cycling. Thus, while this procedure ensures that the same majority agrees upon the case outcome and the merits of every necessary issue to achieve that outcome-thus avoiding the shifting-majority problem - this procedure does not guarantee a decision in every case presented for review. In other words, this decisional process may lead the Court to inaction, which is outside the Court's permissible range. This problem is not unique to multiple cases presenting similar issues. As shown below, it can arise within a single case.

In Kassel, for example, the Court also faced three majorities: ${ }^{186}$ (1) a majority composed of Justices Brennan and Rehnquist favoring a rational basis test over a balancing test; (2) a majority composed of Justices Powell and Rehnquist favoring consideration of trial evidence rather than limiting review to legislative evidence; and (3) a majority composed of Justices Powell and Brennan to strike the Iowa statute. Again, both the motion-and-amendment and packaged-issue procedures would lead the Court into endless cycling.

Assume that if the Court decides to use the deferential rational basis test and to admit outside evidence, giving the court below a broader range of evidence with which to find a rational basis, then the outcome is to uphold the Iowa statute. Assume further that the first motion is to apply the rational basis test. That motion passes with Justices Brennan and Rehnquist prevailing over

185. See supra note 122.

186. For simplicity, this again assumes three voters, any two of whom are sufficient for a ruling on any motion. See supra note 137. 
Justice Powell. A second motion to admit outside evidence also passes with Justices Powell and Rehnquist prevailing over Justice Brennan. The outcome should therefore be to uphold the statute, except a third motion, to strike the statute, also prevails, with Justices Powell and Brennan prevailing over Justice Rehnquist. Justice Rehnquist can now start the motion process again to achieve a majority on each issue necessary to uphold the Iowa statute, but the result, again, may be endless cycling.

Now, with a few minor assumptions, consider packaging the issues for majority resolution. In Kassel, Justice Powell, for a plurality, held that the court should apply a balancing test and should admit trial evidence not considered by the legislature that enacted the statute. Justice Rehnquist, in dissent, maintained that the Court should apply a rational basis test and should be able to consider trial evidence. Justice Brennan, in concurrence, maintained that the Court should apply a rational basis test but should not consider trial evidence. The positions are summarized as follows:

A (Powell): balancing, trial evidence

B (Rehnquist): rational basis, trial evidence

C (Brennan): rational basis, no trial evidence

Assume that Justice Powell believes that a court should be able to consider trial evidence even if the substantive test is rational basis. Thus, his preferences are ranked A, B, C. Assume Justice Rehnquist is more concerned about applying what he considers to be the appropriate test than he is about the evidentiary rule and, thus, his preferences are B, C, A. Finally, assume that Justice Brennan believes that if courts are able to consider trial evidence, then they should apply the more stringent balancing test, rather than the highly deferential rational basis test, when considering such statutes; thus, his preferences are C, A, B. This, again, results in the non-Condorcet-winner paradigm, ${ }^{187}$ which may lead to endless cycling.

The Supreme Court does not actually use either of these two voting procedures, both of which will sometimes lead to endless cycling. Some scholars have concluded that because the Court's voting procedures do not lead to cycling, Arrow's Theorem is an inappropriate framework with which to assess the Court's behavior. ${ }^{188}$ With respect, this argument misses the point. Arrow's Theorem remains extremely useful in assessing Supreme Court behavior because, as just demonstrated, it explains why the Court has adopted decisional processes that sometimes appear to thwart the express will of a

187. See supra note 122.

188. See, e.g., Kornhauser \& Sager, supra note 28, at 109 n.37 (criticizing Easterbrook's application of Arrow's Theorem to Supreme Court decisionmaking); see also Richard L. Revesz \& Pamela S. Karlan, Nonmajority Rules and the Supreme Court, 136 U. PA. L. REv. 1067, 1094 n.120 (1988) (adopting the Kornhauser \& Sager analysis and rejecting the Easterbrook analysis). 
present majority of its members. To avoid the doctrinal incoherence that results from case-by-case voting, the Court would be forced to choose an alternative procedure that would not guarantee an outcome in all cases. This would violate the restriction on the Court's range, risking institutional inaction as an alternative to resolving all cases. This limitation on the Court's range, the requirement that it formally resolve all cases properly before it, explains why its voting procedures, along with those in other appellate courts, are not designed to yield Condorcet winners. In short, case-by-case resolution guarantees results in all cases, albeit at the price of occasional doctrinal incoherence.

\section{B. Universal Domain}

In one respect, universal domain relaxes equally in both the Supreme Court and Congress; neither institutions can aggregate preferences in a manner that violates the Constitution. The Constitution holds some legislative and judicial aggregations off limits, or, in the language of social choice, it limits these bodies' domain. Because of their different voting rules, however, universal domain relaxes in different ways and thus has different implications for these two bodies. The Supreme Court must collectively resolve all cases, so its voting rules allow non-Condorcet winners to prevail. Congressional voting procedures, on the other hand, ensure a higher degree of consensus among its members. Congress' ability to do nothing thus reduces the burdens of reaching a consensus. In another sense, therefore, universal domain poses a second critical distinction between the Supreme Court and Congress. As shown above, Supreme Court decisionmaking sometimes appears irrational precisely because no aggregation of votes is off limits for the Court as a whole. Aggregations are permitted even when the results are incoherent.

Moreover, the Supreme Court renders decisions in which a majority of its members have not achieved any meaningful consensus beyond the binary decision to affirm or reverse. In plurality opinions, for example, the rulings and the precedents they create, by definition, are not accepted by a majority of the Court. ${ }^{189}$ In an extreme case, like Regents of the University of California $v$. Bakke, ${ }^{190}$ only one Justice may agree with all the components of the Court's ruling. ${ }^{191}$ Again, this unusual feature of collective decisionmaking follows

189. Under Marks v. United States, 430 U.S. 188, 193 (1977), the ruling is the narrowest opinion written by a Justice who voted for the outcome; it need not be the plurality opinion. See generally supra note 141 .

190. 438 U.S. 265 (1978).

191. In Bakke, Justice Powell, for a plurality, decided two issues: first, whether the Board of Regents of the University of California Medical School was permitted to consider race as a factor in its admissions decisions, id. at 311-15; and second, whether, if the Board of Regents was permitted to use race as a factor, it had used race in a permissible manner, by creating a separate admissions pool for minority candidates, id. at 314-15. Justice Powell concluded that race was a permissible factor, but that the Regents could not 
from the limitation on range; Justices are not free to default to the status quo simply because they cannot achieve a stronger form of consensus than mere agreement on binary choice of outcome. ${ }^{192}$

Congress, however, must reach a substantially greater degree of consensus as a precondition to formal action, since a majority must agree on the precise language of every bill. In addition, as set forth below, numerous legislative practices increase this majority requirement to a de facto supermajority requirement. ${ }^{193}$ In other words, while Supreme Court voting procedures impose the bare minimum requirement of consensus as a precondition to collective action, congressional voting procedures effectively require supermajority consensus on matters of substance as a precondition to formal collective action. While a complete analysis of these legislative voting procedures is beyond the scope of this Article, a brief discussion of the manner in which these procedures operate to yield seemingly irrational ${ }^{194}$ results will suffice to illustrate the impact of requiring this high level of consensus in Congress. ${ }^{195}$

In Congress, as in many state legislatures, numerous negative legislative checkpoints $^{196}$ render passage of proposed legislation difficult by design. For example, committee structures, the Senate filibuster, and seniority rules, in addition to the requirements of bicameralism and presentment, multiply the

use race to create a separate admissions pool. Id. Instead, he endorsed the Harvard plan, in which race was used as one factor among many in deciding admissions from a unified pool. Id. at 315-19. In an opinion concurring in part and dissenting in part joined by Justices White, Marshall, and Blackmun, Justice Brennan agreed that race was a permissible factor in admissions decisions, but disagreed that the Harvard plan was constitutionally distinguishable. Id. at 325, 378-79 (Brennan, J., concurring in part and dissenting in part). Brennan would have upheld the Davis plan. Id. Finally, in a separate opinion joined by Chief Justice Burger and Justices Stewart and Rehnquist, Justice Stevens concluded that the Davis admissions policy violated Title VI of the 1964 Civil Rights Act and he therefore failed to reach the constitutional issues. Id. at 41112,421 (Stevens, J., concurring in part and dissenting in part). As a result, Justice Powell alone held that the Regents could use race as a qualifying factor but could not use separate admissions pools for minority and nonminority candidates. Even though Justice Powell alone adopted this position, his opinion became the ruling in the case.

192. This directly contradicts Lynn Stout's assertion that "[A] precedent cannot endure without the support of a majority of the several judges who may review it at each stage of the appeals process." Stout, supra note 18, at 1826. In fact, as Bakke illustrates, Supreme Court voting rules, unlike legislative voting rules, impose virtually no consensus requirement beyond agreement on binary choice of outcome.

193. See Maxwell L. Stearns, The Public Choice Case Against the Item Veto, 49 WASH. \& LEE L. REV. 385, 416 n.175 (1992) (explaining that procedural devices in Congress ensure that most bills pass with margins that exceed simple majorities, while the fact that relatively few vetoed bills are overridden suggests that most bills may lack the requisite two-thirds supermajority for an override).

194. Irrationality is not used here to mean intransitivity. Instead the term is used to illustrate the point explained below, infra note 220 and accompanying text, that while individual vote trades that result in procuring pork barrel legislation may be rational to the individual participants, the aggregate effect of such trades may be irrational to all participants because the end result leaves all participants worse off than had no such trades taken place.

195. See infra notes $197-205$ and accompanying text.

196. See Stearns, supra note 193, at 408 n.137 (defining "negative legislative checkpoints" as "the various loci at which an individual legislator or a group of legislators representing minority interests can slow down or stop a bill or, alternatively, at which minority interests can focus their lobbying efforts to procure legislative benefits."). 
opportunities for interested groups to lobby for or against a bill. ${ }^{197}$ In turn, these devices increase the number of points at which proponents of even the most high-minded legislation must make concessions, both substantive and by way of riders, to get favored bills passed. ${ }^{198}$

Many of these practices render legislative processes "path dependent." A corollary of Arrow's Impossibility Theorem, path dependency simply means that the order in which proposals are presented for a vote may influence which proposals pass. If there is no natural stopping point for legislative proposals that lead to cycling, then the only means with which to end cycling is to impose some exogenous and arbitrary rule. Deadlines and limitations on reconsideration, for example, solve the cycling problem; they also provide the person who determines the agenda with significant power to predetermine the path, and thus the outcome, of many legislative proposals. ${ }^{199}$ For example, if, in choosing an ice cream flavor, Alice, Bob, and Carole were bound by a rule that prevented reconsideration of any flavor that was defeated in a pairwise vote, ${ }^{200}$ then the person who determines the order of pairwise votes can actually control which flavor is chosen. Thus if Bob wanted chocolate to prevail, he would first present a choice between vanilla and coffee (vanilla wins), then, having ruled out coffee, between vanilla and chocolate (chocolate wins). Alice and Carole could similarly obtain their first choice if they controlled the agenda.

Both the costs and the benefits of such seemingly arbitrary legislative practices have been discussed at length in the literature. ${ }^{201}$ Indeed, public choice scholars have attributed the development of these seemingly arbitrary practices to the need to resolve the cycling problems associated with Arrow's Theorem. ${ }^{202}$ The point here is simply that such practices have a number of

197. See id. at $397-98$.

198. See id. at 416 \& n.176 (explaining that as a result of legislative bargaining processes "both the substantive content of a bill as well as [the riders it contains] are the product of a series of negotiated compromises.").

199. See Riker, supra note 171 , at 354 . Riker explains that limitations on amendments to bills and motions in both houses of Congress sometimes prevent the necessary number of votes to reveal the presence of cycles. In both houses, voting rules allow a maximum of four amendments for a pending bill or resolution. Id. ("In both houses of Congress, it is permissible to consider simultaneously as many as four amending motions to a bill or resolution."). If there are fewer options than the permitted number of votes, "the existence of an intransitivity is easily discovered." Id. But for complex or contested bills, the limitation on amendments can prevent intransitivities from being revealed, thus rendering outcomes path dependent. See id. ("When, however, the original matter is an elaborate bill, it is quite possible that the existence of an intransitivity will not be discovered and that the House or Senate, unaware of the paradox, will irrationally adopt clauses that are supported only by a minority.").

200. Another way to say this is that the group will allow no more than two votes for three options, a number insufficient to reveal the presence of a cycle. See supra note 171.

201. For an introduction to the interest group literature within public choice, see generally PETER ARANSON, AMERICAN GOVERNMENT: STRATEGY AND CHOICE (1981); MICHAEL T. HAYES, LOBBYISTS AND LEGISLATORS: A THEORY OF POLITICAL MARKETS (1981); MANCUR OLSON, THE LOGIC OF COLleCtive ACTION (1971): BUCHANAN \& TULLOCK, supra note 10; RIKER, supra note 15.

202. See, e.g., Daniel A. Farber \& Philip P. Frickey, The Jurisprudence of Public Choice, 65 TEx. L. REV. 873, 906 (1987) ("Legislatures are not characterized by chaos, but the threat of disorder posed by 
implications for the manner in which the Supreme Court and Congress function as complementary institutions. These practices sometimes appear to have the effect of causing legislatures, including Congress, to spin out of control, meaning that multiple vote trades leave everyone worse off than had no such trades taken place. ${ }^{203}$ This can take any number of forms. The outcome most frequently commented upon in the literature is the tendency of such practices to produce a proliferation of pork barrel legislation. ${ }^{204}$ Such legislation is often the price paid to achieve a legislative outcome that is disadvantageous to particular constituent groups. ${ }^{205}$ For present purposes, however, the more important consequence is statutes that violate the Constitution ${ }^{206}$ or that are internally inconsistent. ${ }^{207}$

Just as a legislature, in creating off-the-rack rules designed to facilitate market negotiations, can remove the seemingly insurmountable problem of market cycling in the absence of a core, so too a court can effectively restore rationality that might result from legislative cycling. If, for example, a legislature codifies intransitive preferences, thus creating an internally inconsistent statute, ordinary rules of statutory interpretation require that courts

Arrow's Theorem may determine much of their structure. Understanding the threat can illuminate the importance of legislative procedures."); see also Elhauge, supra note 91, at 105 (describing legislative procedures that reduce cycling and give closure).

203. But $c f$. Elhauge, supra note 91 (arguing that any normative proposal for statutory interpretation based upon the effects of such institutional devices as those mentioned in the text contains an unstated independent normative baseline concerning the appropriate extent of interest group involvement in the political process).

204. See, e.g., BRIAN Kelly, Adventures IN PORKLAND (1992) (describing practices that lead to proliferation of pork barrel legislation); WILL, supra note 24 (advocating term limits as means to ameliorate effects of many congressional practices that lead to undesirable legislation, including abundant special interest legislation).

205. For my own critical analysis of one proposal to address such irrational legislative results, namely the item veto, see Stearns, supra note 193. That article demonstrates that the item veto is likely to have the opposite of its intended effect of allowing the President to excise pork while leaving unaffected matters of substantive legislative policy. First, the President has substantially greater control in choosing which bills to support than with whom he must bargain to get those bills passed. Second, even with the item veto in place, Congressmen will insist that the President promise not only to give their district a bridge or dam, but also not to exercise the item veto, before they agree to support a bill the President favors. Thus, the item veto is likely to provide the President with substantial control over general legislative policy but relatively little control over the most egregious pork needed to get his favored bills passed. See generally id. at 412-22.

206. The same vote trading that can create a proliferation of pork barrel legislation can also create statutes that violate the Constitution. Consider, for example, Fullilove v. Klutznick, 448 U.S. 448 (1980), and City of Richmond v. J.A. Croson Co., 488 U.S. 469 (1989). The Fullilove Court upheld a provision in the Public Works Employment Act of 1977 that defined minority business enterprises (MBE's) as businesses owned or controlled by citizens of the United States "who are Negroes, Spanish-speaking, Orientals, Indians, Eskimos, and Aleuts," for purposes of a set-aside, even though the provision obviously emerged as the product of vote trading. In contrast, the Croson Court nevertheless struck down a substantially identical provision adopted by the Richmond City Council for its MBE set-aside on the ground that absent specific fact findings as to discrimination against the affected groups, the Fourteenth Amendment prohibited a municipality (as distinguished from Congress) from adopting even benign racebased discriminatory policies.

207. See infra note 208 . 
attempt where possible to avoid the inconsistency. ${ }^{208}$ In addition, if the legislature, as in the hypothetical based upon New York v. United States, ${ }^{209}$ fails to act in response to cycling, the courts, when faced with an actual legal controversy involving related issues, will devise appropriate rules to resolve the case, establishing a precedent, subject to legislative correction. ${ }^{210}$ Again, together, legislative and judicial action avoid cycling if the two institutions do not cycle in the same manner and in response to the same factual phenomena. ${ }^{211}$

More notably, when the legislature enacts a statute that violates the Constitution, in a properly presented case the judiciary will strike the statute as a violation of legislative domain. In addition, because members of the legislature, including Congress, are given extremely wide range to resolve a

208. See, e.g., United States v. Turkette, 452 U.S. 576, 580 (1981) (explaining that in construing statutes, "authoritative administrative constructions should be given the deference to which they are entitled, absurd results are to be avoided and internal inconsistencies in the statute must be dealt with"); Trans Alaska Pipeline Rate Cases, 436 U.S. 631, 643 (1978) ("This Court, in interpreting the words of a statute, has some scope for adopting a restricted rather than a literal or usual meaning of its words where acceptance of that meaning would lead to absurd results ... or would thwart the obvious purpose of the statute ... [b]ut it is otherwise where no such consequences would follow and where . . it appears to be consonant with the purposes of the Act ....") (quoting Commissioner v. Brown, 380 U.S. 563, 571 (1965)) (internal quotations omitted).

For a recent example of an appellate court "avoiding" a potential statutory inconsistency, see Fugere v. Derwinski, 972 F.2d 331 (Fed. Cir. 1992). In Fugere, the court considered the validity of a provision in the Veterans Administration (VA) Adjudication Procedure Manual M21-1, II 50.13(b), that prevented the reduction of a disability benefit based upon changed testing criteria, rather than upon a change in disability. Id. at 332-33. After the VA Chief Benefits Director (the "Director") rescinded II 50.13(b) on the grounds that by statute the Secretary of Veterans Affairs (the "Secretary") was not permitted to create a dual schedule of benefits, the VA reduced the disability benefits of a World War II veteran, who had been retested under newly adopted criteria, from thirty to twenty percent. Id. at 333 . The Court of Veterans Appeals restored the veteran's thirty percent disability rating on the ground that in setting aside II 50.13(b), the Director had enacted a substantive rule for which notice was required under the Administrative Procedure Act. Id. at 333-34. The Secretary then appealed to the Federal Circuit. Id. at 334.

The issue on appeal was whether the Court of Veterans Appeals had improperly restored the veteran's rating by applying an administrative provision, \I 50.13(b), that violated 38 U.S.C.A. $\$ 1155$ (West 1991). Id. Section 1155 provides: "The Administrator [now Secretary] shall adopt and apply $a$ schedule of ratings of reductions in earning capacity from specific injuries or combination of injuries." Id. at 335 (emphasis added by Fugere court). While the appeal was pending, Congress amended $\S 1155$ to add a provision that paraphrased the essential provisions of $\llbracket 50.13(\mathrm{~b})$. Id. As a result, if $\$ 1155$ were interpreted to allow only a single schedule of benefits and if $1150.13(\mathrm{~b})$ created a dual system of benefits, the statute itself became internally inconsistent. Id. at 335-36. The Fugere court rejected the Secretary's argument that the regulation (and the amended statutory provision) created a dual benefit schedule stating:

If the Secretary's interpretation of the "a schedule" language of $\$ 1155$ is correct, then there is an internal inconsistency within the amended version of $\S 1155$. Since we must assume that

Congress does not write internally inconsistent statutes . . . we must conclude that either $\$ 1155$ permits more than one schedule or $\mathbb{I}$ 50.13(b) does not create a dual schedule, or both.

Id. (citations omitted). The court avoided the potential internal inconsistency by construing "a schedule" to mean a method for determining ratings based upon disability, and by holding that 1150.13 (b) merely allowed a claimant to retain a previously determined rating, without providing the Secretary a method for determining that rating in the first instance. Id. at 335. The Fugere court upheld 91 50.13(b), thus affirming the increase in the veteran's benefits based upon a thirty percent disability. Id. at 336.

209. 112 S. Ct. 2408 (1992). For a discussion of the New York decision, see supra notes 80-85 and accompanying text.

210. Indeed, many off-the-rack rules were precisely such judicial creations.

211. In that respect, the relationship between courts and legislatures is analogous to that between markets and lawmaking institutions generally, as shown in Part II, supra. 
virtually unlimited number of policy proposals at any one time, it is not surprising that Congress occasionally stumbles over the border of its permissible legislative domain. When this happens, the judiciary, with its limited range ${ }^{212}$ may be better suited to correct these errors than is Congress, with its broad range. In this respect the two institutions are complementary.

\section{Unanimity and Independence of Irrelevant Alternatives ${ }^{213}$}

The "unanimity" assumption requires that a collective decisionmaking institution proceed with any proposal that leaves one person better off and no persons worse off. While Judge Easterbrook concludes that this criterion applies to the Supreme Court because it "means . . . that the Justices do not delegate their authority to someone else,"214 this conflates the requirements of nondictatorship with the requirement of unanimity. In fact, this criterion applies with less force in the Supreme Court than in Congress, although it is relaxed to a significant extent in both institutions.

In the Supreme Court, the Justices engage in judgment rather than preference aggregation. ${ }^{215}$ This follows directly from the relaxation of the range requirement. Individual Supreme Court Justices, although they no doubt render opinions consistent with their own political ideology, are not empowered under most, if not all, widely accepted jurisprudential theories ${ }^{216}$ to render decisions because of consistency with their own policy preferences. ${ }^{217}$ In fact, they are required to vote based on the law even if the

212. Another way to say this is that the limited range increases the likelihood that in resolving such legislative errors a court will achieve meaningful consensus because it is more likely to be uni-peaked than the legislators who created the error initially.

213. These two Arrovian criteria are discussed together because in the legislative context, the former cannot be explained without the latter.

214. Easterbrook, supra note 28, at 824.

215. See Kornhauser \& Sager, supra note 28 , at $88-89$. The distinction between judgment and preference aggregation lies at the core of virtually all traditional jurisprudential theories. Law, if indeed an autonomous discipline, depends upon choices by decisionmakers restrained by judgment, whereas politics does not. Indeed, rejecting the distinction between judgment and preference aggregation is one of the major characteristics that distinguishes the critical legal studies movement from virtually all traditional jurisprudential theories. See Joseph W. Singer, Legal Realism Now, 76 CaL. L. REV. 467, 539-40 (1988) (reviewing LAURA KALMAN, LEGAL REALISM AT YALE: 1927-1960 (1986)) (characterizing critics of the critical legal studies movement as observing that "[i]f law is 'just politics, . . . then there is no way for judges to decide cases legitimately; they can appeal only to their personal, subjective intuitions about justice, or to theories of economics or morality external to the law. This is the death of law and the possibility of social justice."); $c f$. Steven L. Winter, Indeterminacy and Incommensurability in Constitutional Law, 78 CAL. L. REV. 1441, 1447 (1990) (positing that "[a]lthough the critical legal studies critique of liberal legalism has made important contributions, its concomitant adoption of the indeterminacy and "law is politics' arguments invites endless problems of skepticism and incommensurability.").

The collective action problems posed by Arrow's Theorem apply whether the collective decisionmaking body is trying to aggregate judgments or preferences. As the discussion in the text emphasizes, however, judgment and preference aggregation have different implications for the application of the Arrovian unanimity criterion.

216. Cf. Kornhauser \& Sager, supra note 28, at 88; see also supra note 153 (illustrating the difference between judgment and preference aggregation).

217. Cf. Kornhauser \& Sager, supra note 28 , at 88. 
law flatly conflicts with their preferences. Similarly, a particular Justice is not empowered to vote based upon the judgment or preference of another Justice even if the first Justice is personally indifferent to the outcome of a case. ${ }^{218}$ The failure to decide cases where one Justice strongly favors the outcome and the others are indifferent, violates the Arrovian unanimity condition. For Supreme Court Justices, limited range compels the violation of unanimity. ${ }^{219}$

It may seem counterintuitive to claim that the unanimity criterion, which is essentially a requirement of Pareto optimality, applies in Congress, an institution in which, as we have seen, achieving simple majority consensus is particularly burdensome. In fact, however, the Pareto criterion applies with greater force in Congress, and in legislatures generally, than in the Supreme Court, and in other appellate courts ${ }^{220}$ because another Arrovian criterion, independence of irrelevant alternatives, is relaxed in Congress. ${ }^{221}$

Independence requires that members of a collective decisionmaking body, in this case legislators, vote in accordance with their ordinally ranked preferences in any pairwise vote regardless of extraneous agenda issues. For example, even if Carole knows that Bob's agenda will lead to chocolate, which she dislikes intensely, Carole cannot vote strategically for coffee, her second choice, in a pairwise vote between vanilla and coffee. While such a vote will

218. The range restriction arguably undermines the legitimacy for any particular Justice of assuming a position of indifference, given that the judicial task for that Justice is to ascertain to the best of her ability the result compelled by law.

219. See supra Part IV.A.

220. This analysis is not intended to suggest that the outcomes of legislative processes are Pareto superior in terms of wealth maximization. Instead, the analysis demonstrates that legislative voting processes generally satisfy the Pareto criterion, given the preferences of the legislators. The legislators' preferences, however, if satisfied by legislative voting processes, may produce outcomes that are actually Pareto inferior in that they frustrate rather than enhance wealth maximization. See William H. Riker \& Steven J. Brams, The Paradox of Vote Trading, 67 AM. POL. SCl. REv. 1235, 1236 (1973) (positing that the "paradox [of vote trading] has the property that, while each trade is individually advantageous to the traders, the sum of the trades is disadvantageous to everybody, including the traders themselves"); RIKER, supra note 15, at 166-67 (explaining that individually rational logrolls can lead to aggregate legislative results that are Pareto inferior); Stearns, supra note 193, at 401; see also infra notes $245-50$ and accompanying text (describing processes that result in proliferation of pork barrel legislation, which may be Pareto inferior).

While it may appear counterintuitive that in achieving Pareto superior legislation from the standpoint of legislators' preferences, the legislature can achieve a Pareto inferior aggregate result in terms of frustrating wealth maximization, this result is consistent with the insight from interest group theory that Congressmen, in seeking to provide concrete legislative benefits to their constituents to ensure reelection, engage in individually rational trades that impose costs on everyone and that ultimately leave everyone worse off. See DAVID R. MAYHEW, CONGRESS: THE ELECTORAL CONNECTION 16 (1974) (positing that "[t]he electoral goal ... has to be the proximate goal of everyone, the goal that must be achieved over and over if other ends are to be entertained"); MORRIS P. FIORINA, REPRESENTATIVES, ROLL CALLS, AND CONSTITUENCIES 31 (1974) (positing that "reelection is the primary goal that the constituency controls: the district gives and the district can take away"); cf. ARANSON, supra note 201, at 385 (positing that "the members of Congress have solved their prisoners' dilemma while perpetuating the associated dilemma among constituents and interest groups").

221. As shown below, the independence criterion applies with relatively greater force in the Supreme Court. See infra notes 233-36 and accompanying text. 
prevent chocolate from emerging the ultimate winner, it will also violate the independence criterion. 222

Of course, legislators violate the independence criterion all the time. Some call this strategic voting; others call it logrolling. Strategic voting allows legislators to place relative, or cardinal, weights on preferences instead of merely ranking their preferences ordinally. Similarly, vote trading, or logrolling, ${ }^{223}$ allows legislators to reveal intensity of preferences rather than

222. In contrast with this positive explanation for the relaxation of the independence criterion in Congress, McGrath provides a substantially different normative explanation of why the independence criterion should be relaxed in our constitutional system. See McGrath, supra note 12 . His analysis largely mirrors the Pildes and Anderson criticism of Arrow's Theorem, based upon the rationality criterion. See supra notes 30 and 115 .

McGrath contends that Madison assumed our collective decisionmaking institutions would have to foster interdependent preferences among citizens to remain stable. McGrath, supra note 12, at 9-10, 13 (explaining that Madison, strongly influenced by the writings of David Hume, believed that in a republican form of government the violence of factions could only be avoided if citizens' preference orderings were interdependent). McGrath further contends that individual and societal preference orderings are inherently different and that both sets of preferences will be altered through those filtering processes designed to produce "affectionate orderings." Id. at 10 ("[Madison] believed that this interdependence can be destroyed; and that to survive, therefore, a republic needs institutions which foster interdependence. ... 'Virtuous' citizens are those whose preferences are entangled, by sympathy, with the preferences of other citizens."); $i d$. at 80-81 (explaining that Arrow's independence condition "assumes that the things ordered by the individuals are identical to the things ordered by society," an "identity assumption" that Madison expressly rejected).

\section{McGrath explains that:}

Madison created a theory which attempts to save democracy from the evils he presumed to be incident to it: instability, confusion, and injustice. His primary strategy was to "enlarge the scope" of the society. His reason for this strategy was that enlarging the scope would, he believed, foster affectionate ties.

Id. at 98. McGrath argues that while it may appear counterintuitive that extending the sphere fosters affectionate ties, Madison believed that the vice of factions (which served to reduce interdependent preferences) increased as individuals became strongly affiliated with particular segments of society. Id. at 118 ("Madison felt if he could just keep majority groups from forming, majorities would not be 'blinded" by the sympathy for those 'close' to them, for those in the same groups, and they will then be able to reflect and see that they do care for those "far away."); id. at 160 ("The danger to democracy is not from some total disregard of all others, which to Madison was inhuman, but from disregard of some others because of being so close to a group."). Thus extending the sphere, Madison hoped, would diminish harmful allegiances.

As a result of interdependency, McGrath contends, Madisonian republicanism relaxes the independence criterion by design, since individual and group orderings are altered through deliberative processes. $I d$. at 9 ("Arrow's theorem only holds for individual preference orderings not entangled by a kind of sympathy with the preferences of other citizens."). One interesting implication of McGrath's analysis is the extent to which the filtering processes, used to foster interdependent ties, increase stability by rendering collective preferences uni-peaked. $C f$. id. at 50 . While Madison believed, for example, that even "[if] every Athenian citizen were a Socrates, every Athenian assembly would still have been a mob," id. at 104 (quoting THE FEDERALIST No. 55), he also believed our system of government, with a more ordinary population, capable of much greater stability. In any event, McGrath admits that his understanding of Madisonian republicanism does not correspond with the manner in which our collective decisionmaking processes are understood and operate today. Id. at 164-69. He further expresses doubt as to whether the present system is likely to evolve in a manner that will inculcate the necessary affectionate ties for the vision of republicanism he offers. See id.

223. Assume, for example, that Bob is the agenda setter, with the following, original, non-Condorcetwinner preferences.

Alice: coffee, chocolate, vanilla

Bob: chocolate, vanilla, coffee

Carole: vanilla, coffee, chocolate 
mere ordinal ranking of preferences. ${ }^{224}$ While this commodification of votes may not reveal preference intensities as precisely as do market transactions, ${ }^{225}$ it nonetheless provides some reasonable proxy for intensity of interest, or in the language of game theory, may provide some proxy (or substitute) for a core. ${ }^{226}$

The legislator's ability to reveal intensity of preferences, rather than mere ordinal ranking of preferences, through strategic voting and logrolling, both of which violate Arrovian independence, allows legislatures, in a manner that more closely resembles markets than courts, to move toward Pareto

If Carole knows Bob's planned two-vote agenda is (1) vanilla versus coffee (coffee wins); (2) chocolate versus vanilla (chocolate wins), she can derail his plans by voting strategically for coffee, Bob's last choice, in the first pairwise vote. Because coffee beats chocolate, coffee will prevail overall.

Instead of engaging in this mutually disadvantageous behavior, namely each attempting to ensure that the other's least-favored choice emerges the winner, Bob and Carole can logroll. If Bob will agree to change the agenda to (1) coffee versus chocolate (coffee wins); (2) coffee versus vanilla (vanilla wins), Carole will agree to vote in accordance with her originally ranked preferences in both pairwise votes. The compromise, or logroll, leaves both Bob and Carole better off than if each engages in their original optimizing strategy since neither ends up with his or her last choice. This occurs, however, at Alice's expense.

In MUELLER, supra note 6, at 82-83, the author provides another useful illustration of a mutually beneficial logroll. Assume two proposals, $\mathrm{X}$ and $\mathrm{Y}$, with three voters: $\mathrm{A}, \mathrm{B}$, and $\mathrm{C}$. Further assume that each has the following utility function with respect to the two legislative proposals.

$\begin{array}{ccc}\text { Voters } & \text { Proposal X } & \text { Proposal } Y \\ \text { A } & -2 & -2 \\ \text { B } & 5 & -2 \\ \text { C } & -2 & 5\end{array}$

Without vote trading, both proposals fail. If, however, B and C trade votes, such that each agrees to support the proposal she disfavors, both proposals pass, and $\mathrm{B}$ and $\mathrm{C}$ are each benefited to the extent of three utils. Id. Mueller explains that the "existence of beneficial trades requires a nonuniform distribution of intensities." Id. at 82 . Thus if the 5 's are changed to 2 's, B and $\mathrm{C}$ gain nothing by vote trading. Id.

224. In BUCHANAN \& TULLOCK, supra note 10, the authors explain how logrolling allows moves toward Pareto optimality:

A man who is passionately opposed to a given measure and a man who is slightly favorable but does not care greatly about it are given equal weight in the process of making final decisions [through ordinary voting processes, including majority rule]. It seems obvious that both of these individuals could be made better off, in terms of their own expressed preferences, if the man strongly opposed should be permitted in some way to "trade" or exchange something with the relatively indifferent supporter of the proposed measure.

Id. at 132. The authors add: "Applying the strict Pareto rules for determining whether one social situation represents an improvement over another, almost any system of voting that allows some such exchange to take place would be superior to that system which weights all preferences equally on each issue." Id. at 132-33.

225. Cf. id. at 158. The authors explain that as logrolling becomes increasingly complex, embracing more issues and expanding the nature of payments, the analogy to markets is strengthened. Id. The authors explain:

Complex logrolling . . . remains a "barter" system, but it merges into a pure "monetary" system (that is, one with full side payments) as the range of issues undertaken collectively is broadened. ... If the voter is enabled to choose from among a sufficiently large number of alternative sets, his effective "purchasing power" approaches the limit that would be available Id. to him under a "monetary" system.

226. See supra Part II. 
optimality. $^{227}$ As stated above, Daniel A. Farber and Philip P. Frickey ${ }^{228}$ reject Judge Easterbrook's contention that agendas in legislatures are "an additional source of arbitrariness and unpredictability," claiming instead that "recent public choice literature suggests that agenda rules make outcomes more predictable and therefore more understandable."229 Farber and Frickey erroneously suggest that because legislative outcomes are predictable and understandable, they cannot simultaneously be arbitrary. ${ }^{230}$ Nevertheless, the above analysis can be used to strengthen their argument to a limited extent. Increasing the participants' abilities to predict and understand outcomes also increases their power to prevent outcomes that are arbitrary and irrational. While congressional procedures sometimes disallow a sufficient number of votes on amendments to reveal all cycles, ${ }^{231}$ the predictability (as distinguished from rationality) of these procedures may enable legislators to respond through logrolling to enhance legislative rationality. Specifically, legislators can exert appropriate pressure through logrolling to ensure that those empowered to control outcomes through arbitrary (and path dependent) procedures will not choose paths that lead to strongly disfavored outcomes. ${ }^{232}$ In that manner, logrolling, coupled with predictable (but arbitrary) procedures, may serve to enhance both legislative predictability and rationality. Thus, the removal of the independence criterion in legislatures increases the extent to which the unanimity criterion applies in legislatures, increasing legislative rationality.

In the Supreme Court, however, the independence criterion applies with substantially greater force. If Justices vote based on their analysis of applicable law, rather than in response to their personal preferences, ${ }^{233}$ their decisions on particular issues should not be influenced by the order in which those issues are presented. The difficulty, though, as we have already seen, is that the order, or "path," in which options are presented to a body that votes strictly in accordance with previously set preferences can control substantive issue resolution. Compliance with the irrelevance criterion can thus render Supreme Court decisional processes, and appellate court decisional processes generally, path dependent.

Path dependence simply means that the outcome depends upon the path, or order, in which choices are presented. As demonstrated above, an agenda

227. Cf. RIKER, supra note 15 , at 160 (explaining that sophisticated vote trading enables legislators to "force the choice of the Condorcet winner.").

228. See Farber \& Frickey, supra note 29, at 431.

229. Id.

230. See id.

231. See Riker, supra note 171 , at 354.

232. For a very simplified example, see supra note 223.

233. See Kornhauser \& Sager, supra note 28, at 88-89; see also supra note 215; Elhauge, supra note 91 , at 105 (positing that aggregation problem for appellate courts may be greater than in legislatures because "under prevailing ethical norms judges cannot engage in the sort of logrolling that legislators commonly employ"). 
setter can control the flavor of Diane's ice cream cake through the order of pairwise votes. ${ }^{234}$ Similarly, if the Court decided Seattle and Crawford one year apart, instead of on the same day, the order in which the cases reached the Court would have controlled the outcome of the second case, assuming either compliance with a rule of stare decisis or that the majority favoring consistency prevails in the second case. ${ }^{235}$ In other words, because the independence criterion applies in the Supreme Court, stare decisis renders the evolution of legal doctrine path dependent. ${ }^{236}$

\section{Nondictatorship}

The nondictatorship criterion is relaxed in both institutions, but substantially more so in Congress. Both institutions relax nondictatorship by giving agenda control to less than a majority of the institution as a whole. In the Supreme Court, the Rule of Four for granting petitions of certiorari modifies the nondictatorship criterion by allowing a minority of four to control the Court's agenda. ${ }^{237}$ While developing a certiorari theory is beyond the scope of this Article, ${ }^{238}$ three points are relevant. First, the certiorari process is unique, at least in federal practice. ${ }^{239}$ Thus, in appellate courts generally, which lack discretionary appeals processes, the nondictatorship criterion is not relaxed. Second, votes on certiorari petitions may be substantially closer to preference than to judgment aggregation in that the standards governing the certiorari process are extremely broad and susceptible of contrary interpretation as applied in particular cases. ${ }^{240}$ Finally, after the petition is granted in a particular case, except in the fairly rare instance when the Court determines

234. See supra note 200 and accompanying text.

235. If, for example, Seattle were decided first, then a majority of the Court who believed the cases indistinguishable would have felt obligated to follow the Seattle rule in Crawford. Applying the same assumption, the opposite outcome in both cases would result if Crawford were decided first.

236. In recent years, constitutional stare decisis has come under sharp attack, from among other sources, Chief Justice Rehnquist. See, e.g., Planned Parenthood v. Casey, 112 S. Ct. 2791, 2861 (1992) (Rehnquist, C.J., dissenting) ("Erroneous decisions in such constitutional cases are uniquely durable, because correction through legislative action, save for constitutional amendment, is impossible.").

237. Cf. Levine \& Plott, supra note 15, at 594 ("IT]he Supreme Court, through its power to limit grants of certiorari to particular issues in a case, may itself consciously attempt to neutralize or accentuate agenda influence.").

238. For a thorough analysis of the Rule of Four for granting petitions for certiorari and the related Rule of Three for granting stays pending certiorari, see Revesz \& Karlan, supra note 188.

239. Many states provide their appellate courts with similar certiorari jurisdiction. See, e.g., VA. CODE ANN. § 17-123 (Michie 1988) (providing circuit courts with certiorari jurisdiction).

240. See Robert L. STERN ET AL., SUPREME COURT PRACTICE $\$ 4.2$, at 194 (6th ed. 1986) (observing that Rule 17, which lists factors the Supreme Court considers in evaluating petitions for writs of certiorari, "reveal[s] nothing significantly new or different; no bright lines are drawn as to what the Justices deem relevant or decisive in reaching their subjective and collective judgments"). Rule 17 provides that the factors it lists as relevant are "neither controlling nor fully measuring the Court's discretion." Id:; see also $i d$. at 195 ("Certiorari is a discretionary jurisdiction, one that can be invoked or withheld for any reason that the Court sees fit."). 
that it granted certiorari improvidently, ${ }^{241}$ the Court proceeds with the case as if there had been no agenda manipulation by a dictator, or in this case, by the minority of four. ${ }^{242}$ In analyzing actual decisions based on Arrow's Theorem, therefore, the Rule of Four is likely to be of limited value. ${ }^{243}$

Aside from this notable exception, ${ }^{244}$ the nondictatorship criterion generally applies in the Supreme Court in that cases, once taken, are decided based upon assessments of the merits by individual Justices without agenda manipulation. Indeed, the avoidance of procedures that would allow agenda manipulation, as shown above, causes the Court to miss available Condorcet winners.

Congressional procedures, in contrast, provide individual members with powerful opportunities to set the agenda and to exact rents for procurement of legislative benefits. Perhaps the most noted current member who illustrates this is Senator Robert Byrd, the Chairman of the Senate Appropriations Committee, a master at charging substantial tolls benefitting his home state of West Virginia as a precondition to getting favored bills out of his committee. ${ }^{245}$ While these processes may lead to seemingly irrational, or Pareto inferior legislative outcomes, ${ }^{246}$ this form of irrationality is not subject to Supreme Court correction unless it independently violates the Constitution. ${ }^{247}$

241. See Revesz \& Karlan, supra note 188 , at 1082-95 (describing process to determine improvident grant of certiorari); see also STERN ET AL., supra note 240, at 262-63, 288-93.

242. But cf. supra note 158 (discussing standing).

243. Certainly if we would predict doctrinal confusion even with majority rule, we would predict even greater doctrinal confusion with minority rule. Cf. Revesz \& Karlan, supra note 188, at 1131-32 (positing that the Court's treatment of certiorari process has defied consistency and coherence).

244. One additional exception is the opinion assigning function. The Chief Justice, if he votes with the majority, or the senior Justice who agrees with the majority, if the Chief Justice does not vote with the majority, assigns the opinion. See Jon O. Newman, The Second Circuit Review-19\$2-19S3 Term-Foreword: In Banc Practice in the Second Circuit: The Virtues of Restraint, 50 BROOK. L. REv. $365,378 \mathrm{n} .85$ (1984) ("In the Supreme Court, when the Chief Justice is in the minority, the opinion writing assignment is made by the senior judge in the majority."). Authorship can have a substantial effect on an opinion's content. This function can be so significant in affecting development of legal doctrine that former Chief Justice Warren Burger is reputed to have sometimes voted with a majority with which he disagreed in order to control the opinion assignments. He would then switch sides and dissent after the opinion was written, a tactic for which he was criticized. See BERNARD SCHWARTZ, THE ASCENT OF PRAGMATISM: THE BURGER COURT IN ACTION (1990). Schwartz quotes an unnamed Supreme Court Justice as stating in an interview: "[A]ll too damned often the Chief Justice [Burger] will vote with the majority so as to assign the opinion, and then he ends up in dissent." Id. at 14. Schwartz adds: "Voting with the majority in this way certainly appears contrary to the spirit, if not the letter, of the Court's assignment practice." Id.; see also LAWRENCE BAUM, THE SUPREME COURT 165 (4th ed. 1992), quoted in CHRISTOPHER E. SMITH, Justice ANTONIN SCALIA AND THE CRIMINAL Justice CASES, 81 KY. L.J. 187, 189 n.13 (1993). Of course, if the opinion as written is unacceptable to others who formed part of the plurality or majority, the latter Justices can decline to sign the opinion and instead vrite separately. In at least some cases, however, there is little question that the assignment function can affect the development of legal doctrine.

245. For a recent popular account of Senator Robert Byrd's acumen in obtaining pork for his home state, see generally KELLY, supra note 204.

246. See, e.g., RIKER, supra note 15, at 166-67; see also supra note 220.

247. Pork barrel legislation per se, however, is not unconstitutional, which is why proposals for constitutional amendments like germaneness rules and the item veto have each gained substantial support in recent years. These proposals are intended to render this form of legislative irrationality unconstitutional. 
The aggregate effect of procedural rules that provide dictatorial, or at least agenda-setting, power to individual members of Congress is to broaden the constituent base required for many, if not most, bills. ${ }^{248}$ These procedures, which often result in substantive legislative compromises, can further result in a proliferation of special interest legislation that remains unchecked by the judiciary. ${ }^{249}$ They can also contribute to outcomes that extend outside of Congress' permitted range, thus requiring the Supreme Court to exercise its negative check in the form of judicial review. ${ }^{250}$

\section{E. Rationality}

For the reasons outlined above, the Supreme Court's major Arrovian deficiency is its inability to guarantee that the preferences of a majority of its members will be reflected in resulting doctrine-even within particular cases. $^{251}$ In short, the requirement of rationality in Supreme Court decisionmaking is subordinated to the requirement that the Court decide all cases before it.

This is not to suggest that we are inevitably stuck with wholly irrational law. It is to suggest, however, that proposals to expand the scope of judicial review must themselves be closely scrutinized. ${ }^{252}$ One factor that may enhance rationality in Supreme Court decisionmaking, at least under more traditional jurisprudential theories of judicial review, is uni-peakedness. To the extent that the Justices share a doctrinal framework, whether it is based upon original intent, utilitarianism, federalism, or something else entirely, the Court is more likely to achieve meaningful compromise even absent majority consensus on particular outcomes. While the analysis does not suggest that Arrow's Theorem itself proves any particular doctrinal framework to be superior, it does suggest that the theorem demonstrates that some common doctrinal framework is superior to none, to the extent that rationality is considered important in judicial decisionmaking. ${ }^{253}$

248. Cf. William H. Riker, The THeORY of Political Coalitions 54-66 (1962) (evaluating instances in which Congress has achieved supermajorities that appear inconsistent with principle of minimum winning coalitions); see also Steams, supra note 193, at 408 (positing that "[i]n the language of public choice theorists, these negative legislative checkpoints serve to increase the size of coalitions necessary to succeed in achieving procurement of desired legislation").

249. See supra note 247.

250. Cf. note 206 and citations therein.

251. See supra Part IV.A.

252. See, e.g., Stout, supra note 18 (arguing that social choice theory justifies broadly expanded judicial review).

253. One implication of the analysis is that it may add to the burden of those advancing nontraditional theories of judicial review. The merits of any particular proposal aside, the issue remains whether it is likely to be adopted by the requisite number of Justices to render Supreme Court decisionmaking uni-peaked. If less than a majority, for example, adopts even a superior normative framework, the end result may be to decrease, rather than to enhance, institutional rationality because the effect may be to increase the extent to which the judicial preferences are multi-peaked. 
In contrast, within Congress, a common doctrinal framework among participants is not a precondition to achieving institutional rationality because Congress is better able to achieve meaningful compromise through logrolling or strategic voting. These processes allow legislators to cardinalize preferences, even when preferences are multi-peaked. In other words, by commodifying votes, legislators can achieve consensus acceptable to all, even if no member would rank the resulting package of legislation as her first choice. ${ }^{254}$ Cardinalizing preferences thus provides legislative bodies with a proxy for a core. $^{255}$ This is not intended to suggest that legislatures are incapable of codifying intransitivities ${ }^{256}$ or that the logrolling process itself is entirely path independent. The point instead is that various forms of legislative compromise, whether through logrolling or strategic voting, serve to enhance legislative rationality, whereas Supreme Court voting procedures, coupled with the requirement that the Court decide all cases properly before it, undermine rationality. Again, because both institutions are imperfect, proposals to shift decisional authority from one to the other must be analyzed with the following question in mind: which institution contains the imperfections that are least bad in resolving the cases or issues in question?

Ironically, proposals to expand judicial review, based on social choice theory, would transfer issues for which legislatures have a proxy for a core, to appellate courts, when those courts lack a proxy for a core. Courts lack a proxy for a core over those issues because the cases presenting those issues are not obviously resolved through reference to the Constitution. If they were so resolved, there would be no need to rely on social choice theory for expanded judicial review. As a result, in the very cases for which expanded judicial review is sought, the preferences of Supreme Court Justices are least likely to be uni-peaked. There is no obvious means, therefore, to ensure that the Court's

254. This may provide a better explanation for general acceptance of our constitutional lawmaking bodies than that advanced by Pildes and Anderson, see supra notes 30 and 115 (explaining and critiquing the Pildes and Anderson thesis). This analysis is not intended to suggest that legislatures are incapable of arriving at compromises that virtually everyone finds unacceptable. President Clinton's proposed "Don't ask, Don't tell, Don't pursue" solution to the issue of whether gays should be admitted to the military appears to be a good example of the latter form of compromise. See, e.g., Maia Davis, Both Sides Dislike New Gay Policy; Military: Some Ventura County Residents Say Clinton's Compromise Goes Too Far, Others Say it Doesn't Go Far Enough, Los ANGELES TiMES, July 20, 1993, at B1.

255. Buchanan and Tullock make an analogous argument: "The more perfect the vote-trading 'market," the wider the range of collective activities that will tend to be selected at the stage of constitutional choice. The less perfect the 'market,' the more restrictive must be the range and scope of collective action." BUCHANAN \& TulLOCK, supra note 10, at 209. The authors conclude: "The society that is characterized by strong and effective ethical and moral restraints, which prevent vote-trading, will find it more essential to place constitutional curbs on the political decisions of the majority than will the society in which these restraints are less effective." Id. (footnote omitted). Because legislatures encourage vote trading, legislators are able to achieve a more rational form of consensus on issues lacking majority support for one option than are appellate courts, in which commodification of votes is not an accepted practice. See supra notes 223-32 and accompanying text; $c f$. Levmore, supra note 10, at 150-51 (describing methods through which legislative preferences can be expressed with near-market precision).

256. See supra note 208 and accompanying text. 
members will apply a common doctrinal framework to achieve rational outcomes. Any commonality is a matter of coincidence and coincidence, of course, is just that.

Moreover, while legislatures, especially when allocating benefits of capital gains and burdens of capital losses, can cycle, ${ }^{257}$ they can avoid irrationality by defaulting to the status quo through inaction. Appellate courts, including the Supreme Court, do not have that option. In addition, when Congress does enact incoherent, because intransitive, policies, the Supreme Court can restore coherence without any additional justification. ${ }^{258}$ That, along with the requirement that in construing statutes, courts are to avoid absurd results, is a traditional judicial task. ${ }^{259}$ No separate institution is available to restore rationality to intransitive judicial decisions rendered under the guise of constitutional judicial review.

\section{F. Summary}

To summarize the discussion thus far, Table 1 analyzes the Supreme Court and Congress based upon the Arrovian and Condorcet criteria.

257. As shown above, legislative practices are most likely to be rational when preferences among legislators are uni-peaked, and preferences are most likely to be uni-peaked when the legislature is not allocating the burdens of a capital loss or the benefits of a capital gain. Of course, most legislative proposals are far more complex and not susceptible of such precise classification. Many, if not most, laws contain both distributive and nondistributive elements.

258. For examples, see cases cited supra note 208.

259. United States v. Turkette, 452 U.S. 576, 580 (1981); Trans Alaska Pipeline Rate Cases, 436 U.S. 631,643 (1978). 


\begin{tabular}{|c|c|c|}
\hline Arrovian Criteria & Supreme Court & Congress \\
\hline Range & $\begin{array}{l}\text { Limited to negative check } \\
\text { based upon constitutional } \\
\text { text (Congress) or federal } \\
\text { law (states); range does not } \\
\text { include inaction }\end{array}$ & $\begin{array}{l}\text { Wide range, except as } \\
\text { limited by Art. I, } \$ 8 \\
\text { delegation (floor) and } \\
\text { independent constitutional } \\
\text { provisions (ceiling); range } \\
\text { does include inaction }\end{array}$ \\
\hline Universal Domain & $\begin{array}{l}\text { Restricted by constitutional } \\
\text { ceiling but otherwise } \\
\text { applies, allowing } \\
\text { aggregations that do not } \\
\text { reflect issue-by-issue } \\
\text { preferences of majority }\end{array}$ & $\begin{array}{l}\text { Restricted by constitutional } \\
\text { floor and ceiling }\end{array}$ \\
\hline Unanimity & $\begin{array}{l}\text { Does not apply because } \\
\text { Court engages in judgment } \\
\text { not preference aggregation }\end{array}$ & $\begin{array}{l}\text { Pareto optimality } \\
\text { approximated by strategic } \\
\text { voting and logrolling }\end{array}$ \\
\hline Nondictatorship & $\begin{array}{l}\text { Applies, except in grants of } \\
\text { certiorari }\end{array}$ & $\begin{array}{l}\text { Relaxed through procedures } \\
\text { that provide individual } \\
\text { members with substantial } \\
\text { agenda control }\end{array}$ \\
\hline $\begin{array}{l}\text { Independence of } \\
\text { Irrelevant Alternatives }\end{array}$ & $\begin{array}{l}\text { Applies, resulting in } \\
\text { development of doctrine that } \\
\text { is path dependent }\end{array}$ & $\begin{array}{l}\text { Relaxed through strategic } \\
\text { voting and logrolling }\end{array}$ \\
\hline Rationality & $\begin{array}{l}\text { Subordinated by requirement } \\
\text { that all cases be formally } \\
\text { resolved }\end{array}$ & $\begin{array}{l}\text { Assisted by judicial review; } \\
\text { but Pareto inferior pork } \\
\text { barrel legislation remains }\end{array}$ \\
\hline Condorcet Criterion & $\begin{array}{l}\text { Not satisfied because } \\
\text { Condorcet-producing rules } \\
\text { result in endless cycling } \\
\text { absent a Condorcet winner, } \\
\text { thus infringing upon judicial } \\
\text { range }\end{array}$ & $\begin{array}{l}\text { Better satisfied, but because } \\
\text { logrolling accounts for } \\
\text { preference intensity, } \\
\text { Congress sometimes } \\
\text { maximizes utility by } \\
\text { missing Condorcet winners }\end{array}$ \\
\hline
\end{tabular}

TABLE 1. The Supreme Court and Congress Through an Arrovian Lens 


\section{Collective Decisionmakers Through a Wide-ANgle ArRovian \\ LENS}

At the risk of unduly extending what has already been a rather long walk, this Part will offer one final snapshot of some scenery along the way, this time with the benefit of a wide-angle Arrovian lens. This Article has demonstrated that while Arrow's Theorem provides an invaluable framework for analyzing the collective decisionmaking institutions created in the Constitution, the real benefit of the theorem is in explaining how these institutions operate in conjunction to achieve a greater level of rationality than each would achieve if it operated alone. At the same time, the Article demonstrated the importance of avoiding the "nirvana," "isolation," and "composition" fallacies when studying virtually any collective decisionmaking body.

This Part will offer a final snapshot designed to place legislatures and appellate courts, generally, within a broader framework of collective decisionmaking bodies, one that includes markets at one extreme and agencies at another. A final table will summarize this discussion.

\section{A. Markets}

Assuming preexisting wealth allocations and zero transactions costs, markets-which allow full cardinalization of preferences-are superior (or "least inferior") $)^{260}$ at allocating resources to their best and highest uses. The problem of the empty core is often viewed as a phenomenon associated with noncompetitive markets. ${ }^{261}$ This is only partially correct. Although the empty core problem does arise when markets are noncompetitive, the problem also is a function of timing, regardless of whether the market is competitive. Opportunities to negotiate in the absence of a core notoriously arise postcontractually, even when parties entered into the initial contract in competitive circumstances. ${ }^{262}$ The cycling problem is ameliorated to the extent that ex ante legal rules clarify postcontractual obligations in situations that the parties failed to consider and to provide for in terms. In that respect, legislatures and courts can increase the rationality of markets as collective decisionmaking bodies.

260. See supra note 33 .

261. See, e.g., Bittlingmayer, supra note 68 , at 202-04 (describing properties of markets that lead to cycling); see also supra note 86 and accompanying text.

262. Cf. Hovenkamp, supra note 68 , at 297. 


\section{B. Legislatures and Appellate Courts}

Legislatures, like private markets, can cycle, especially when allocating the benefits of capital gains or the burdens of capital losses. ${ }^{263}$ In those situations, legislatures may opt for inaction, leaving the status quo by default. In crafting ex ante rules, however, legislatures are less likely to cycle because the preferences of legislators are more likely to be uni-peaked. In this respect, legislatures are most beneficial in enhancing private market rationality when market participants negotiate in the absence of a core.

Legislative outcomes, however, are often path dependent and, as a result of logrolling, may extend beyond the legislature's permissible domain. Appellate courts, because they do not cycle in the same manner and in response to the same factual phenomena, can render legislative processes more rational through judicial review and statutory interpretation that avoids internal inconsistencies. These processes allow courts, first, to ensure that legislatures act within their permissible domain; and, second, to ameliorate codified intransitive preferences. These procedures, however, do not prevent pork barrel legislation which is often Pareto inferior. ${ }^{264}$

Unlike legislatures, however, appellate courts do not have the option of declining to resolve necessary issues contained in cases properly presented for review. As a result, their decisional processes must be structured to ensure an outcome in every case. Motion-and-amendment or packaged-issue decisionmaking, ${ }^{265}$ while capable of yielding available Condorcet winners, can lead to cycling and thus do not guarantee outcomes in every case. Caseby-case resolution, in contrast, does guarantee an outcome in nearly all cases, but sometimes leads to doctrinal incoherence. This form of incoherence is exacerbated when the Court's members lack a common doctrinal foundation because their preferences are less likely to be uni-peaked. Proposals for expanded judicial review would remove issues from legislatures, which have a proxy for a core even when preferences are multi-peaked, and would place them in appellate courts, in precisely the circumstances in which those courts lack any proxy for a core and in which judicial preferences are most likely to be multi-peaked. Moreover, to the extent that resulting decisions under the guise of constitutional judicial review are irrational, no separate collective

263. This form of legislative cycling is not limited to capital losses and capital gains; it also can arise in negotiating redistributive legislation. Dividing benefits and losses is likely to be negotiated in the absence of a core. $C f$. supra note 86 and accompanying text (comparing the need for facilitating legal rules in empty core negotiations with the need for facilitating legal rules in other contexts, such as postcontractual negotiations).

264. See Stearns, supra note 193, at 396 (observing that "there is no [federal] judicial decision prohibiting the attachment of nongermane riders"); see also supra note 220 and citations therein.

265. These processes are discussed supra notes 169-87 and accompanying text. 
decisionmaking institution within our constitutional system can restore rationality. ${ }^{266}$

\section{Agencies}

While a complete analysis of legislative delegation is beyond the scope of this Article, the foregoing discussion has some implications for agency decisionmaking. Specifically, traditional notions of agency expertise are well rooted in the notion of legislative irrationality resulting from problems posed by Arrow's Theorem. ${ }^{267}$ One often cited difficulty is that legislative delegation is frequently used to avoid difficult decisionmaking rather than to ensure enactment of more cogent policies. ${ }^{268}$ The nondelegation doctrine, which has been largely abandoned, ${ }^{269}$ may be viewed as a judicial attempt to ensure that delegation is employed only to achieve greater policy rationality through sufficiently clear legislative mandates that ensure uni-peakedness, rather than as a legislative avoidance device.

In any event, by providing a small group of decisionmakers with a common legislative mandate, legislatures can ensure that agencies create policies with the benefit of uni-peaked preferences. The problem is that while delegating to agencies increases the likelihood that uni-peaked preferences will yield rational policies, it does so by removing the most basic element of collective decisionmaking, namely the requirement that such bodies act collectively. In other words, to achieve rationality, legislatures, through such delegations, eviscerate the Arrovian nondictatorship criterion. Of course, because agencies operate in a quasi-legislative or quasi-judicial capacity, they

266. The obvious caveat is the ultimate collective decisionmaker, namely the power to amend vested in the people and in the states. The amending process has only been used to reverse Supreme Court decisions four times in more than 200 years. See U.S. CONST. amends. XI (limiting jurisdiction of federal courts to hear suits brought against states); XIV (providing that all persons born and naturalized in the United States are citizens); XVI (broadening Congress's taxing power); XXVI (establishing 18 as voting age).

267. See JerRY L. MASHAW \& Richard A. MERRILl, Administrative LaW: The AMERICAN Public LAW SYSTEM 29-30 (1985) (explaining that while Arrow's Theorem appears to justify broad delegations of legislative power to promote rational policies, scholars have observed that Congress more often uses delegations to avoid making difficult decisions); Farber \& Frickey, supra note 202, at 903 (positing that "It]he likelihood of having sufficiently 'well-behaved' preferences to avoid Arrow's theorem is presumably much greater in a small group such as a legislative committee").

268. See, e.g., THEODORE J. LOWI, THE END OF LiBERALISM 59 (1979) (describing legislatures' abdication of control over policymaking to interest groups and administrative agencies); HAYES, supra note 201, at 108 (discussing factors that lead legislators to opt for delegation).

269. See, e.g., 1 JACOB A. STEIN ET AL., ADMINISTRATIVE LAW \& 3.03[5] (1993). The authors observe that "with the exception of the Panama Refining [v. Ryan, 293 U.S. 388 (1935)] and Schechter Poultry [Corp. v. United States, 295 U.S. 495 (1935)] decisions, the Supreme Court has regularly validated the delegation by Congress to the President, to federal officials, and to administrative agencies of extremely broad-virtually standardless-legislative powers." Id. The authors add: "Yet, the Court in doing so has repeatedly stated that legislative power as such cannot lawfully be delegated." Id.; see also FARBER \& FRICKEY, supra note 24, at 79 ("Yet, it would be a mistake to view the [nondelegation] doctrine as wholly moribund. On occasion, it has served as a justification for narrowly construing a grant of authority to an administrative agency."). 
are also subject to many of the same aggregation problems described previously. ${ }^{270}$

\section{Summary}

Table 2 summarizes the above discussion, thus demonstrating the manner in which each of these four collective decisionmaking bodies acts to enhance the collective rationality of the overall system.

\begin{tabular}{|l|l|l|l|l||}
\hline & Markets & Legislatures & Appellate Courts & Agencies \\
\hline \hline $\begin{array}{l}\text { Major } \\
\text { Deficiency }\end{array}$ & $\begin{array}{l}\text { Cycling in the } \\
\text { absence of a core }\end{array}$ & $\begin{array}{l}\text { Cycling when } \\
\text { allocating } \\
\text { capital losses or } \\
\text { capital gains }\end{array}$ & $\begin{array}{l}\text { Requirement that all } \\
\text { cases be resolved } \\
\text { leads to occasional } \\
\text { doctrinal } \\
\text { incoherence }\end{array}$ & $\begin{array}{l}\text { Nondictatorship } \\
\text { criterion is } \\
\text { removed }\end{array}$ \\
\hline $\begin{array}{l}\text { Major } \\
\text { Arrovian } \\
\text { Attribute }\end{array}$ & $\begin{array}{l}\text { Optimizing } \\
\text { resource allocation } \\
\text { assuming } \\
\text { preexisting wealth } \\
\text { distributions and } \\
\text { zero transactions } \\
\text { costs }\end{array}$ & $\begin{array}{l}\text { Creating ex ante } \\
\text { rules to facilitate } \\
\text { market } \\
\text { transactions in } \\
\text { the absence of a } \\
\text { core and } \\
\text { advancing } \\
\text { meaningful } \\
\text { compromises } \\
\text { with multi- } \\
\text { peaked } \\
\text { preferences }\end{array}$ & $\begin{array}{l}\text { Limited range and } \\
\text { uni-peakedness } \\
\text { enables courts to } \\
\text { increase legislative } \\
\text { rationality by } \\
\text { ensuring that } \\
\text { legislatures act } \\
\text { within their limited } \\
\text { domain }\end{array}$ & $\begin{array}{l}\text { Administrative } \\
\text { uni-peakedness } \\
\text { provides substitute } \\
\text { for multi-peaked } \\
\text { legislative } \\
\text { preferences, thus } \\
\text { increasing } \\
\text { legislative } \\
\text { rationality }\end{array}$ \\
\hline
\end{tabular}

TABLE 2. Collective Decisionmakers Through a Wide-Angle Arrovian Lens

270. See supra Part IV. 


\section{CONCLUSION}

Arrow's Theorem is a useful tool for explaining and comparing congressional and Supreme Court decisionmaking processes. The analysis presented in this Article demonstrated why decisional processes in the Supreme Court, like those of most appellate courts, are not designed to yield Condorcet winners, even when such winners are available. It questioned arguments for expanding judicial review based on social choice theory by showing that legislatures have a superior proxy for a core relative to appellate courts in the very range of issues for which advocates argue for judicial, as opposed to legislative, resolution.

While Arrow's Theorem proves that every collective decisionmaking body, including the Supreme Court and Congress, will inevitably contain some deficiency, no single institution can be viewed in isolation to determine its rationality in aggregating collective preferences. When Congress and the Supreme Court are properly analyzed and then compared through an Arrovian lens, it becomes clear that most social-choice-based normative proposals undermine, rather than enhance, the rationality of these institutions. Finally, placing legislatures and appellate courts within a broader framework of collective decisionmaking bodies, including markets and agencies, the Article showed that each institution under review behaves more rationally when operating in conjunction with other collective decisionmaking institutions than it would if it operated alone.

Like core theory, social choice theory reveals the shadow cast by the invisible hand over our constitutionally established collective decisionmaking bodies. Perhaps the flaw, rendering the social choice renaissance at least partially misguided, is the failure to recognize that the Framers gave us two hands, albeit with two shadows, rather than one.

\section{APPENDIX}

\section{A. Arrow's Theorem Proof}

As previously stated, understanding the Arrow's Theorem proof is not essential to following the analysis in the text. Nonetheless, the proof is edifying in that it further illustrates the nature of the underlying assumptions and demonstrates why they inevitably conflict. A very simplified proof is therefore presented below. ${ }^{271}$

271. For those familiar with other Arrow's Theorem proofs, the proof that follows will be overly simplified. It is taken from Hovenkamp, supra note 68, at 319-21. Those readers, and others who find all equations a precursor to cold sweats, can disregard this appendix altogether. For additional, and more elaborate, proofs of the theorem, see MUELLER, supra note 6, at 385-\$7 (1989); AMARTYA K. SEN, COllective ChOICE AND SOCIAL Welfare 41-46 (1970); Vickrey, supra note 100. 
Assume that A and B are two groups of voters, of unequal size, in a state legislature. They must again choose where to locate a toxic waste dump and the choices are townships $\mathrm{X}, \mathrm{Y}$, and $\mathrm{Z}$. Assume further that A contains the minimum number of voters necessary to pass a piece of legislation; in other words, $\mathrm{A}$ is a simple majority. Group A prefers location $\mathrm{X}$ to location $\mathrm{Y}$. This is noted as $\mathrm{A}$ : $\mathrm{XpY}$, where "p" is defined as "preferred to." Because A is the bare minimum needed to impose its preferences upon the group, A minus one person is insufficient to control the group. Now assume that $A$ is subdivided into two groups $A_{1}$ and $A_{2}$, such that $A_{1}$ consists of a single person and $A_{2}$ consists of the remainder of the individuals in group $A$.

Because all members of group $A$ prefer $X$ to $Y$, then for both $A_{1}$ and $A_{2}$, $\mathrm{XpY}$. Assume that the two groups do not otherwise share the same preference orderings. Thus, for $A_{1}, X p Y p Z$ and for $A_{2}, Z p X p Y$. Assume further that group $B$, all the voters not in $A$, has the preference ordering $Y \mathrm{pZpX}$. It should be readily apparent that all three groups, $A_{1}, A_{2}$, and $B$ have different preference orderings. ${ }^{272}$ While $A_{2}$ prefers $Z$ to $Y$, neither $A_{1}$ nor $B$ share that preference. This means that, consistent with the requirement of majority rule or, stated in Arrow's Theorem terms, the condition of nondictatorship, the group's preference as between $\mathrm{Z}$ and $\mathrm{Y}$ must either be $\mathrm{YpZ}$ or YiZ, where "i" means "indifferent to."

Recall that $\mathrm{XpY}$ for the entire group, including $\mathrm{A}$ and $\mathrm{B}$, based upon the preference of $\mathrm{A}$, a simple majority. Given that $\mathrm{YpZ}$ or $\mathrm{YiZ}$, it follows that $\mathrm{XpZ}$. In other words if the group prefers site $\mathrm{X}$ to site $\mathrm{Y}$, and prefers site $\mathrm{Y}$ to site $Z$, then under the requirement of transitivity, the group must prefer site $\mathrm{X}$ to site $\mathrm{Z}$. Alternatively if the group prefers site $\mathrm{X}$ to site $\mathrm{Y}$ but is indifferent as between sites $Y$ and $Z$, then the group must again prefer site $X$ to site $Z$. The problem is that only one person, $A_{1}$, actually prefers site $X$ to site $Z$, which means that to satisfy the requirement of transitivity, the group must agree to make $A_{1}$ the dictator.

\section{B. Arrow's Theorem Explanation}

The logic of the proof may require a bit more explanation. The proof assumes that for the legislative choice between two options $\mathrm{X}$ and $\mathrm{Y}$, there is some nonunanimous subset that satisfies the majority criterion, such that XpY. Within that first nonunanimous subset, $A$, however, is another nonunanimous subset, $A_{2}$, that alone prefers $Z$ to $Y$. Because neither $A_{1}$ nor $B$ prefer $Z$ to $Y$, that means that $A_{2}$, the subset of $A$, cannot control. But this also means that the opposite relation, either in the form of a preference or an indifference, such that $\mathrm{YpZ}$ or YiZ, must control the entire group. Applying transitivity, then

272. A brief comparison will also show that the three preference orderings in the proof are identical to those in the ice cream cake hypothetical, supra p. 1221-22. 
$\mathrm{XpZ}$. The difficulty is that another subset of $\mathrm{A}$, this time $A_{1}$, is the only group with this preference. This, in turn, means that the group must choose between satisfying the requirements of rationality or nondictatorship, which means that both cannot coexist simultaneously. ${ }^{273}$

273. In Hovenkamp, supra note 68 , at 319 , the author explains the logic of the proof as follows: The Theorem ... proceeds by assuming that on any choice between two alternatives there must be some minimum nonunanimous subset of voters that is decisive-that is, who constitute a sufficiently large proportion of the whole that their preference for any alternative will make that alternative the social choice. The Theorem then shows that if there is such a nonunanimous subset, this subset will in turn contain a nonunanimous subset which is itself decisive of the outcome; this second subset will then contain yet a third decisive nonunanimous subset, and so on until the final subset is a single individual, or dictator. Because nondictatorship is an assumption of the Theorem, there cannot be a decisive, nonunanimous, and nondictatorial subset.

Id. at 319. Hovenkamp's proof, upon which the proof in the text is based, dispenses with all but one iteration to get to the dictator. Other, more elaborate, proofs add degrees of complexity at every turn, e.g., numbers of groups and preference orderings. Each additional complexity simply exacerbates the cycling problem. 
HeinOnline -- 103 Yale L.J. 1294 1993-1994 
HeinOnline -- 103 Yale L.J. 1295 1993-1994 
HeinOnline -- 103 Yale L.J. 1296 1993-1994 